\title{
Social-Ecological Preferences AND URBANIZATION IN INDIA
}

\author{
Dissertation \\ To attain the degree doctor rerum politicarum \\ Of the Faculty of Agricultural Sciences, \\ Georg-August-University Goettingen, Germany
}

\author{
Presented by \\ Johannes Bettin \\ born on the $21^{\text {st }}$ of June, 1989 in Dresden, Germany
}

Göttingen, March 2019 
D7

Committee of supervisors and examinors:

$1^{\text {st }}$ supervisor and referee: Prof. Dr. Meike Wollni

$2^{\text {nd }}$ referee: Prof. Dr. Tobias Plieninger

$2^{\text {nd }}$ supervisor: Prof. Dr. Kilian Bizer

$3^{\text {rd }}$ supervisor: Prof. Dr. Stephan von Cramon-Taubadel

Date of dissertation: April 30 ${ }^{\text {th }}, 2019$ 


\section{Summary}

Urbanization has been recognized as one of the major forces in shaping the $21^{\text {st }}$ century on planet earth. The by far largest increase in the share of humans living in cities is expected to take place in the Global South. The consequences of this development for the environment are not fully understood: In the aggregate, cities consume and pollute natural resources far beyond their immediate environments, and they might do so more than income differentials suggest. However, there are also examples of demand-pattern changes conducive to environmental conservation.

Learning from such examples to mitigate overall environmental degradation appears decisive, yet ambiguity of real-world urban resource depletion is matched by a lack of theoretical models facilitating understanding of the underlying processes: Social-Ecological Systems literature may be considered one of the most profound theoretical approaches to predict the complexity of urban human-environment interactions. But the social subsystem within which urbanization originates remains simplistic in most urban SES models to date. This may reflect three problems with integrating known psychological mechanisms into such models: Southern urban contexts are prone to alter mechanisms that often originate in Northern lab settings (a). Causal quantification is moreover often incomplete in general (b). a and b could mutually reinforce each other in Southern urban contexts, where interaction and feedback with other such mechanisms will likely bias simple aggregation of extant literature (c).

This thesis hence hypothesizes that predictive abilities of urban SES models, and eventually policy leverage, can be increased by integrating culturally and environmentally contextualized, as well as less statistically biased psychological mechanisms into these models. This is operationalized as revisiting a simple framework that so far predicts a transition from 'green-loop' to 'red-loop' dynamics with urbanization more or less deterministically; that is, decreasing salience of natural environments may not automatically result in reduced pro-environmental attitudes (path i), that translate even less into stewardship behavior (path ii). Chapter I introduces this overarching research question and analytical framework, against both an empirical and a theoretical background.

Empirical evaluation proceeds with latent variable structural equation models of moderated mediation, where feedback is controlled through spatial lags of exogenous variables utilized as instruments. They are calibrated on a random sample of 1200 decisionmakers stratified for urbanization along two rural-urban gradients in Bangalore / India. The water problems of this rapidly growing Southern megacity exemplify global trends, much like its globalization- 
induced social change could point to more general developments. Measurement is achieved by shortened psychological scales, combined to decomposed games and manifest indicators.

As a first operatinalization of the research question, chapter II hypothesizes that loss of salient nature experience may be substituted by alternative, urban drivers of pro-environmental attitude (path $\mathrm{i}$ above). That is, policymakers may not have to take preference-driven transitions toward a red-loop as given, once culturally and environmentally contextualized quantification of societal feedback allows for more realistic urban SES (problems a and c above). This is achieved via jointly modeling psychological mechanisms mediating the effect of urbanization onto environmental concern - beyond potential nature experience loss. Separately documented, Northern urban features like anonymity suggest reinforcement of such loss. But Southern urban dynamics like modernization-induced value change could acquire a positive meaning neglected by extant, simplistic urban SES models; they could even interact with and change the meaning of more traditional constructs.

Positive aggregate effects of urbanization on environmental concern replicate extant literature here. However, they emerge only after instrumenting and due to unexpected, uniquely Indian feedback between mediating urban features. These findings are interpreted as contributing not only to more differentiated predictions of urban SES, but also to generalizability of known aggregate effects within urban psychology.

The second essay (chapter III) questions the undifferentiated loss of all types of nature experience for everyone under urbanization-related income growth (path $\mathrm{i}$ above). It hypothesizes that urban SES models could benefit from integration of literature relating positive emotional connections with nature to environmental concern. Extant models may be drawing on decreasing negative degradation experiences only, as this effect already features prominently in income-concern literature. But especially memories of positive experiences could exhibit more differentiated loss patterns under income growth.

Chapter III therefore investigates persistent influence of remembered, positive experiences on environmental concern across an urbanizing, Southern income distribution (problems a and c above). Differential influence of this type is found to bridge the minimum of an otherwise Ushaped income-concern relationship. I.e., particularly pronounced effects of nature experience at intermediate income allow for monotonic increases of concern in income, because beneficial psychological traits are present particularly among those urbanizing individuals that abandon agriculture. Like the second essay, these results imply positive equilibrium dynamics for Bangalore's SES, and can thus not explain the current empirically obvious red loop. Such 
differential bridging may however be exploited particularly by policy-makers at the ruralurban interface, and it also explains previous sample-sensitivity of the income-concern link.

A third essay (chapter IV) finally tests for statistical confounding in cultural relativity of one of the urbanization-induced moderators of the society-ecology link (problems a and $b$ for path ii above). Generalized social trust is known to increase in urbanization, and it is conducive to acting upon preferences originating in environmental concern. This relationship is assumed to be mediated by collectivism. Yet the link from collectivism to generalized trust still lacks quantification beyond mere correlation. Only this would facilitate integration into urban SES models besides extant, mostly negative moderators of path ii, and justify promoting certain cultural traits for sustainability.

Previous results are found to be explained by a complex interplay of confounders. Collectivism only affects generalized trust negatively under absence of voluntary cross-group interaction, and given either reverse causality through bad experiences with generalized morality, or emphasis of the hierarchical vertical dimension of collectivism over horizontal, distance based sociability. As not only cross-group experiences but also collectivism increase with Indian urbanization, these results once again imply dynamics toward positive socialecological equilibria in Bangalore.

The thesis concludes with a comparative discussion in chapter $V$. All three essays exemplify benefits from inclusion of culturally and environmentally contextualized psychological mechanisms into SES models of urbanization. More complex models can then point to specific policy leverages against red-loop transitions, beyond reinforcing Southern roots of nature experience. But additional research is still needed for truly realistic calibration of such models. Future studies should explore further moderators of path ii, but also alternative psychological constructs that truly predict pro-environmental behavior best in a given context. Alternative representations of natural environments besides water could strengthen internal validity further, whereas external validity would benefit from replication in less globalized Southern cases. 


\section{Acknowledgements}

I would like to thank my supervisor, Prof. Dr. M. Wollni, for her guidance throughout all stages of my thesis - for the freedom to explore and grow, and helpful comments and discussion. I am also grateful to Prof. Dr. K. Bizer and Prof. Dr. S. v. Cramon-Taubadel for support as members of my thesis committee, as well as to Prof. Dr. T. Plieninger for reviewing this thesis.

I further owe special thanks to my friends and colleagues, Dr. Monish J., J. Wegmann \& M. Erler, O.-K. Haase and L. Steinhübel. Thank you for endless discussions and making 'boot camp' a very special time that I would not want to miss. I would further like to thank our team in the field, as well as our former assistant J.M. Gather, for going the extra mile in getting the most out of our survey data. Credit also goes to our counterparts at GKVK / UAS Bangalore.

Most of all, I feel indepted to my beloved wife, Phi E., for constructive reflection, enduring emotional support, and contagious 'groundedness'. I would finally like to express my gratitude also to the rest of my family and friends, without whom the last three years would have been very much different.

This research was funded by the German Research Foundation (DFG), grant number WO 1470/3-1 as part of the Research Unit For2432/1: Social-Ecologial Systems in the Indian Rural-Urban Interface: Functions, scales and dynamics of transition. 


\section{Contents}

\section{Table of Contents}

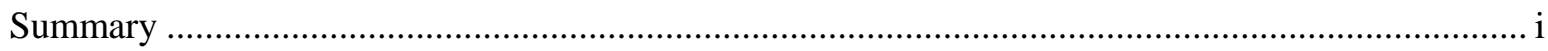

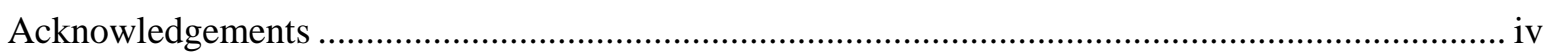

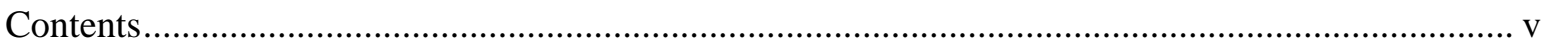

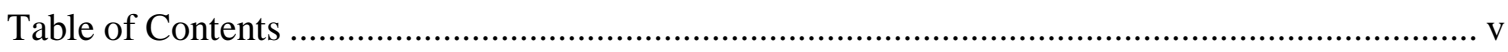

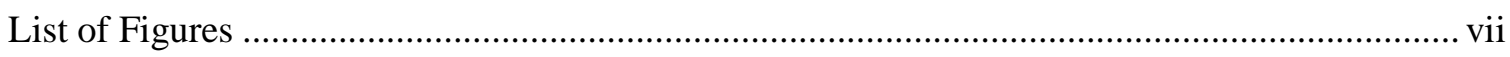

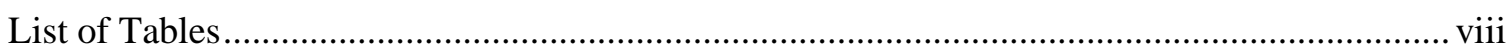

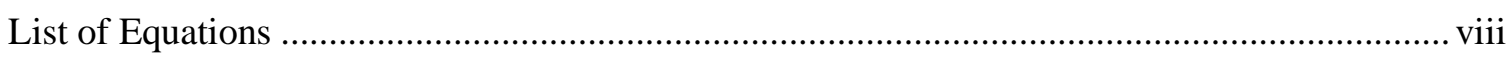

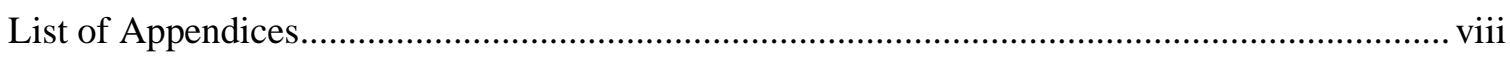

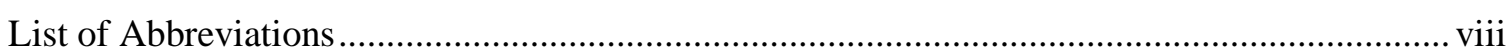

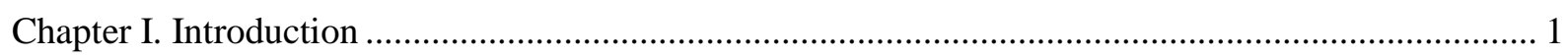

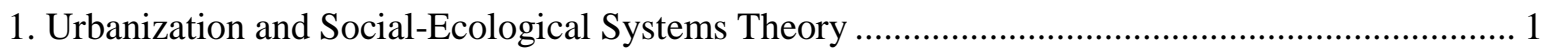

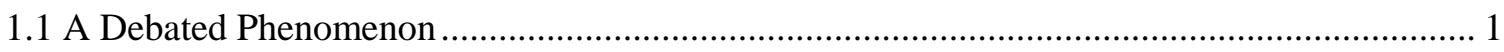

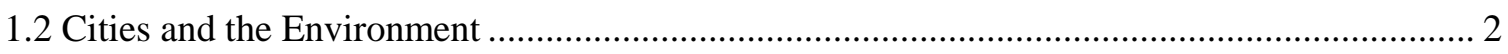

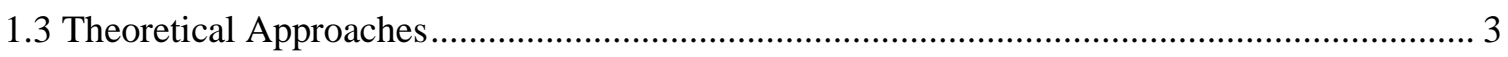

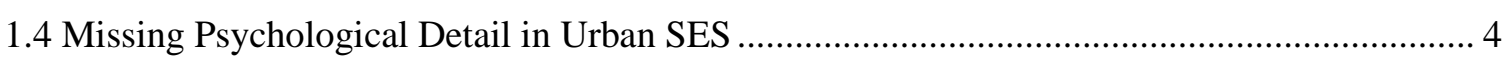

2. The Present Research: General Aim and Analytical Framework .................................................. 5

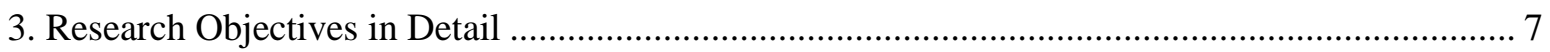

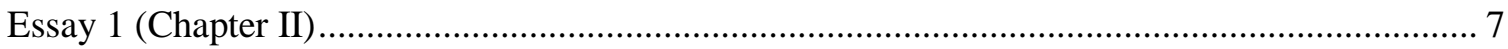

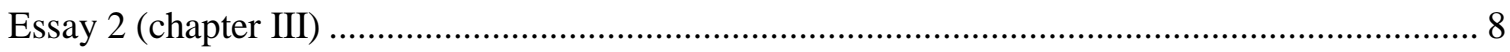

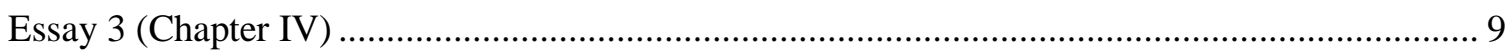

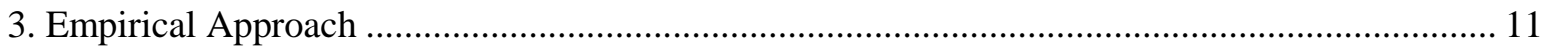

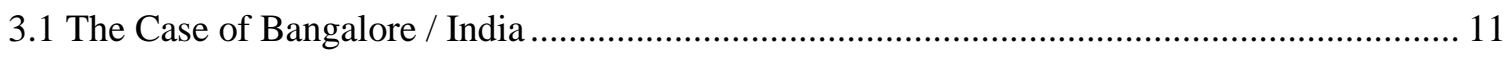

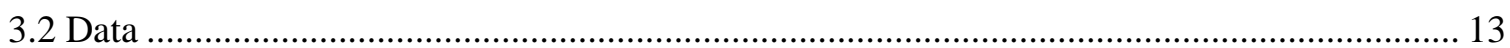

Chapter II. Decomposing the "Experience of Living in Cities": The Example of Environmental

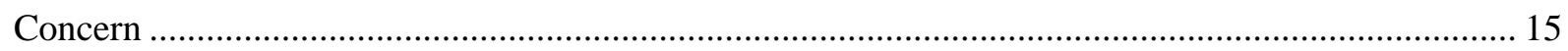

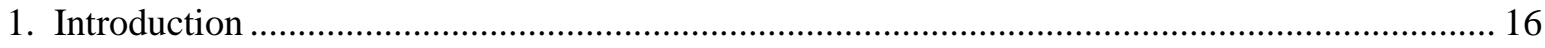

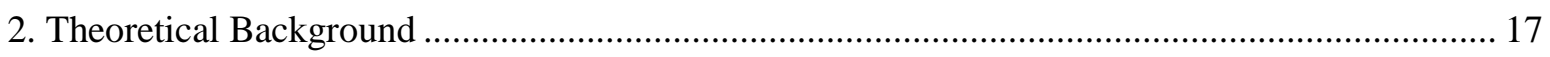

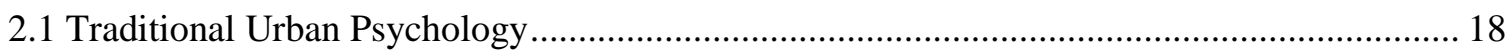

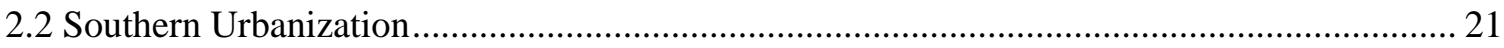

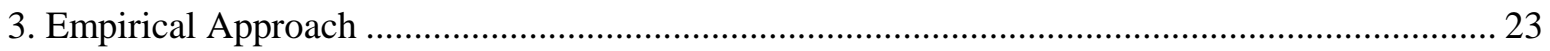

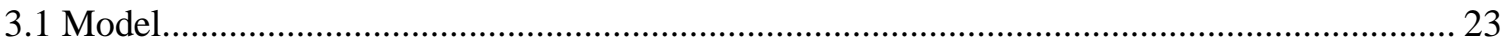




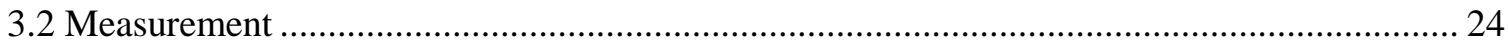

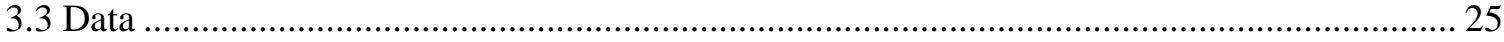

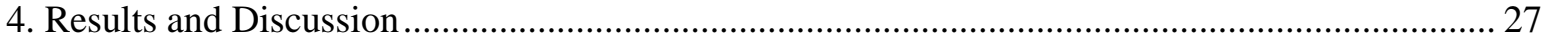

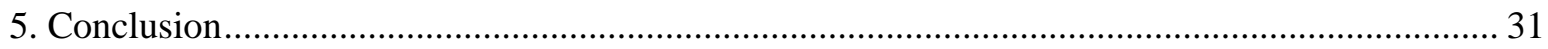

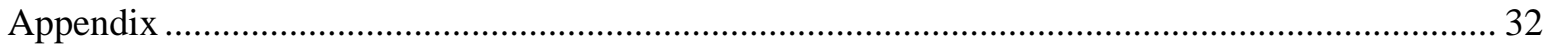

Chapter III. Environmental Concern, Income and Nature Experience in India ................................... 41

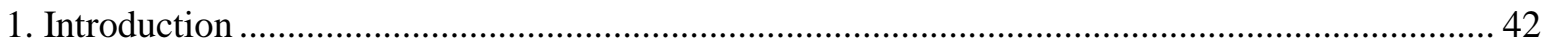

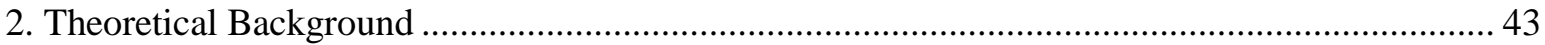

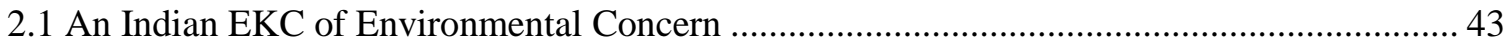

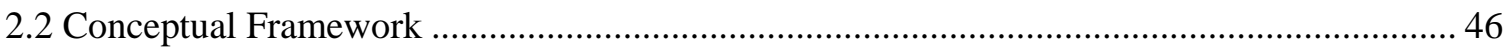

2.3 Environmentalism of the Poor as Nature Experience............................................................. 48

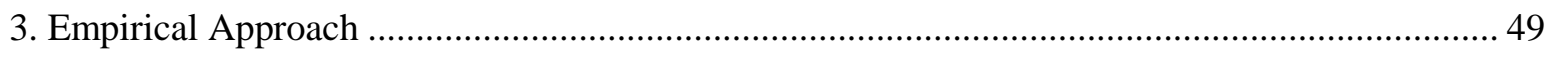

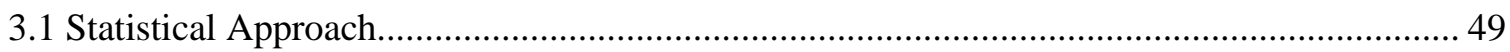

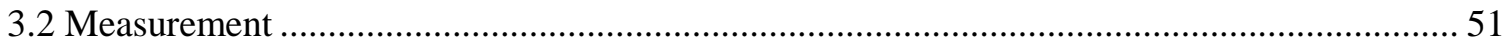

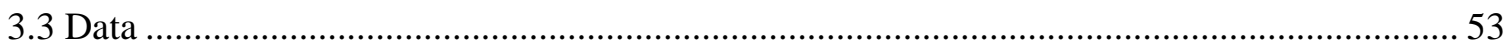

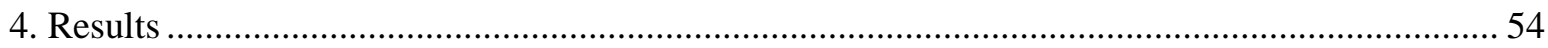

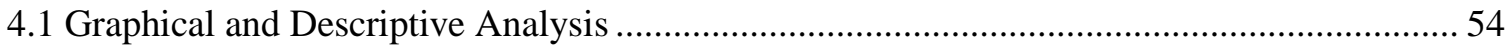

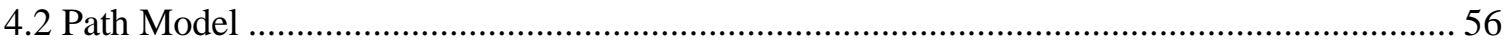

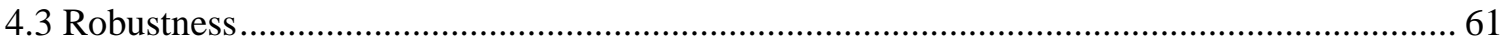

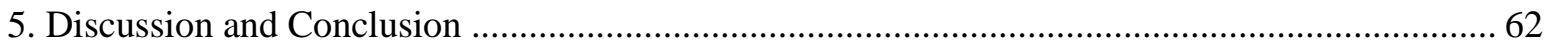

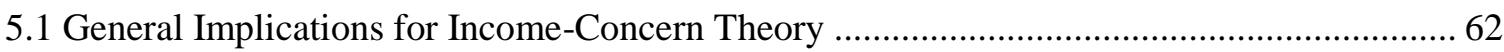

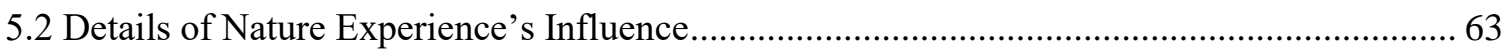

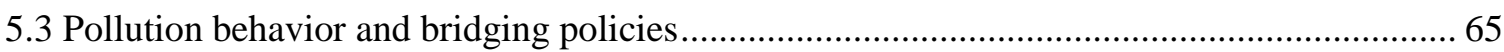

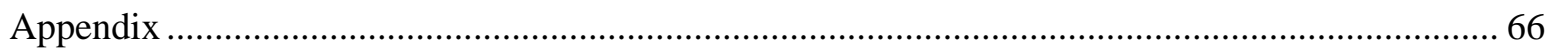

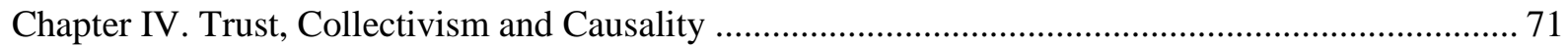

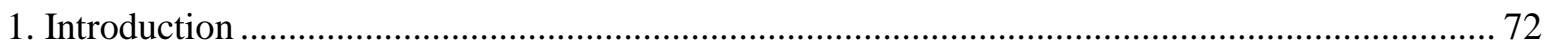

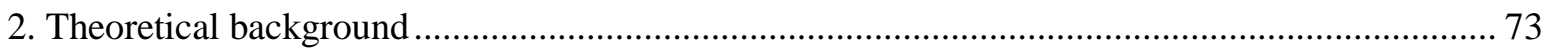

2.1 Collectivist Preferences, Dimensionality Confounding and Ingroup Bias ............................. 73

2.2 Collectivist Trustworthiness, Mediation Confounding and the Social Dilemma ..................... 76

2.3 Collectivist Tightness, Common Causes and Generalization.................................................... 78

2.4 Further Confounding: Moderation and Reverse Causality …................................................... 79

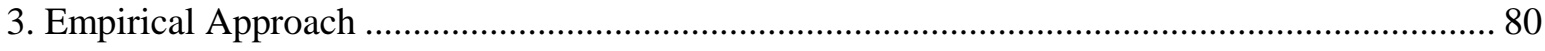

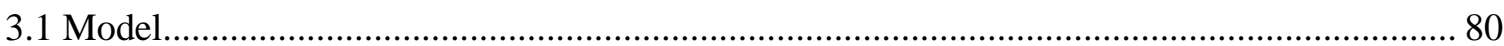




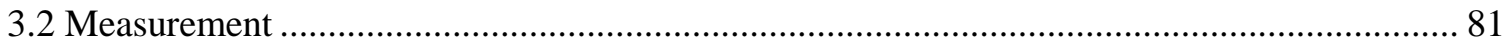

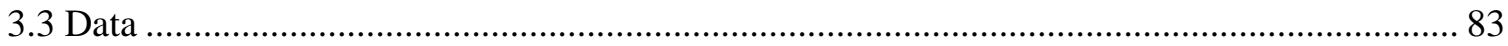

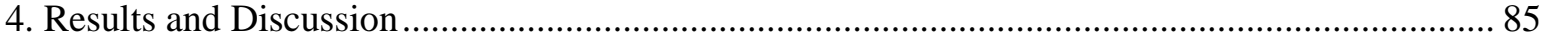

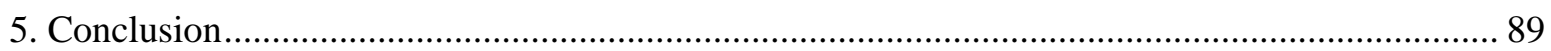

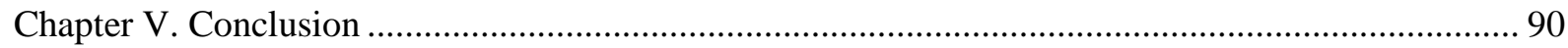

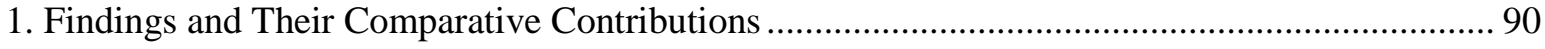

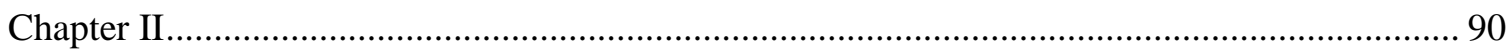

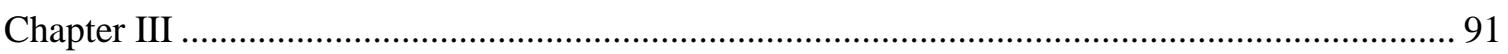

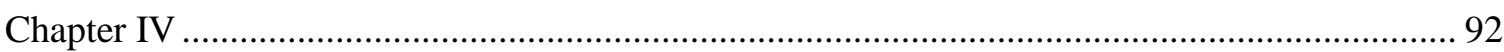

2. General Implications for Modeling and Governing Urban SES.................................................... 93

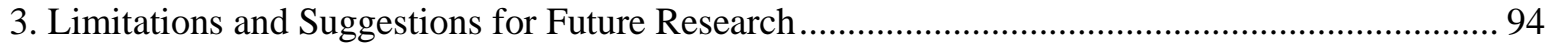

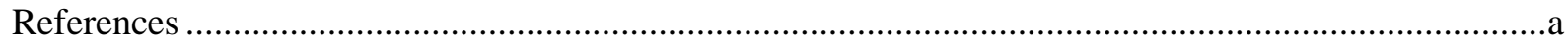

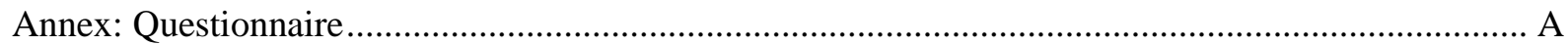

\section{List of Figures}

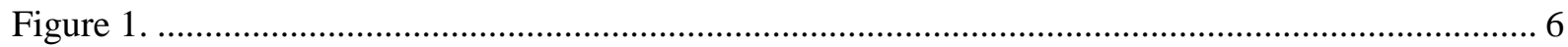

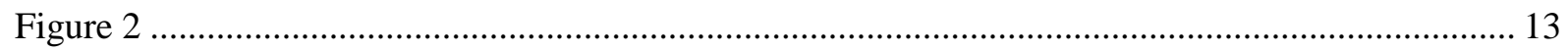

Figure 3.

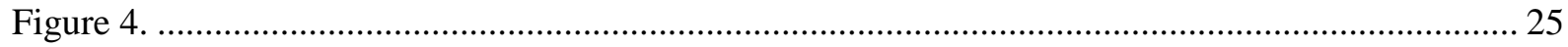

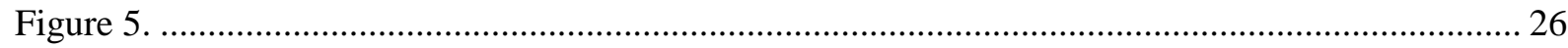

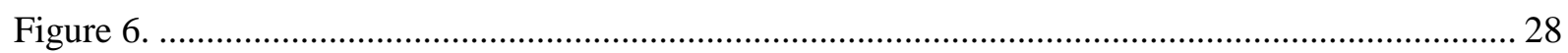

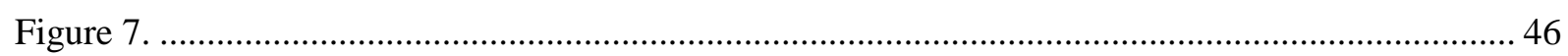

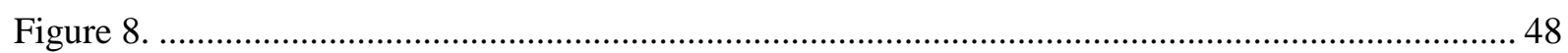

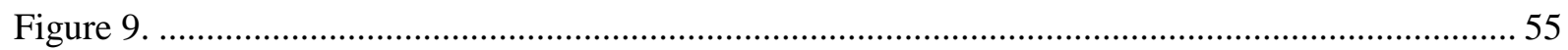

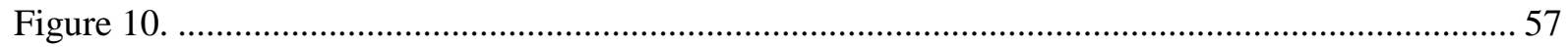

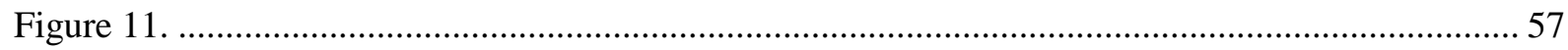

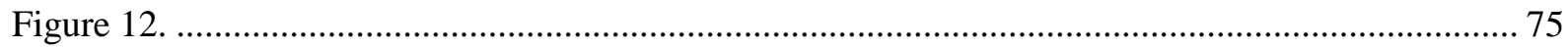

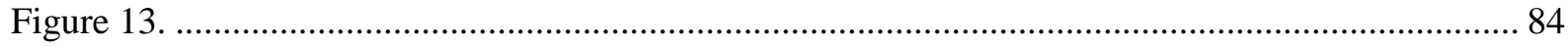

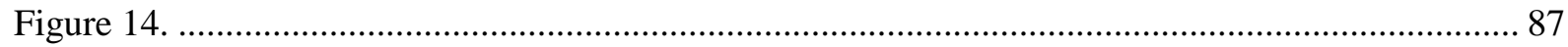




\section{List of Tables}

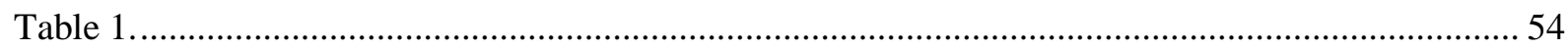

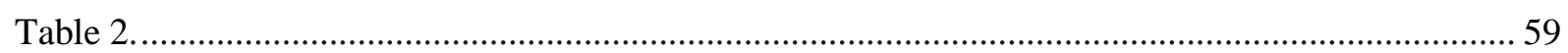

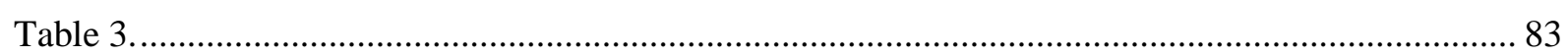

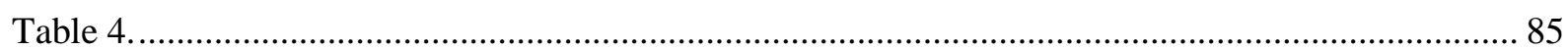

\section{List of Equations}

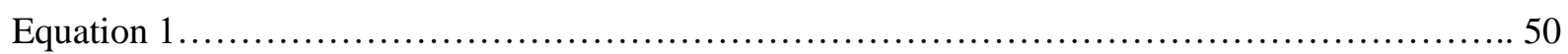

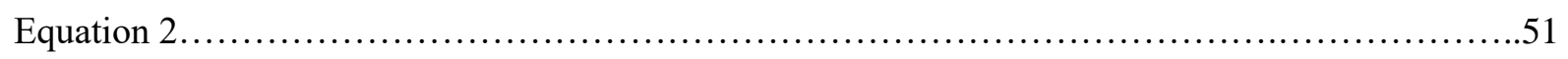

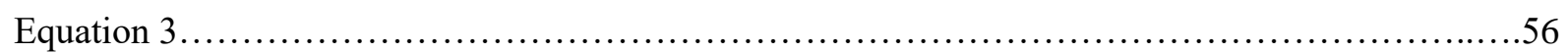

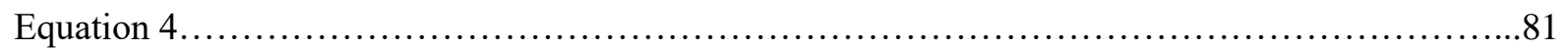

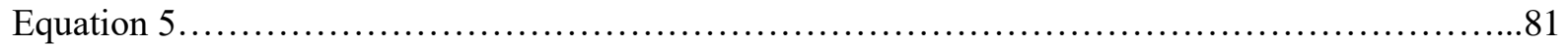

\section{List of Appendices}

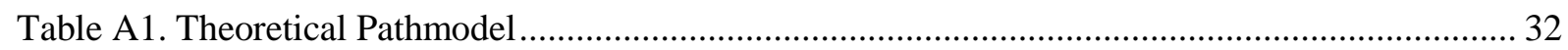

Table A2. Item Statistics: Factor Analysis, Reliability and Descriptive Statistics................................. 34

Table A3. Regression Results for Pathmodel incl. Robustness............................................................ 36

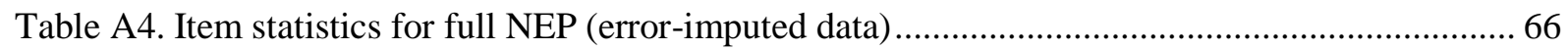

Table A5. Structural Equation Regressions Including Robustness (selected controls) ........................ 67

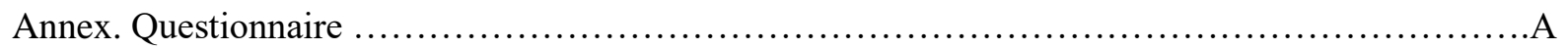

\section{List of Abbreviations}

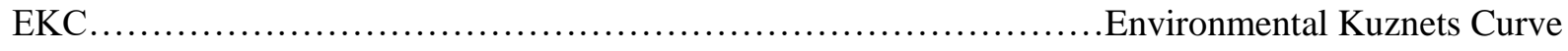

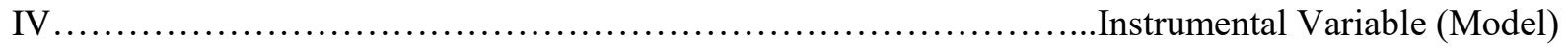

OLS ......................................................... Ordinary Least Squares (Model)

NEP ...................................................... Eew Environmental Paradigm (Scale)

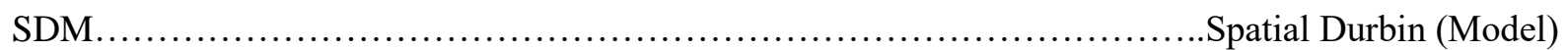

SES ........................................................... Social-Ecological System(s)

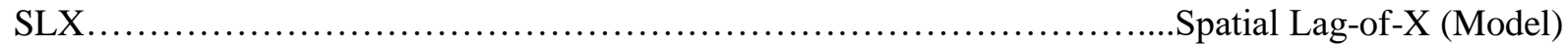




\section{Chapter I. Introduction}

\section{Urbanization and Social-Ecological Systems Theory}

\subsection{A Debated Phenomenon}

Urbanization has recently been called one of the major "forces of our time", and "developments in human history" by an advisory council to the German federal government (WBGU, 2016). And indeed, the numbers of the underlying phenomenon are bound to impress: The global share of people living in cities, in percentage points, is estimated to more than double between 1950 and 2050 - from 30 to 68 percent (United Nations, 2018). While urbanization rates are still growing in the Global North, the majority of this development is taking place in the Global South: The urban population here is expected to reach four billion individuals in 2030 already, and hence more than double in absolute numbers compared to the beginning of the century (Bettencourt, Lobo, Helbing, Kühnert, \& West, 2007).

The debate however starts with these numbers already. Various disciplines loosely connected in what some like to call "urban studies" are still struggling for a definition of what constitutes the urban at all. This debate encompasses gradual definitions and absolute ones, political and psychological as well as natural science approaches (Bettencourt \& West, 2010); some important voices continue to refuse accepting any overarching definition (Roy, 2009). Dense human agglomerations of a certain size perhaps represent the broadest currently available, minimum consensus on such a definition; it emerges from most of the applied work on the subject, as well as from some recent economic scholarship, and will be applied henceforth (Scott \& Storper, 2015).

The controversy continues when moving to a definition of urbanization: While it is sometimes considered to refer to static shares of people living in mentioned settlements (Parnell \& Oldfield, 2014), many of the most pressing challenges today arise from the growth of these numbers within relatively short timespans (United Nations, 2018). Depending on the underlying static definition however, such dynamics operationalize differently. An increasing share of individuals with a certain habitus in fixed, rural areas over time (Milgram, 1970) is paralleled here by artificial environments sprawling in space (Simon, 2008), and by certain individuals migrating from rural to urban regions (Diao, McMillan, \& Rodrik, 2017). This thesis will employ a combination of more relevant dynamic definitions of urbanization, making explicit in-situ change over time as spread in space.

Across debates, processes and regions however, practitioners and scientists alike agree on the "force" of urbanization in continuing to affect our planet. What is more, there is a consensus 
that even a static minimum understanding entails social and environmental consequences which require policy intervention in many cases. But as urbanization only emerges as such a recent development, supportive evidence-based understanding remains scarce in many areas (WBGU, 2016; United Nations, 2018).

\subsection{Cities and the Environment}

Consequences of urbanization for the environment seem particularly worrying. Increasing shares of people living in cities have been accompanied both by direct local and by indirect global imbalances in ecosystems, resulting from consumption of resources and environmental degradation (Seto, Parnell, \& Elmqvist, 2013). Cities have led to the extinction of a variety of species, deteriorated soils and created heat islands, caused flooding and even epidemics locally (Sudhira \& Nagendra, 2013). Moreover, they have globally consumed "up to $60 \%$ of water resources for residential purposes, generating over $50 \%$ of waste, and producing 60 $80 \%$ of the world's greenhouse gas emissions“ (Frank, Delano, \& Schaefer Caniglia, 2017).

Yet, urbanization may at least potentially also be able to contribute to mitigation of global environmental change, rather than exacerbating it. This is illustrated, first, by examples of increased pro-environmental behavior due to changes in type but not quantity even of local ecosystem service demand (Nagendra, 2016). Secondly, this could be complemented by increasing returns to scale when providing material bases for human flourishing (Bettencourt et al., 2007): Cities condense affluence and more general human development in space, but they may do so more efficiently than rural environments. For example, public goods are shared by more people and travel times are reduced, such that urban sustainability accounting as referred to above may suffer from a certain degree of confounding (Poumanyvong \& Kaneko, 2010). However, such potential may be counteracted in many Southern cities at least to some degree, because third, urbanization is often accompanied there in addition by increasing demand for resource-intensive goods (Dhakal, 2009).

All in all and in general, to date it thus remains difficult to quantify whether urbanization simply embodies, benefits from or even exacerbates environmental consequences of economic growth (Taylor, 2017). Mitigation of such consequences has in any case become the most decisive challenge humanity is faced with today (IPCC, 2018), but mentioned economies of scale may not automatically be reaped. Once again and to be exemplified below, we are only beginning to understand the mechanisms behind the particular approach which may be required to tackle this challenge as embodied by cities (Andersson et al., 2014). 


\subsection{Theoretical Approaches}

When attempting to frame this issue as a whole theoretically, it seems most intuitive to start from a simple observation: Cities harbor the highest concentrations of human activity on earth, yet urban residents' consumption continues to be coupled to natural resource depletion (see section 1.2). It follows that cities constitute the most intense example of humanenvironment interactions on earth (Cosier \& Shen, 2009).

A number of theories compete in capturing such interactions at system level both in general (Pulver et al., 2018), as well as for the urban case (McPhearson et al., 2016). While most of them originate in (urban) ecology, they increasingly draw on neighboring disciplines in an attempt to capture the complexity of human-environment interactions. Among these theories, the social ecological systems framework (SES; (Ostrom, 2009)) stands out as one of the most integrative approaches (Frank et al., 2017), and this thesis will also rely on it. SES theories capture human-environment interaction as a "dynamic, complex system [comprising] flow and use [...] of biophysical and social factors [...] with continuous adaptation" (Redman, Grove, \& Kuby, 2004).

Advantages derive, first, from its generality: As opposed to theories centering on "vulnerability" or "resilience", it allows for capturing all types of issues associated to humanenvironment interaction. Furthermore and as opposed to the "coupled human-natural systems" or "human and ecological processes" models, SES is one of the most detailed frameworks available, which facilitates operationalization. Perhaps because of this, it has rapidly become one of the most widely applied lenses to focus on human-environment interactions in various projects across the globe (Universidad Autonoma de Madrid, 2019; University of Washington, 2019); cross-cultural validity is hence more robustly proven than in case of other approaches. Finally, SES connects to adjacent theories better than the, in many ways comparable "integrated assessment of ecosystem services" or "human ecosystems" frameworks. This is due to the fact that the latter two are more policy-oriented and therefore rely on pre-specified and often theoretically overly simplistic rules, e.g. of decision-making.

All in all, SES is thus particularly well suited to allow for the still most realistic, quantitative prediction in essentially uncertain systems comprising interaction of a multitude of processes requiring context-sensitive and multidisciplinary theoretical explanation (Frank et al., 2017). 


\subsection{Missing Psychological Detail in Urban SES}

SES dynamics from urbanization by definition originate in society. But the very complexity SES theories promote for the ecological subsystem has long been absent from the social subsystem, particularly so in case of urban SES (Schlüter et al., 2017).

At least as much as ecological systems, human behavior is characterized by non-linear relationships deviating from rational, utility maximizing individuals in systematic ways that do not cancel out in the aggregate (Thaler, 2016). Behavior targeted at the environment in particular is characterized by social and contextual influence, habits and a number of cognitive biases leading to e.g. thresholds and feedback from other elements of the system (Jackson, 2005; Klöckner, 2013).

But such complex effects of cultural ecosystem services on society, much like non-linear adaptations within the latter and eventual dynamic feedback to ecosystems, remain to be systematically integrated in SES models (Haase \& Schwarz, 2009; WBGU, 2016). With regard to many of these aspects, this theory in general still suffers from "broad gaps of knowledge", leading to quantification attempts without truly "generalizable findings" (Gaston, 2010; Groeneveld et al., 2017)). This is true in particular for SES models of cities and urbanization: Even the most detailed approaches to date build on utility-maximizing, disconnected individuals driven by economic or population dynamics (Grimm, Cook, Hale, \& Iwaniec, 2015; Grove, Pickett, Whitmer, \& Cadenasso, 2013).

The scope for further research opens up here, first, because known effects may often be altered in specifically urban and uniqely Southern, cultural contexts. Environmental and in particular urban psychology, as well as adjacent disciplines, provide a host of relevant mechanism quantification (Berenguer, Corraliza, \& Martín, 2005; Thomas et al., 2005). But most findings have emerged from laboratory experiments with Northern, educated and relatively wealthy populations, sometimes even without any specific reference to urban contexts (Henrich, Heine, \& Norenzayan, 2010). At the same time, their very nature as perceptions of natural and social environments makes these effects highly prone to be affected differently by contemporary, Southern urbanization (Nagendra, 2018).

A second problem with simply integrating extant literature into urban SES arises from a lack of thorough quantification of many relationships e.g. in areas like urban studies. Confounding is often not controlled explicitly, such that the required causality can rarely be assumed (Schlüter et al., 2017). 
A third and final problem results from a partial combination of the first two problems. Adding up known mechanisms from separate analysis would be prone to miss interactions from, to and between them in a particular urban context (Pulver et al., 2018). Pro-environmental behavior illustrates the case in point: Not only does it change under urbanization, but it also influences the very urban environments that feed back into a variety of behavioral determinants, that even themselves interact (Seto et al., 2013).

\section{The Present Research: General Aim and Analytical Framework}

Ambiguous findings about sustainability effects of urbanization hence mirror a lack of psychological detail in urban SES models. Adding such detail may therefore contribute to enhanced understanding of pro-environmental leverages in the urbanization to come. The research question this thesis aims at exploring within three exemplary essays can thus be summarized as follows: Can predictive abilities of urban SES models be improved by integration of complex psychological mechanisms, adequately quantified within particularly urban cultural and environmental contexts?

The contribution of each of these essays is perhaps most conveniently illustrated within a simplified version of one of the most widely-cited models of urban SES ((Cumming et al., 2014), Figure 1). Every model faces a trade-off between capturing empirical complexity and generalizing through theoretical parsimony. While this 'simple model' does not represent the most psychologically explicit urban SES model available (see e.g. human ecosystems framework above), its generality allows for incorporation of a variety of theories and detailed quantification of relevant system dynamics (Cumming \& Cramon-Taubadel, 2018). It thus readily frames the more complex models presented below.

The central assumption behind this model may be described as increasing physical distance of society and ecology due to urbanization. As humans cease to perceive their connectedness to ecosystems with increasing economic development (arrow a), they start depleting them in unsustainable manners at multiple scales (arrow b), even though they in fact still depend on them physically ("green loop"-to-"red loop" transition, ibd.). 


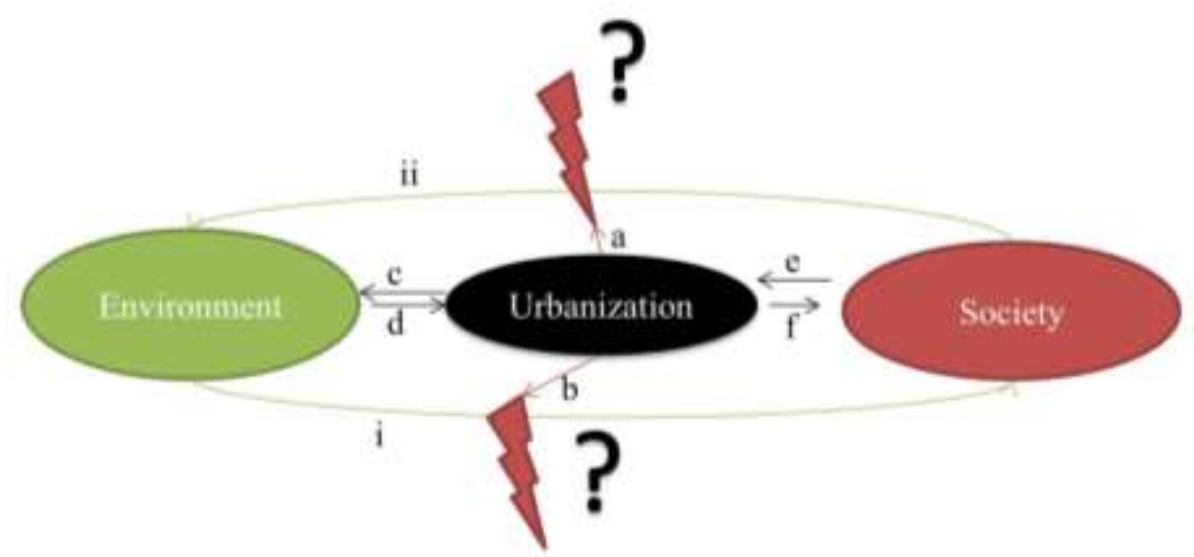

Figure 1. A simplified representation of the "green loop"-to-"red loop" transition in an urbanizing SES. Flashes represent red loop - type disruptions of green loop, as represented by green arrows. Note that urbanization only appears separate from society for parsimony in demonstration. Own depiction, adapted from the model proposed by Cumming et al., 2014.

This framework allows for further operationalization of the general research question: Even though disconnected, qualitative or more ecological in nature, numerous examples already illustrate that the proposed green-loop to red-loop transitions are far from automatic (see section 2). Each of the three essays presented in this thesis therefore exemplifies one way of testing the hypothesis that the transition of SES to a red loop under urbanization withstands nuanced quantification of complex, societal mechanisms as well. That is, the thesis aims at adding quantitative and contextualized psychological detail to the presumed disruptions of the green loop.

As an aside, note that the research gap addressed is understood here as implying a focus on preferences: Environmental concern is proposed as the central nexus representing society in the model across cases here ${ }^{1}$. This is because many of the current advances in psychological decision theory can be modeled as extensions to the theory of planned behavior (Thaler, 2016). Within such a framework, (environmental) attitudes like concern occupy a central, if by no means unique or even proximate position as predictors of pro-environmental behavior (Burger et al., 2015; Groeneveld et al., 2017). Furthermore, environmental concern has long been at the center of scientific attention and hence constitutes a convenient hub to organize effects emanating from both ecology on society, and from other societal processes (Gifford \& Nilsson, 2014). To enhance mutual understanding with much of extant SES literature, this thesis opts for terming such attitudes "preferences". 


\section{Research Objectives in Detail}

Essays one and two (chapters II and III) will look into path b in Figure 1. I.e., they investigate how urbanization affects the link from the environment to environmental concern in the social system. Here, transition to a red loop is understood as a specific, negative influence of urbanization on consuming and polluting resources. That is, urban individuals participate in economic development (Diao et al., 2017) that increases its coupling to resource depletion (Mardani, Streimikiene, Cavallaro, Loganathan, \& Khoshnoudi, 2019). Essays one and two question the automaticity of such development (moderation of path i by path $b$ ), with regard to urbanization's influence on society in terms of a preference change - represented additionally by environmental concern dynamics (path f).

The central theoretical assumption behind a preference-driven transition toward a red loop is loss of nature experience (Amel, Manning, Scott, \& Koger, 2017; Meyfroidt, 2013): Greenloop dynamics are kept in equilibrium because society's concern (and hence proenvironmental behavior) allegedly increases, if it experiences environmental degradation. I.e., environmental repercussions of economic growth should go along with mitigation strategies. But this link depends on emotional and physical distance to nature (salience), both of which are assumed to increase with urbanization and associated economic development. That is, an emotional connection to nature is assumed to decrease with physical distance to it, without being replaced by other sources of concern (Davis, Green, \& Reed, 2009).

\section{Essay 1 (Chapter II)}

The first essay enquires into potential substituting mechanisms for nature experience introduced by urbanization. Suggestions of how to directly inhibit loss of nature experience abound in recent literature (see e.g. (Giusti, Barthel, \& Marcus, 2014)). But multiple wellresearched drivers of environmental concern (Gifford \& Nilsson, 2014) also seem prone to increase under urban social transitions (Chen \& Ren, 2016; Thomas et al., 2005). However, the potential of each psychological urban feature to substitute nature experience is not integrated in extant urban SES models (e.g. income growth: Frank et al., 2017).

The reason might be a combination especially of problems one and three, but as a consequence also two, when aggregating known psychological mechanisms here (see section 1.4): Extant literature has rarely analyzed them jointly, even though feedback will likely bias causal interpretations in separate analysis. Effects will also be altered in the Southern urban

\footnotetext{
${ }^{1}$ For further operationalization of urbanization see above, and of environmental variables below.
} 
contexts (Evans, Lepore, \& Allen, 2000). A discrepancy between known aggregate effects of urbanization onto concern and real-world behavior could already point to such incomplete generalizable quantification of system effects (Berenguer et al., 2005).

The essay presented in chapter II jointly models a culturally diverse set of urban features in a Southern context, and how they interactively cause aggregate concern. They cover traditional urban psychological fields of enquiry like altruism reduction, anonymity or population heterogeneity, but also more Southern understandings derived from more qualitative sciences, like modernization and globalization alike (Rao, 1992; Scott \& Storper, 2015).

These psychological mediators of urbanization as such are then linked to both each other and environmental concern within a structural equations model ${ }^{2}$. Aggregating over paths thereby allows for less biased prediction of each mechanisms' substitution potential. The model is estimated on parceled scales and equation-by-equation, to allow for instrumentation of feedback by spatially lagged exogenous variables (Drukker, Egger, \& Prucha, 2013). General equilibrium effects in Figure 1 are thus directly observable, whereas individual complex relationships may in some cases need to be simplified, i.e. reduced to direct linear effects.

\section{Essay 2 (chapter III)}

The thesis proceeds with a second essay that questions the automaticity of path b (Figure 1) in isolation, i.e. of nature experience loss under urbanization. This enquiry derives its justification from a missing, quantitative link in extant literature between the environmental concern-related debates about nature experience (Chawla, 1998), and about income growth (Summers \& VanHeuvelen, 2017) - as it is associated to urbanization. The first body of literature has put forward ample evidence for a positive emotional connection to nature as a decisive cause of environmental concern, whereas the second one derives explanations from increasing physical distance to negative experiences of environmental degradation. But as it remains unclear whether positive experiences also decrease with urbanization unequivocally, urban SES models so far draw on the second mechanism only (Meyfroidt, 2013).

More differentiated prediction of red-loop transitions could thus obtain from integration of positive nature experience into urban SES. However, this would require quantitative contextualization of this effect within the particular context of income growth under Southern urbanization (first and third problem of section 1.4). In exchange for some system generality,

\footnotetext{
${ }^{2}$ Note that path ii, c (expected to be negative, see chapter II) and d (expected to be positive, ibd.) are controlled, whereas e is assumed to be mediated by environment, and path a will be analyzed below.
} 
essay 2 aims at providing such procedural and cultural complexity. Put differently, it asks whether policymakers could learn from differential persistence of positive memories of nature experience beyond rural, low income contexts (Guha \& Martinez-Alier, 2013).

The model captures persistence over time in a cross-section and becomes statistically identified $^{3}$, because past nature experience is regressed on current concern. Differential switching out of agriculture allows for conditioning chances for policy leverage on psychological differences between individuals as a second moderator (Dawson \& Richter, 2006). In particular, positive influence at sometimes concluded, minimum concern under middle income (U-shape or Kuznets pattern (Fairbrother, 2013)) would point to preferencedriven chances of "bridging” (Munasinghe, 1999).

\section{Essay 3 (Chapter IV)}

The third and final essay explores the transition toward a red loop with respect to path a. Even if urbanization meant overall increases in environmental concern, it could in addition hamper mechanisms translating such preference into actual, pro-environmental behavior (Scarlett, Boyd, Brittain, Shabma, \& Brennan, 2013). Extant SES literature features certain 'rational', but negative moderators here already: Urban income growth could cause particular forms of status-oriented and resource intensive consumption, for example. However, social and environmental psychology have depicted many more potential moderators of the attitudebehavior link, some of which may also be positive (Jackson, 2005). Urbanization could contribute to breaking habits, reducing a number of cognitive biases through education or introducing globalized, progressive social norms. Exploiting system-effect predictions of such preference change may be of interest to policy-makers.

Essay 3 focuses on generalized social trust as an example of such a potentially positive moderator that still requires proper quantification for integration into urban SES models (van Lange, Rockenbach, \& Yamagishi, 2015). Many pro-environmental behavioral outcomes resemble a public good problem. In such cases, preferences are only acted upon if a sufficient number of others is also believed, or trusted to do so. I.e., despite conducive preferences one cannot be sure ex-ante that individual cost will actually be lower than benefit, as the latter also depends on others' contributions.

Positive moderation by generalized trust is however expected to vary with cultural context. First, trust is known to increase in urbanization directly (Sørensen, 2014). But this 
relationship has secondly been found to be mediated by collectivism. Urbanization is known to influence collectivism negatively (Sinha, 2014; Tönnies, 1887), and collectivism has been found to correlate with generalized trust negatively too. The latter is attributed to increased negative outgroup discrimination among collectivists (Fukuyama, 1996; van Hoorn, 2014).

Chapter IV questions causal interpretations of this second association, between collectivism and trust. That is, it aims at enhancing extant quantifications of cultural relativity through control of statistical confounding (first and second problem in section 1.4). Only this would allow for integration of this potentially positive moderator into urban SES, and the resultant double negation could, ceteris paribus, really be interpreted as support for promoting persistence of collectivist, traditional norms for sustainability.

Disentangling causality has been complicated by latent institutions like trust and collectivism coevolving together empirically in the long-run (Bowles, 2010; Putnam, 1993). Negative correlations could alternatively stem from cultures where vertical collectivism dominates; hierarchically structured morality may lead to ingroup bias in some cultures, if horizontal, harmonic sociability in fact benefited generalized trust (Krishna, 2007). Further, generalized morality could mediate collectivism negatively in some societies, but be elastic to policy intervention much more than collectivism (Yuki, 2003). Collectivism may finally unfold its pro-relational potential only conditional upon voluntary, cross-group interaction, which could even be introduced as a side effect of urbanization (Paxton, 2007).

This essay again exploits availability advantages of spatial instrumental variables over panel or experimental data to control for such confounding. Besides all this, note how this approach trades generality of paths included for specification and cultural detail of a certain relationship even more than the second essay, such that equilibrium effects in the simple illustration of Figure 1 depend on further, established effects. ${ }^{4}$

\footnotetext{
${ }^{3}$ This controls path ii. Urbanization not explicitly included, and income only appears as interaction with the environment.

${ }^{4}$ Equilibrium effects depend on the relationships between urbanization, environment and concern that were discussed above already. Then, reverse causality is generally not assumed and does not seem plausible for influence of urbanization on both trust and collectivism. Whereas literature so far does not acknowledge any direct effects between environmental concern and generalized trust, and influence of the latter on the environment seems logical to assume only as a moderator (see main text), positive influence of intact environment on generalized trust is well established (Kong (2012); Kolstad and Wiig (2012)). Then, it is easy to imagine how harsh environments can cause collectivism (Romano, Balliet, Yamagishi, and Liu (2017), but the reverse is likely embodied by trust-related moderators (see main text). Finally, collectivism could benefit environmental concern through altruism (see chapter II), while the reverse is much harder to imagine.
} 


\section{Empirical Approach}

\subsection{The Case of Bangalore / India}

The emerging megacity Bangalore in India constitutes the empirical context within which the essays proposed are evaluated. Bangalore is known today primarily as India's Silicon valley, but has already played a major role in India's economic, military and scientific development during kings' rule and the colonial era (Nair, 2005).

Understanding urbanization in Bangalore could become decisive, as it constitutes a particularly strong and fast example of both Indian and global urbanization, at least with respect to a minimum definition ((Kraas \& Mertins, 2014), section 1): 90 percent of the likely increase in urban population until 2050 are expected to take place in Asia and Africa, but the largest increase in absolute numbers is projected for the case of India (United Nations, 2018). Amongst Indian cities, Bangalore's population count is among the largest and at the same time fastest growing: Increases of just below 5 percent per annum had brought the count up from 160000 at the start of the $20^{\text {th }}$, to 8 million at the start of the $21^{\text {st }}$ century already thereby making it the $5^{\text {th }}$ largest city in India (Census of India, 2016).

India also constitutes an interesting context regarding the environmental problems frequently associated to urbanization: Indian city dwellers' income in general is among the ones that explain cities' environmental degradation least (Franco, Mandla, \& Ram Mohan Rao, 2017). As frequently illustrated even by Northern media coverage too, urban SES in India have clearly tilted toward a red loop in many cases.

Bangalore once again represents such a transition at an exacerbated degree. Because of its rapid growth compared to being situated in the Southern central dry plateau, as well as many other factors to be detailed below, particularly the water situation exemplifies urban environmental degradation particularly well (Nagendra \& Ostrom, 2014): Once the city had been famous not only for its trees and parks, but also for its unique irrigation infrastructure consisting of collectively maintained reservoirs called "tanks" that resembled common pools. Since the onset of borewells however, private overextraction has depleted the resource not only within city boundaries, but within the whole higher region toward the North of Bangalore; it furthermore increased run-off but dramatically decreased quality of the water available within the whole watershed toward the South (Lele et al., 2013).

Yet on the other hand, the city's water problem may additionally exhibit variation of red-loop transitions that could be exploited for preventive policies; in the simple model depicted in Figure 1, water is thus chosen as a representation of the environment. This is because on the 
other hand, water bodies polluted so severely they literally burn are complemented by urban lakes restored for new purposes (ibd.). A typical societal case with regard to preference variation may hence become observable in Bangalore (Seawright \& Gerring, 2008).

But this megacity is also unique in many ways that make it a particularly interesting case for the specific relationships explored by the essays in this thesis. This is true, first of all, for the second essay: In the wake of its technology sector, Bangalore has opened up not only economically, but also culturally in the last decades to a very strong globalization (Nair, 2005). First of all, this has led to especially strong income differentials compared to the rural surroundings (100 percent on average; Census of India, 2016). Due to steep rises in the opportunity cost of agricultural labor (Diao et al., 2017), this has also led to large shares of individuals abandoning agriculture. Strong income variation can hence be studied here in conjunction with loss of at least the nature experience traditionally associated to environmental concern.

Furthermore, the first essay is also expected to be able to observe here a broad spectrum of peculiar Southern urban features potentially substituting nature experience in supporting environmental concern: Globalization has introduced to Bangalore many psychological urban features traditionally studied in the North (Nair, 2005). However, Indian cultural modernization in general is known also both for its resistance to norm change, and also a unique hybridization (Sinha, 2014): For example, whereas anonymity is simply absent from many marginalized yet dense African settlements, it has been suggested to even increase in density under collectivism.

Finally, globalized norms much like encounters with strangers are also likely to introduce stronger variation to both collectivism and generalized social trust then elsewhere; in general, negative lock-in into a low trust - high collectivism equilibrium is considered particularly stable across India (Inglehart, Haerpfer, Moreno, \& et al., 2018). Hence, Bangalore could be considered a critical case for the third essay more than for the first two ones (Seawright \& Gerring, 2008): The city provides theoretically ideal variation to observe sizeable effects for the first two essays, that could then generalize - even though less pronouncedly. In case of the third essay however, a positive relationship would be more likely to be encountered almost everywhere else. 


\subsection{Data}

The data to evaluate these hypotheses were collected as the socio-economic contribution to a large collaborative, Indo-German research project (Universities of Kassel \& Göttingen, 2016). It focuses on agricultural issues arising from transitions in the Indian rural-urban, which are mainly analyzed under an agricultural, or broader natural science point of view.

A stratified sample was taken along two rural-urban gradients to ensure representativeness for urbanization in Bangalore (Figure 2). Spatial dynamics then represent temporal ones (LeSage \& Pace, 2009), hypothetically also for all the associated constructs of interest. This stratification by a minimum-consensus measure (Hoffmann, Jose, Nölke, \& Möckel, 2017) was applied at village or ward level, such that 61 clusters were selected from a Northern and a Southern transect covering a distance of about 40 kilometers from the city center each. ${ }^{5}$ From each cluster, households were sampled at simple random but proportional to size.

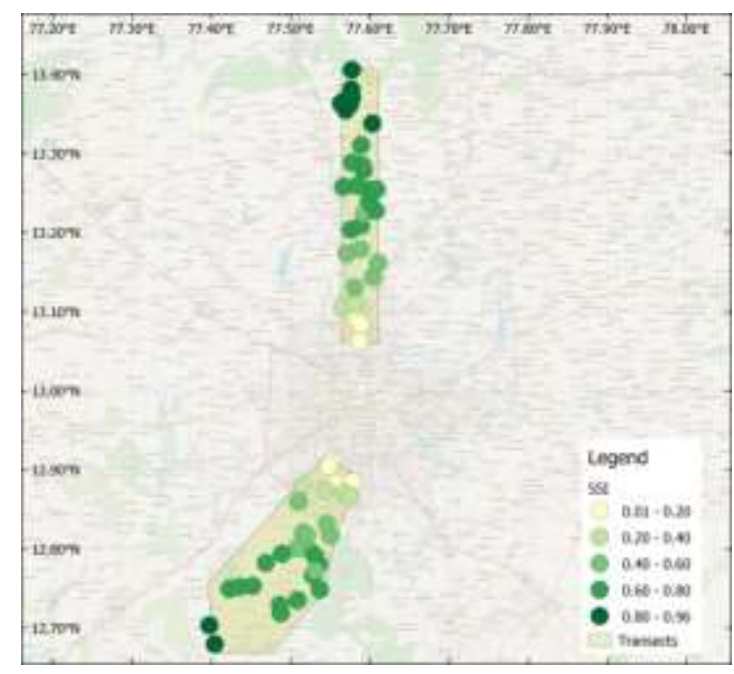

Figure 2. Sample of 61 villages, stratified by urbanization (SSI, increases in rurality) within two rural-urban transects of Bangalore / India. Author's own depiction based on Hoffman et al. (2017).

Structured questionnaires were then employed to conduct CAPI-assisted interviews with 1200 decision-makers as the most sustainability-relevant unit of analysis in the still hierarchical Indian society (Agarwal, 1992). These interviews took place between November 2016 and May 2017, in several local languages and in family homes. ${ }^{6}$

Questionnaire items comprised a large, multidisciplinary range of methodological approaches (see general annex, and below for detailed justification). Environmental variables often reflect expert interviews (see chapter II). Other manifest indicators obtain from collaborative efforts

\footnotetext{
${ }^{5}$ Such a large interval is required because whereas the population density decreases relatively quickly, socio-economic structures remain tied to the urban center through commuting much longer.
} 
with natural scientist, e.g. remote sensing yields the built-up cover for urbanization (Hoffmann et al., 2017). Societal variables were measured by decomposed games wherever possible to ensure the most realistic representation of behavioral variables, such as e.g. in case of trust and morality (Johnson \& Mislin, 2011).

Finally, many societal variables like environmental concern are latent and had to be operationalized by condensing extant, psychological scales (New Environmental Paradigm scale, NEP; (Dunlap, van Liere, Mertig, \& Jones, 2000)). Here, utmost care was taken to ensure measurement validity across this Southern heterogeneous sample: Several rounds of translation were combined here with 'thinking aloud' and discussions with local scientists (van de Vijver \& Tanzer, 2004). However, again incorporation of generality comes at a certain cost in terms of complexity (i.e. length of scales employed, and hence item statistics).

\footnotetext{
${ }^{6}$ Participation was only upon informed, written consent and entirely voluntary.
} 


\title{
Chapter II. Decomposing the "Experience of Living in Cities": The Example of Environmental Concern ${ }^{7}$
}

\begin{abstract}
:
Cities contribute overproportionally to environmental problems, but traditional urban psychology suggests positive influence of urbanization on environmental concern. This study demonstrates that where and when this correlation holds depends on how population density as such is mediated by other culturally relative urban features that only eventually translate into psychological drivers of concern. We jointly model a comprehensive set of such mechanisms including feedback between them, and estimate the resultant structural equations on original, representative and spatially explicit survey data from a globalized Southern megacity. Traditional urban psychological mechanisms are altered and complemented in Bangalore / India, such that the positive relationship found here seems unlikely to replicate in those cities currently still driving real-world emissions.
\end{abstract}

Keywords: urbanization, urban psychology, environmental concern, global south, spatial instrument

\footnotetext{
${ }^{7}$ This chapter is co-authored by Meike Wollni. Authors' contributions are as follows: Conceptualization, J. Bettin \& M. Wollni; Methodology, J. Bettin \& M. Wollni; Software, J. Bettin; Validation, J. Bettin \& M. Wollni; Formal Analysis, J. Bettin; Investigation, J. Bettin \& others (see acknowledgements); Resources, J.Bettin; Data Curation, J. Bettin, Monish Jose \& Johanna Gather; Writing - Original Draft Preparation, J. Bettin; Writing - Review \& Editing, J. Bettin \& M. Wollni; Visualization, J. Bettin; Supervision, M. Wollni; Project Administration, M. Wollni; Funding Acquisition, M. Wollni
} 


\section{Introduction}

Urbanization is to spike in the years to come, especially in the Global South: The share of people living in cities is projected to increase from $55 \%$ to $68 \%$ in 2050 , with $90 \%$ of the increase happening in Asia and Africa (United Nations, 2018). At the same time, urbanization creates greenhouse gas emissions beyond its contribution to economic growth, i.e. people in cities behave differently (Taylor, 2017). In general, environmental concern constitutes one of the most widely studied psychological predictors, and hence policy leverages of such environmental behavior; this holds across a variety of cultural contexts and despite a certain attitude-behavior gap (Gifford \& Nilsson, 2014). But extant literature is unable to explain urban environmental footprints in at least one decisive regard: To date, living in cities has been found to affect environmental concern positively - both in the Global North and the South (Berenguer et al., 2005; Yu, 2014).

This study aims at resolving this discrepancy by decomposing this more abstract example of "the experience of living in cities" (Milgram, 1970) into underlying mechanisms. Real-world emissions may be driven by cities where correlations between urbanization and concern differ from the cases examined so far. A model of how population density as such translates into a variety of mediating aspects differently in different places could predict this more accurately, and contribute to identifying policy options.

But such a model is absent from extant literature: Documentations of psychological consequences of specific urban socio-environmental stimuli mostly remain separate even within Northern contexts, or they focus on repercussions for mental health (Thomas et al., 2005). Moreover, such more traditional urban psychology mostly implies negative effects for environmental concern due to altruism reduction induced by stress (ibd.). This contradicts both aggregate effects, and mechanisms like modernization evident in the Global South but still disconnected from urban psychology (Chen \& Ren, 2016).

However, the desired decomposition is equally not available by simply adding up mentioned known mechanisms. First, Southern and urban contexts are likely to alter relationships as such, because many of them have emerged from Northern lab settings (Henrich et al., 2010). Second, they are likely to interact with and receive feedback from all other mediators in complex urban social-ecological systems, such that aggregation would suffer from statistical bias (Schlüter et al., 2017).

This study demonstrates how jointly modeling a more diverse set of mediating features of urbanization allows for improved predictions of aggregate psychological effects, such as 
environmental concern. Our decomposition of urban phenomena may hence be understood additionally as a contribution toward "a more unified theory of urban living" (Bettencourt \& West, 2010). Our approach consists in first deriving a multidisciplinary set of urban features mediating urbanization as such and potentially affecting environmental concern. This involves theoretical ambiguity of aggregate predictions emerging from feedback and cultural relativity. We then calibrate the resultant structural equations model on original, representative survey data from the rural-urban gradient of the highly globalized, but Southern megacity Bangalore / India ( $\mathrm{N}=1200)$. Our sample thus captures continuous variation of all constructs of interest in space, which also provides instrumental variables to control for feedback endogeneity.

The model explains an overall positive relationship in our sample by a uniquely Southern interplay of urban mechanisms: Beyond strong positive influence of mostly Southern urban features such as modernization, it is unexpected, aggregate positive contributions of e.g. more traditional nature experience that may also persist into later stages of urbanization. And it is explicitely modeling Indian understandings of e.g. individualism and its interactions with traditional urban psychological mechanisms that allows us to draw more general conclusions about aggregate relationships: Our results raise hopes that current, aggregate and unsustainable urban behaviors may be driven by mechanisms unlikely to replicate in the Global South of the $21^{\text {st }}$ century, or the urbanization to come.

Section 2 derives our theoretical framework, section 3 introduces the empirical approach, section 4 discusses results and section 5 concludes with suggestions for future research.

\section{Theoretical Background}

This section explains how we derive underlying mechanisms capable of explaining the overall urbanization-concern link. See Appendix A1 for a systematic overview of theoretical justifications for each path included in the final model.

We commence by drawing from an ongoing debate within urban psychology, urban studies and other disciplines, on what the urban universally constitutes. This analysis moves from urban features studied by traditional urban psychology to how they are altered and complemented in the Global South of the $21^{\text {st }}$ century. Maximum possible explanatory power of the framework is achieved by selecting features that map onto well-known drivers of environmental concern more or less directly (Gifford \& Nilsson, 2014). This process is aided 
by a long tradition in environmental psychology, originating in urban sociology (Tönnies, 1887), on how the human psyche is altered by individual urban socio-environmental stimuli.

Some of the urban features analyzed then already mediate others and thus further simplify sketching pathways toward drivers of environmental concern. We will focus on these paths rather than discussing every imaginable mediation. Below we exemplifiy how feedback between the main, traditional urban psychological mechanisms already implies theoretically ambiguous and highly context dependent aggregate effects for environmental concern.

\subsection{Traditional Urban Psychology}

From the Chicago school (Wirth, 1938) to the postcolonial discourse (Amin \& Graham, 1997), new economic geography (Scott \& Storper, 2015) or even planetary urbanization (Brenner \& Schmid, 2014); everybody can agree that human agglomeration in space of some magnitude, or gradients in population density precede all urban phenomena. We expect this minimum consensus on the urban as such to be distinguishable more clearly in many Southern societies (Harpham, 1994). Extant, partially joint analysis of such crowding and associated changes to social and physical environments in traditional urban psychology (Figure 3, purple constructs) suggest mostly negative effects for environmental concern (Figure 3, red paths). This however becomes less clear when taken to different cultural settings, and might even become positive in India.

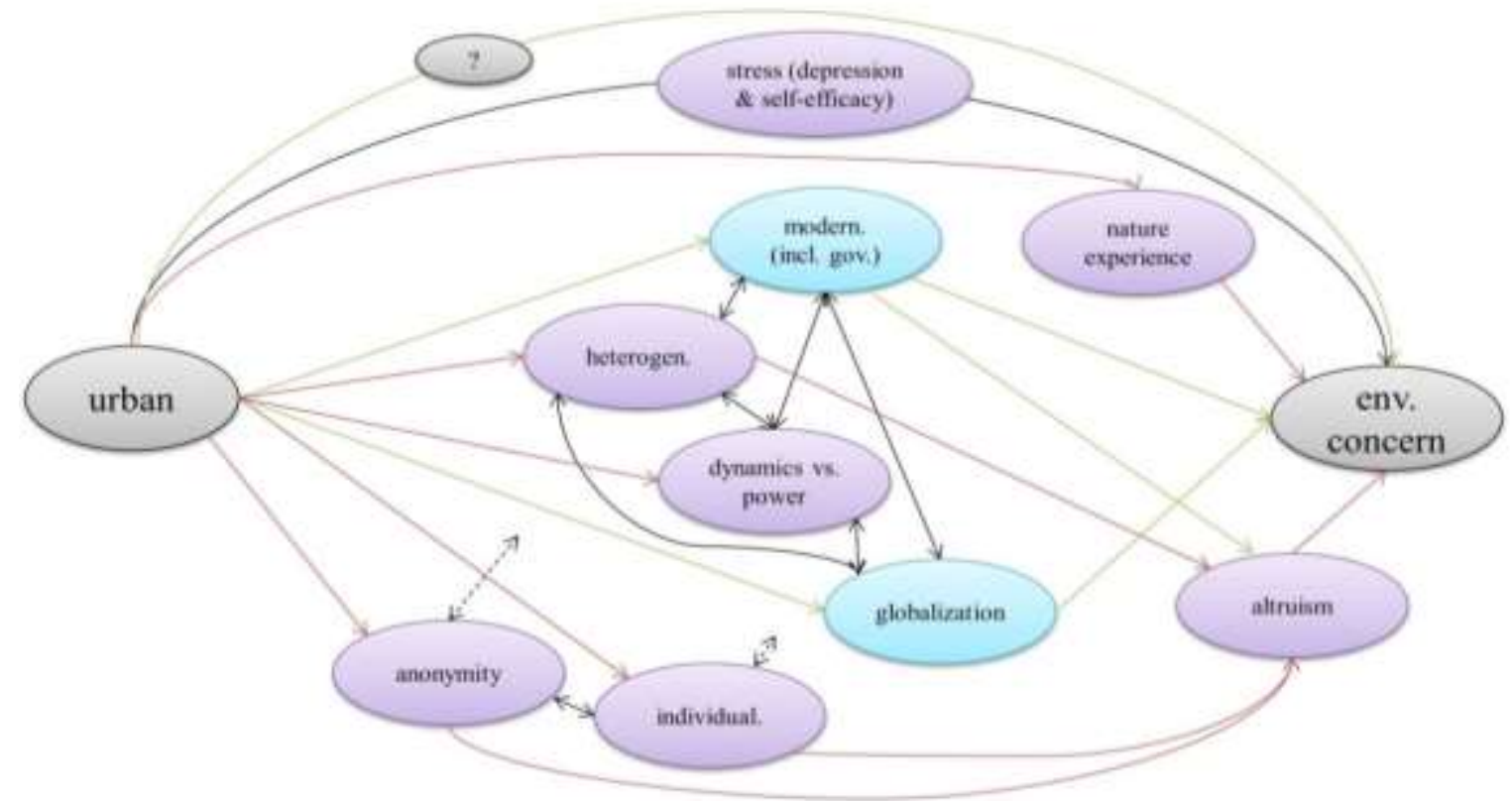

Figure 3. Theoretical Pathmodel (selective). Selective representation of theoretically motivated pathways. Purple denotes more "traditional", and blue more "Southern" mediators. Green arrows denote main suspected positive contribution to overall positive effect, red arrows suspected negative contribution, and black unclear contributions even without cultural uncertainties. 
Perhaps most frequently examined here, and most direct psychological consequence of urbanization as such too, is increased sensory stimulation. It is widely accepted to result in stress, and eventually often depression (Evans, 2003). Worrying however exhibits direct positive links to environmental concern (Helm, Pollitt, Barnett, Curran, \& Craig, 2018), such that positive influence from urbanization on concern seems plausible. On the other hand, overstimulation also drives depression through loss of self-efficacy (Evans, 2003). Since the latter has been established as a positive covariate of environmental concern (Gifford \& Nilsson, 2014), direct psychological effects of urbanization have to remain theoretically ambiguous. Uncertainty in predictions also results from cultural relativity of the psychological effects of crowding in general (Evans et al., 2000).

But there are more specific psychological consequences of large, dense agglomerations that have even been considered defining elements of urbanization. They traditionally imply negative effects on EC more clearly this time, conclusions however become ambiguous when taking the relationships to the Global South: First of all, an overload of stimulation is associated with social withdrawal that causes increased anonymity (Milgram, 1970). Because lack of supportive relationships results in mental health problems, this construct is sometimes analyzed in traditional urban psychology jointly with other effects of crowding (Evans, 2003). As reinforced by anonymity, urban sociology has emphasized how crowding furthermore causes social distinction, or individualism (Tönnies, 1887). But once again, both constructs may acquire different meanings, even leading to adverse effects e.g. in India (Sinha, 2014).

Overall negative mediation of urbanization's effect on EC is then expected for both these constructs most prominently because they are known to reduce altruism (Videras, Owen, Conover, \& Wu, 2012); it is one of the main predictors of environmental concern (Gifford \& Nilsson, 2014), because it is traditionally considered to generalize from concrete experiences to abstract public goods (Brosig, Riechmann, \& Weimann, 2007). Such altruism reduction even through crowding directly is another classic of urban sociology (Milgram, 1970). But again, different cultural contexts may imply mitigation if not reversal of the whole relationship: For example, very low anonymity may cause reactance (Houser, Xiao, McCabe, \& Smith, 2008), and generalization cannot be taken for granted particularly under low generalized morality often found in India (Platteau, 2000).

Beyond mere increases in stimulation, changes in the type of stimulation afforded by cities have also played a role from the beginning - both in defining the urban as such, as well as in studying psychological effects: Further negative mediation of urbanization's effect on EC is expected from heterogeneity. Inevitably, condensing social differences in space emphasizes 
cultural much like economic differences between people. These differences have been documented to affect altruism negatively through dilemma behavior (Anderson, Mellor, \& Milyo, 2008) ${ }^{8}$. Moreover, heterogeneity likely experiences positive feedback from exacerbating anonymity, which links to heterogeneity through individualism (Alesina \& La Ferrara, 2000). However, segregation might limit perception of differences particularly in many polarized, Southern cities (Edensor \& Jayne, 2012). Cultural relativity also casts doubts on heterogeneity effects in general, and of inequality and cultural heterogeneity consequences for (generalized) altruism under Indian beliefs in dharma in particular (Matilal, 2017).

Emergence of such heterogeneity then relies on opportunities for socio-economic dynamics as a catalysator, and may even itself produce them (Simone, 2014). Increased physical mobility required by dense built environments often fosters freedom for social change (Fielding, 1992). But it favors e.g. the rise of individualism also through increasing anonymity, and all of these ultimately lead to negative repercussions for altruism (Marwell \& Schmitt, 1972). All in all, negative mediation of urbanization's effect on environmental concern is suggested by traditional urban psychology again here. This claim is reinforced by negative repercussions on place attachment: It decreases in dynamics even more than in anonymity and individualism, but positively predicts environmental concern (Lewicka, 2011). Prediction in this case however is further complicated by cultural relativity again: Under social hierarchies across the Global South, norm change in general may still fail because of the very social rigidities it is capable of surmounting (Rao, 1992). Particularly in India, power structures help maintain social norms and meet new ideas with reactance (Nijman, 2015). Generalized morality resulting from altruism, or increased anonymity could ease such control (Platteau, 2000); otherwise and paradoxically, we would expect power to limit dynamics' negative mediation of urbanization.

One last unambiguous aspect traditionally studied by urban psychology exemplifies qualitative changes to the physical built environment: Loss of nature experience and replacement of restorative environments with stressors is an obvious effect of urbanization especially in Southern megacities (Amel et al., 2017). Joint analysis of urban stressors also extends to this construct already (Evans, 2003). Nature experience has been established as one of the strongest positive predictors of environmental concern across societies (Gifford $\&$ Nilsson, 2014). But since concern usually affects the natural environment positively, this relationship likely exhibits self-reinforcing effects (Bettencourt \& West, 2010).

\footnotetext{
${ }^{8}$ If not stated otherwise, effects apply to particularized altruism first, before generalizing.
} 
In sum, we hypothesize that traditional urban features like heterogeneity and socio-economic dynamics, anonymity and individualism, as well as altruism reduction and loss of nature experience will lead to reduced environmental concern. Crowding may either reinforce this through decreased self-efficacy, or mitigate it through depression, whereas Indian particularities could inhibit many of the effects (e.g. power structures in case of dynamics).

\subsection{Southern Urbanization}

Urbanization in the Global South of the $21^{\text {st }}$ century is moreover associated with qualitative changes in some stimuli that are already widespread in rural areas in the North. These processes (Figure 3, blue bubbles) do thus not regularly feature in (Northern) psychological analyses of urbanization to date. But even though this too is much less clear particularly in India, positive net effects on environmental concern become more likely when adding them to the model. This is because of individually well-established direct links to both concern (green arrows), and some of the traditional mediators outlined above.

Modernization perhaps constitutes the most prominent example here: Economic activity inevitably starts out from where humans settle, and some cities reversely only came to exist historically as "giant capitalist factories" (Harvey, 1973). ${ }^{9}$ Often even confused with the urban as such, lifestyles associated to economic modernization are equally found e.g. in remote Northern mountain resorts today, and sometimes even considered to vary within Northern cities most strongly (Dear, 2000). While such variation is also found within many Southern cities, persistant dual economies still tie economic development to urbanization closely on a larger scale (Edensor \& Jayne, 2012; Roy, 2009). Wealthy gated communities, for an extreme example, are only found relatively close to cities. But they are often less urban than informal settlements, i.e. smaller and less dense.

Southern urban psychology has already decomposed effects of urbanization as such with regard to this construct too, but neglected others thereby (Chen \& Ren, 2016). Even in the North but without explicit modeling, modernization is the presumed main mediator behind positive overall effects of urbanization on environmental concern (Berenguer et al., 2005). Rather than to economic development directly, this has been attributed to many empirical correlates that drive environmental concern (Inglehart \& Baker, 2000) and can be subsumed under a wider, sociological concept of modernization: Education, rationality, longterm orientation, self-efficacy and openness to experience all foster pro-environmental attitudes.

\footnotetext{
${ }^{9}$ Socio-economic and physical dynamics (migration) should mediate such feedback.
} 
Large, dense agglomerations may finally also result in political 'modernization', or improvements in governance: Agglomerations of people create incentives for public good provision (Roy, 2009), and rule of law can result from formalization of land titles required under increasing density (Scott \& Storper, 15). Other elements of modernization often exhibit mutual reinforcement with improved governance, and thus also with power structures (Glaeser, La Porta, Lopez-de-Silanes, \& Shleifer, 2004).

Such cultural relativity extends to other elements of modernization as well, and hence to positive mediation in the aggregate (Heitzman, 2008). But perhaps more importantly, modernization in addition carries the potential to mitigate if not invert negative expectations for effects of more traditional mediators of urbanization on environmental concern: We expect socio-economic but also physical dynamics to equally facilitate e.g. economic development and itself benefit from e.g. education (Harding \& Blokland, 2014). Because of this and through a competition for ideas and economic success, modernization will likely also increase in heterogeneity (Herzer \& Vollmer, 2012). Further, modernization could mitigate anonymity because it fosters openness to experience (McCrae, Terracciano, \& et al., 2005), even though the reverse is also possible due to reduced dependence on informal insurance (Simone, 2014). It is commonly assumed that modernization moreover exacerbates individualism (Vandello \& Cohen, 1999), which is reinforced by feedback through heterogeneity (McCrae et al., 2005). ${ }^{10}$ But under Indian collectivism, relational independence with positive repercussions on altruism might be more likely (Sinha, 2014).

Income could finally boost altruism directly, because the latter is often considered a luxury good. Positive direct effects could extend to generalized altruism, a norm learned through education or experiences with modern governance. Generalized altruism may thus reinforce modernization, as it reversely benefits modern economic exchange. Note however that such reinforcement might be limited by negative feedback to environmental conditions, and if Indian power rigidities, or polarized interests because of heterogeneity, prevent positive feedback through governance (Hirschman, 1970).

Another positive mediator, and one of the main reasons why modernization may be concentrated in cities, is furthermore its mutual causation with globalization (Brenner, 1998). Even though this link remains controversial again under Indian extractivism (Sinha, 2014), globalization-induced norm spread also benefits from citiy infrustructure directly (Sassen, 1993). This effect could be enhanced under lack of technological innovation still widespread

\footnotetext{
${ }^{10}$ Heterogeneity, dynamics and anonymity may also inhibit modern governance, partially through lack of generalized morality (Hirschman, 1970).
} 
in many Southern countries (Woods, 2016). In addition to mentioned reinforcement with modernization, we expect positive aggregate mediation of urbanization's effect on environmental concern by globalization, because it is a vehicle for potentially progressive norms, that may enhance innovation of attitudes in modernization processes (Leung, Koh, \& Tam, 2015), but are strong positive predictors of environmental concern more generally as well (Gifford \& Nilsson, 2014). Partially, norm innovation will moreover be due to globalization also affecting dynamics and heterogeneity positively (Parnell \& Oldfield, 2014). Whereas this effect could be reversed when new norms smoothen traditional heterogeneities in India (Bhowmik, 2009), commonly assumed mutual causation of globalization with individualism might also be inverted here (see both modernization and power above).

In sum, we hypothesize that Southern urban features like modernization, globalization and governance should positively mediate urbanization's influence on environmental concern, partially because of interaction with traditional features.

\section{Empirical Approach}

\subsection{Model}

Aggregate effects of urbanization onto environmental concern have been shown to result from complex feedbacks between mediators unique to each city. Such an interplay is operationalized most comprehensively by a structural equations model (Appendix A1). To facilitate testing for presence of feedback, it includes all theoretically relevant paths, rather than relying on modification or fit indices.

Interpretation is then facilitated by aggregation into total effects, over all indirect or feedback path coefficients, at a) each mediator from urbanization as such, and at b) environmental concern from each mediator (Bollen, 1987). That is, in the system of equations of significant effects, either a) urbanization as such or b) one mediator at a time is set to 1 . Then the system is solved for a) one mediator at a time, or b) environmental concern to obtain total effects.

Estimation of the structural equation model has to take into account that, on one hand, mediation spreads issues arising from reverse causality to all equations of the system, and on the other hand, the lack of available exogenous variables compared to the number of such endogenous variables. We overcome this by obtaining additional instruments from spatial lags of exogenous variables like distance to city center or caste (Drukker et al., 2013), and by then 
(re-) estimating one equation at a time (Wooldridge, 1996) ${ }^{11}$. As distance goes to infinity, such lags have been found to validly instrument right hand side variables without separately affecting the left hand side (Halleck Vega \& Elhorst, 2015). All conventional validity checks and corrections are also avaiable, and robust test statistics are applied in case of weakness (Stock et al., 2002). Because this estimation procedure has not been extended to latent variable models, we first confirm generalization of latent variable results to parceling, or average factors (Little, Cunningham, Shahar, \& Widaman, 2002).

\subsection{Measurement}

Operationalization of constructs of interest from the respective literature (see section 2) yields a multidisciplinary indicator set with mostly multiple measures per variable (see Appendix A2 for details). We obtain these measures from a large survey that first of all provides manifest variables at village level, like remote sensing data as a measure of population density (Hoffmann et al., 2017). Other manifest examples at the household level comprise the degree of formalization of land titles. Some constructs such as altruism are available from incentivized games: Our altruism measure is the $2^{\text {nd }}$-mover decision of a trust game.

A standardized questionnaire was embedded in the survey to measure latent variables, but here the survey context required condensation of extant scales to very few items each (Raubenheimer, 2004). ${ }^{12}$ As far as possible, we still applied utmost care in ensuring highest possible measurement validity: Counseling from local scientists, several rounds of translation, as well as thinking aloud fed into scale development (van de Vijver \& Tanzer, 2004) ${ }^{13}$.

As the main example of such a latent variable, we measure environmental concern by a shortened version of the popular New Environmental Paradigm (Dunlap et al., 2000). While the meaning of environmental concern may arguably vary substantially with cultural context, the scale has been found applicable to a variety of Southern understandings (Schultz et al., 2016). In India, a four-factor structure turned out to be most appropriate (Khan, Khan, \& Adil, 2012); selecting only one item each seems feasible considering reports of high overall reliability. However, we regress on a narrowed, face-valid measure of concern as a baseline measure (two items only): Only this scale exhibits satisfactory split-half reliability in the

\footnotetext{
${ }^{11}$ Limited information estimation entails efficiency losses compared to full (system) information approaches, but remains (asymptotically) unbiased.

${ }^{12}$ Operationalization of depression, self-efficacy and place attachment not feasible within constraints of our survey. Likely mediation discussed based on unexplained overall effect (see section 4).

${ }^{13}$ Explicit modeling of respondent bias is not feasible in our case, since the most important sources of respondent bias (understanding of item content and social desirability) are controlled already by education and individualism (P. M.
} 
original data (0.5), whereas omega-reliability of the full four-factor version only becomes acceptable (0.55) when correcting for interviewer bias through imputing $22 \%$ of observations with audiorecord-based paradata (Blackwell, Honaker, \& King, 2015). We ensure generalization of our conclusions to this sample as a robustness check. ${ }^{14}$

All mediator items are eventually subjected to exploratory factor analysis to justify indexing in case of multiple indicators per variable, and to maximize model parsimony and facilitate estimation in case of single item constructs (i.e. reduce number of variables to be instrumented). Factors extracted by and large conform to theoretical mediators of urbanization, at least when taking into account for loadings as well as reliability the breadth of the concepts: Solely one distinction sharpens only in separate analysis (modernization and dynamics), few superfactors emerge that are kept disaggregated (e.g. power and nature experience), and the hypothesized factor is not evident in the data only for the case of heterogeneity (inequality enters path model separately) $)^{15}$.

\subsection{Data}

We conduct a randomized survey with 1204 individuals across two rural-urban transects in Bangalore / India (Figure 4, see also introduction).

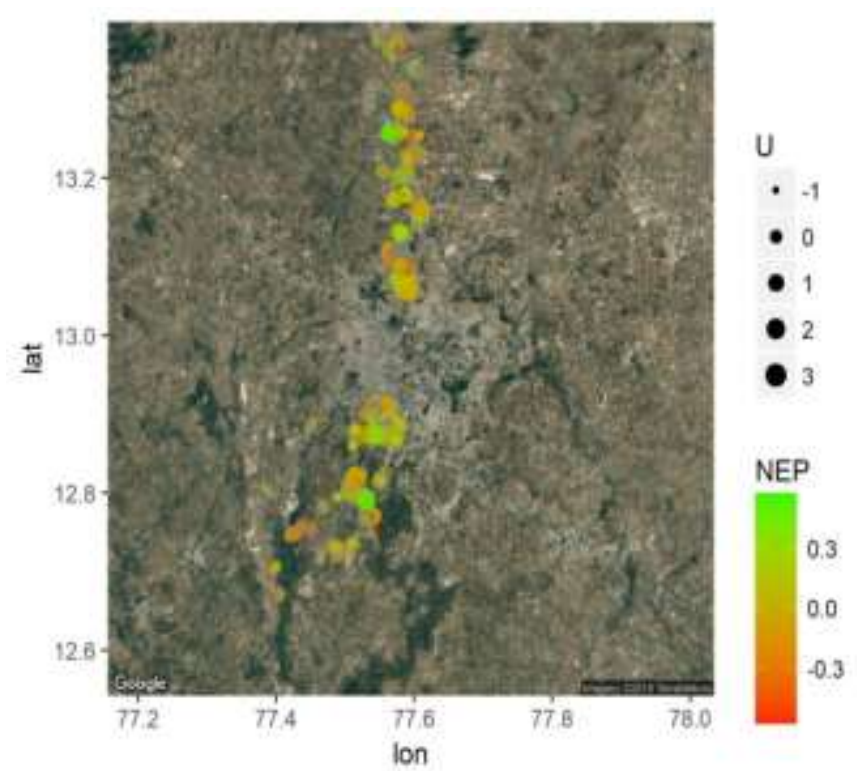

Figure 4. Environmental Concern (NEP) by Urbanization (U). Location of observations on two transects in Bangalore / India. Narrow, face-valid concern, but error-imputed data for emphasis in demonstration.

Podsakoff, MacKenzie, Lee, and Podsakoff (2003)). For interviewer bias, see the example of dependent variable measurement.

${ }^{14}$ Convergent validity for concern was mixed, which could however at least partially be due to culture rather than measurement. Correlations were as hypothesized in case of altruism, income, education, age, status (caste) and being female, but not for agreeableness, openness, knowledge, abstract thinking and time preference.

${ }^{15}$ Mutual dependence is still suggested by literature (e.g. Scott \& Storper, 2015). Pathways modeled reflect slightly different dependencies e.g. on modernization (Herzer \& Vollmer, 2012). 
Continuous and representative variation with regard to constructs of interest is thereby ensured via stratification by urbanization at the level of 61 village clusters (Hoffmann et al., 2017), applying sampling weights as an additional robustness check ${ }^{16}$, and modeling duration of residence as a control for migration. In particular, we go beyond within-city variation by reaching out up to 40 kilometers from the city center into agriculture-dominated, village-only India.

Understanding the environmental impact of Indian urbanization may be decisive to climate change predictions, since the largest absolute increases of urban dwellers until 2050 are projected to emanate here (United Nations, 2018). But what is more, we regard this Southern megacity as a promising example of joint influence of all hypothesized mechanisms, and hence a critical case for added value from the "unified" urban psychology proposed more generally: On the one hand, Bangalore exhibits strong variation with regard to many Southern urban phenomena; intertemporal development can be observed in a cross-section here (Kraas $\&$ Mertins, 2014). But on the other hand and where not already covered by these, many of the phenomena known from traditional urbanization are introduced by strong globalization e.g. through norm transfer as well; decisively, especially these have also been documented to be reinterpreted according to uniquely Indian mechanisms (Nair, 2005).
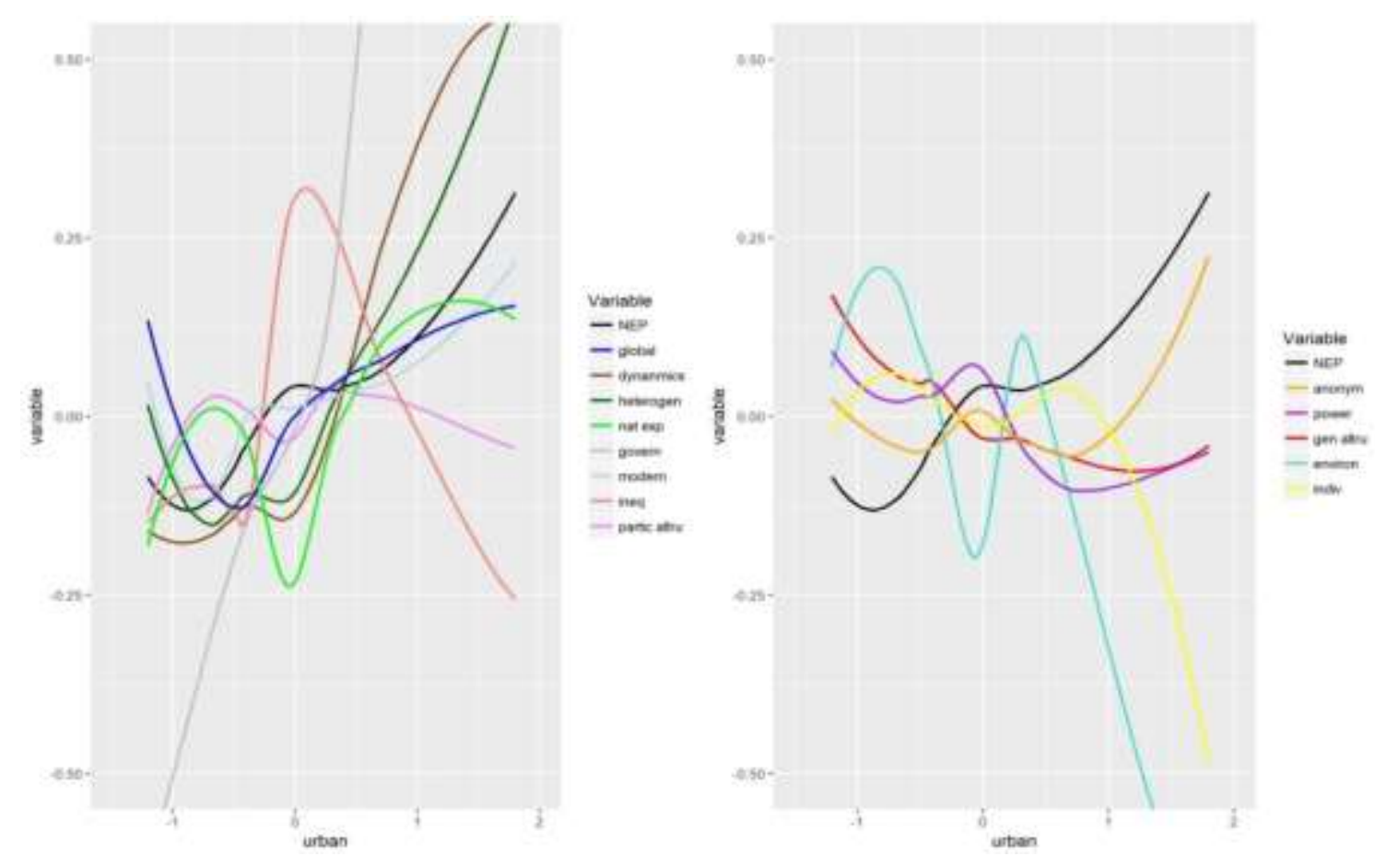

Figure 5. All model variables positively correlated to urbanization on the left, and negatively on the right. Plots of locally weighted regression of all model variables on urbanization. For emphasis in demonstration, error imputed standardized data used.

\footnotetext{
${ }^{16}$ Underrepresentation of densily populated urban wards may result from sampling at simple random within villages. Given the Indian hierarchical background, within households we selected decision makers as the practically relevant analysis.
} 
Such variation is captured by our sample: All constructs of interest vary significantly with urbanization (Figure 5, Appendix A2). High means and standard deviations in case of modernization $(0.5(0.15))$, globalization $(0.6(0.28))$ and heterogeneity $(0.38(0.14))$ suggest particularly strong Southern influences. Uniquely Indian effects in case of some traditional mediators are hinted at by (still) low means, but high standard deviations and unexpected signs of the link to urbanization (from a Northern point of view, e.g. anonymity $(0.25(0.27))$ and individualism $(0.17(0.19)))$.

\section{Results and Discussion}

Inferential findings confirm the contribution of each of the paths modeled to explaining how the unique Indian nature of urbanization in Bangalore creates positive effects for environmental concern (Figure 6): Positive mediation by Southern understandings of urbanization (modernization and globalization) still dominates negative contributions from some traditional subjects of urban psychological investigation (heterogeneity and dynamics); but other more traditional effects of crowding acquire positive meaning in Bangalore (anonymity and generalized altruism), some of which could even persist beyond modernization (individualism and governance), or even generalize to other Southern cities (nature experience). Compared to minor efficiency gains when moving from parcels to latent variable modeling, when regressing on the full NEP scale or applying sampling weights, we thereby regard spatial instrumental variable regression as the best model and employ it for aggregation and interpretation. This is because despite signs of weak instrument problems in a few cases (e.g. governance and generalized altruism) ${ }^{17}$, this specification replicates most effects from OLS, but sometimes adds to them in case of many other constructs (modernization, anonymity and nature experience; Appendix A3).

At more detail and as expected, overall positive effects of urbanization on environmental concern are driven largely by two mediators unique to both urbanization of the Global South in general, and Bangalore in particular: Positive aggregate coefficients both from urbanization to modernization, and from it to concern exceed effect sizes in case of traditional constructs by about factor 50 to 1000 . Considering its many significant relationships to other constructs that instrumentation even contributes to further (Appendix A3), comparatively weak factoring apparently does not harm findings in this case. Increased efficiency through better instruments is thus expected to only sharpen results. 


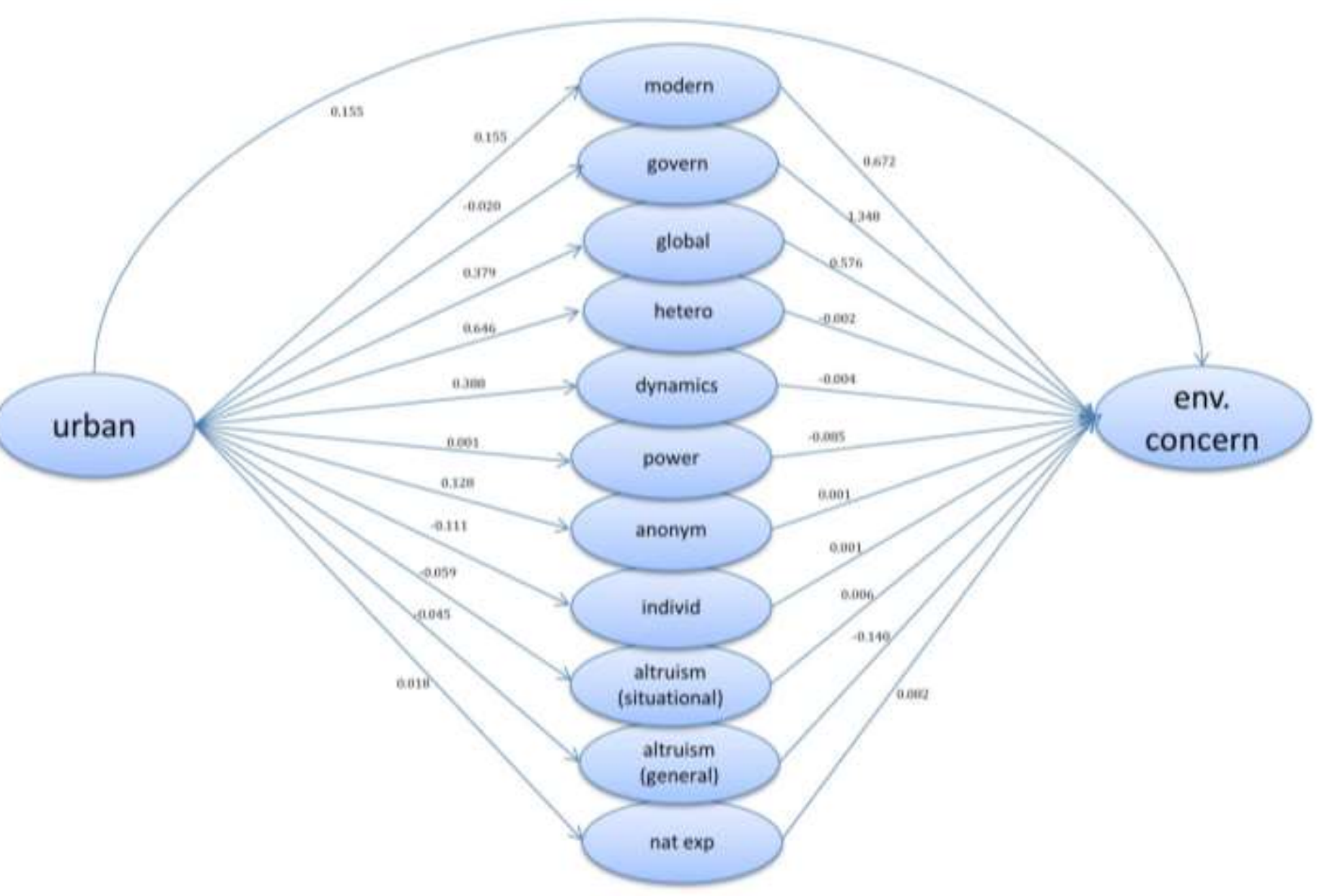

Figure 6. Calibrated Path Model (Aggregated). Coefficients aggregated over all robust effects from equationwise spatial instrument estimation of structural model (raw data, no population weights, parceled variables). Hence, paths between mediators not shown. For parsimony too, social norms of NEP and dynamics, as well as environmental conditions and inequality omitted from representation.

Bangalore's strong globalization then acts as the main enhancer of modernization's effect through mutually positive causation; additionally, it mediates urbanization for concern positively itself (Figure 6). Further reinforcement of modernization's effect stems from positive mediation by governance: It decreases in urbanization, which may be explained by the speed of this process in Bangalore. But in addition, governance also exerts negative repercussions on modernization (Appendix A3), which could be understood as crowding out of economic activity by initially bad bureaucratic traditions in India. Both effects do not conform to our hypotheses (section 2.2) and are expected to change sign in other Southern cities, or under stronger instruments even in Bangalore.

Qualitative stimulus change implied by socio-economic dynamics and heterogeneity acquires its traditional, negative connotation in Bangalore (Figure 6): Both constructs increase in

\footnotetext{
${ }^{17}$ We suspect weak instruments leading to efficiency issues even under robust statistics, if coefficients stable across most other specifications become significant when dropping other instrumented (endogenous) variables in two-stage least squares. In these cases, we include the insignificant but instrumented coefficient in aggregation and interpretation.
} 
urbanization, but affect altruism negatively. Dynamics and heterogeneity thus mediate negative effects of urbanization on altruism, rather than reinforcing positive contributions of modernization and globalization as hypothesized. Modernization and globalization are partially responsible for positive influence from urbanization, but any direct reinforcing feedback disappears under instrumentation - after it had already been unstable across OLS specifications. ${ }^{18}$ Bangalore's unique strength in facilitating environmental concern through the Southern urban notion of globalization may thus have a downside of reinforcing traditional, negative pathways. One could imagine how feedback from dynamics to modernization would more than compensate this in other Southern cities or with stronger instruments, such that uniquely Southern factors still account for the largest share of a positive overall effect. But low levels of dynamics perhaps indicative of famed Indian social rigidities prevent this in our sample. Because of strong influence of the social norm of dynamics, we consider it unlikely that Southern urban correlates will break these rigidities before losing their own, direct beneficial influence on environmental concern.

Other, traditional and more direct psychological implications of urbanization as such acquire a more positive and uniquely Indian meaning for environmental concern, especially once we consider feedback. Albeit unlikely to remain stable across time and space, these mechanisms rarely depend decisively on Southern notions of the urban. The ones that persist might thus even become decisive for aggregate positive mediation once effects of modernization and globalization fade away. First, environmental concern is not affected by its social norm. Still low levels of concern in India could be the reason, given that the norm usually exerts strong influence there. More positive effects are thus likely as urbanization progresses.

Then, unexpectedly positive albeit small mediation emerges from anonymity not due to, but despite links to modernization: Anonymity benefits from urbanization as expected, but also leads to increases in altruism. One possible reason for this could be mentioned reactance to initially very low levels of anonymity in India. As anonymity is reinforced in addition by heterogeneity and dynamics, it thus even partially mitigates negative contributions of other traditional constructs in our sample. But its positive aggregate contribution also remains limited, because aspects of modernization like openness to experience lead to decreases in anonymity. This unexpected mediation only appears after instrumenting, such that it may be regarded as robust to efficiency concerns. If the sign of the relationship changed to confirm our hypothesis at a later stage of urbanization, this would create further positive reinforcement of a Southern notion of urbanization through a traditional one. But given comparative effect

\footnotetext{
${ }^{18}$ This replicates in case of economic inequality, despite of it being unrelated to heterogeneity.
} 
sizes, in the aggregate we would then still expect dominant negative contribution of anonymity for our case much like in general.

We find individualism to neutralize anonymity's positive contribution through negative aggregate mediation (Figure 6). Individualism affects environmental concern positively because of already expected positive reinforcement between the two traditional constructs on the one hand, but also because individualism in fact decreases in both urbanization and modernization on the other hand robustly. This could be explained by cultural relativity of psychological consequences of crowding, and by relational independence replacing collectivism in the case of India. Again, likely persistent Indian particularities thus lead to reinforcement by Southern urban correlates, rather than mitigation of negative contributions. If anonymity changes sign at later stages of urbanization, positive contributions of individualism may hence obtain. This will however depend on normalization of anonymity's effect much like relative magnitudes of other feedback.

In nature experience we encounter another unexpected positive mediator of urbanization materializing despite influence from modernization. Environmental conditions decrease with urbanization (Appendix A3). But nature experience still benefits from aggregate urbanization, and transmits this to environmental concern. An explanation for this might be mediation of the relationship by emotional connection to nature; farmers' struggle for livelihood may not create positive experiences conducive to this (Bettin \& Wollni, 2019). This effect is only revealed by controlling reverse causality, and logically seems to generalize to other Southern cities readily, too.

One last positive mediation finally emerges for the case of the traditional construct generalized altruism. It parallels particularized altruism in decreasing in density-induced sensory overstimulation. But it furthermore exhibits negative direct effects on concern, which may point to substitution between relationship investments (Mikulincer \& Shaver, 2003): Once survival does not depend on concern for concrete environments anymore, the circle of humans one cares for widens first. ${ }^{19}$ This double negation may thus not persist for long even in India. It could moreover merely be due to efficiency issues caused by weak instruments for power and governance (Appendix A3).

The remaining portion of the overall effect unexplained by our model could finally point to confirmation of traditional effects beneficial to environmental concern and likely to persist: If

\footnotetext{
${ }^{19}$ Note that positive mediation is reinforced also by counterintuitive, likely uniquely Indian feedback through power structures: They prevent modern governance, but perhaps because of motivated reasoning, increase in both urbanization and generalzed altruism (Friedman et al. (2018).
} 
urbanization as such indeed resulted in increased stress, depression could foster concern more generally and explain the remaining positive effect. Compared to that, we regard mediation by both self-efficacy and place attachment as less decisive at least in our case; they would predict negative mediation. Despite all this and given the magnitude of the unexplained effect, it seems plausible that prediction will not only be improved by operationalizing these constructs; further theorizing may benefit our understanding as well.

\section{Conclusion}

Extant urban psychology has barely considered how different aspects of the urban experience differentially and interactively affect the human psyche. We demonstrate how predicting urbanization's effect on environmental concern depends on this: Our replication of a positive urbanization-concern nexus is driven by the Southern mediators modernization and globalization; generalization from Northern cities would have been misguided because of the narrow underlying set of mechanisms. But individual modeling of mediators may equally lead to false predictions: Effects of Indian urbanization are only fully understood once considering how negative contributions of some traditional urban features are reinforced by modernization and globalization, whereas others acquire a completely new and sometimes positive meaning in Bangalore (see section 4). Only this detailed understanding allows us to predict that some of the positive mechanisms encountered seem likely to endure, or replicate at certain stages of Southern urbanization more generally. In many Northern cities that current climate change is still driven by, this seems less likely due to dominance of more traditional mediation.

This promising finding however needs substantiation from case sensitive replication of our results in other cities in the future. Like urban studies in general, this remains an ongoing project also with respect to exploring further culturally relative theories of psychologically relevant urban features. Last but not least, these findings will have to be scrutinized for their relation to actual pro-environmental behavior: An attitude-behavior gap could explain negative real-world repercussions also of cities like Bangalore.

On a methodological note, we finally consider further research on both universal validity of constructs and validity of scales as decisive. More extensive measures than we had the chance to employ e.g. in case of environmental concern would certainly improve faith in findings. But from our point of view, cross-cultural measurement invariance could still mask culturally relative understandings of item content, and more gravely, miss more relevant mental patterns to predict pro-environmental behavior (Van de Vijver \& Tanzer, 2004). 


\section{Appendix}

Table A1. Theoretical Pathmodel

\begin{tabular}{|c|c|c|c|c|c|c|c|c|c|c|c|c|c|c|}
\hline $\begin{array}{l}\text { INDEPENT } \\
\text { VARIABLES }\end{array}$ & dependent (eq & $\begin{array}{l}\text { tions) } \\
\text { GEN. } \\
\text { ALTRU. }\end{array}$ & $\begin{array}{l}\text { PART. } \\
\text { ALTRUISM } \\
\end{array}$ & DYNAM. & $\begin{array}{l}\text { HETERO. } \\
\text { (INEQ.) }\end{array}$ & POWER & ANONYM. & $\begin{array}{l}\text { INDIVI- } \\
\text { DUALISM } \\
\end{array}$ & MODERN. & GLOBAL. & GOVERN. & $\begin{array}{l}\text { NAT. } \\
\text { EXPE- } \\
\text { RIENCE } \\
\end{array}$ & $\begin{array}{l}\text { ENVIRON. } \\
\text { CONDITIONS }\end{array}$ & URBAN \\
\hline $\begin{array}{l}\text { NEP } \\
\text { (LAG_NEP) }\end{array}$ & $\begin{array}{l}\text { Gifford \& } \\
\text { Nilsson, } \\
2014\end{array}$ & & & & & & & & & & & & $\begin{array}{l}\text { Bettencourt } \\
\& \text { West, } \\
2010\end{array}$ & \\
\hline $\begin{array}{l}\text { GENERALIZED } \\
\text { ALTRUISM }\end{array}$ & $\begin{array}{l}\text { Gifford \& } \\
\text { Nilsson, } \\
2014\end{array}$ & & $\begin{array}{l}\text { (no } \\
\text { evidence) }\end{array}$ & & & $\begin{array}{l}\text { Platteau, } \\
2000\end{array}$ & & & & & $\begin{array}{l}\text { Platteau, } \\
2000\end{array}$ & & & \\
\hline $\begin{array}{l}\text { PARTICULAR. } \\
\text { ALTRUISM }\end{array}$ & $\begin{array}{l}\text { (double } \\
\text { check for } \\
\text { partic. NEP) }\end{array}$ & $\begin{array}{l}\text { Brosig et } \\
\text { al., } 2007\end{array}$ & & & & & & & & & & & & \\
\hline DYNAMICS & & $\begin{array}{l}\text { (through } \\
\text { part. } \\
\text { altru.: see } \\
\text { there) }\end{array}$ & $\begin{array}{l}\text { (through } \\
\text { anonymity: } \\
\text { Marwell et } \\
\text { al., 1971) }\end{array}$ & & $\begin{array}{l}\text { Simone, } \\
2014\end{array}$ & $\begin{array}{l}\text { (see } \\
\text { heterog. } \\
\text { below) }\end{array}$ & $\begin{array}{l}\text { (logical } \\
\text { reverse } \\
\text { cause) }\end{array}$ & $\begin{array}{l}\text { (see } \\
\text { heterog. } \\
\text { below) }\end{array}$ & $\begin{array}{l}\text { Harding \& } \\
\text { Blokland, } \\
2014\end{array}$ & & $\begin{array}{l}\text { (through } \\
\text { heterog. } \\
\text { logically) }\end{array}$ & & & $\begin{array}{l}\text { Harvey, } \\
1979\end{array}$ \\
\hline (LAG_DYN) & & & & $\begin{array}{l}\text { (alternat. } \\
\text { rigidity } \\
\text { measure) }\end{array}$ & & & & & & & & & & \\
\hline POWER & & $\begin{array}{l}\text { Platteau, } \\
2000\end{array}$ & $\begin{array}{l}\text { Anderson et } \\
\text { al., } 2008\end{array}$ & $\begin{array}{l}\text { Simone, } \\
2014 \\
\\
\text { Rao, } \\
1992\end{array}$ & & $\begin{array}{l}\text { (through } \\
\text { anonymity: } \\
\text { Hirschman, } \\
\text { 1970) }\end{array}$ & $\begin{array}{l}\text { Alesina \& } \\
\text { La } \\
\text { Ferrara, } \\
2000\end{array}$ & $\begin{array}{l}\text { (through } \\
\text { anonymity: } \\
\text { Alesina \& } \\
\text { La Ferrara, } \\
\text { 2000) }\end{array}$ & $\begin{array}{l}\text { Herzer \& } \\
\text { Vollmer, } \\
2012 \\
\text { (logical } \\
\text { through } \\
\text { governance } \\
\text {,...) }\end{array}$ & & $\begin{array}{l}\text { Hirschman, } \\
1970 \\
\text { (obvious) }\end{array}$ & & & \\
\hline ANONYMITY & & $\begin{array}{l}\text { (through } \\
\text { part. } \\
\text { altru.: see } \\
\text { there) }\end{array}$ & $\begin{array}{l}\text { Videras et } \\
\text { al., } 2012\end{array}$ & $\begin{array}{l}\text { (through } \\
\text { power) }\end{array}$ & & $\begin{array}{l}\text { Platteau, } \\
2000\end{array}$ & & (classic) & & & $\begin{array}{l}\text { (through gen. } \\
\text { altru.: } \\
\text { Hirschman, } \\
\text { 1970) }\end{array}$ & & & \\
\hline
\end{tabular}




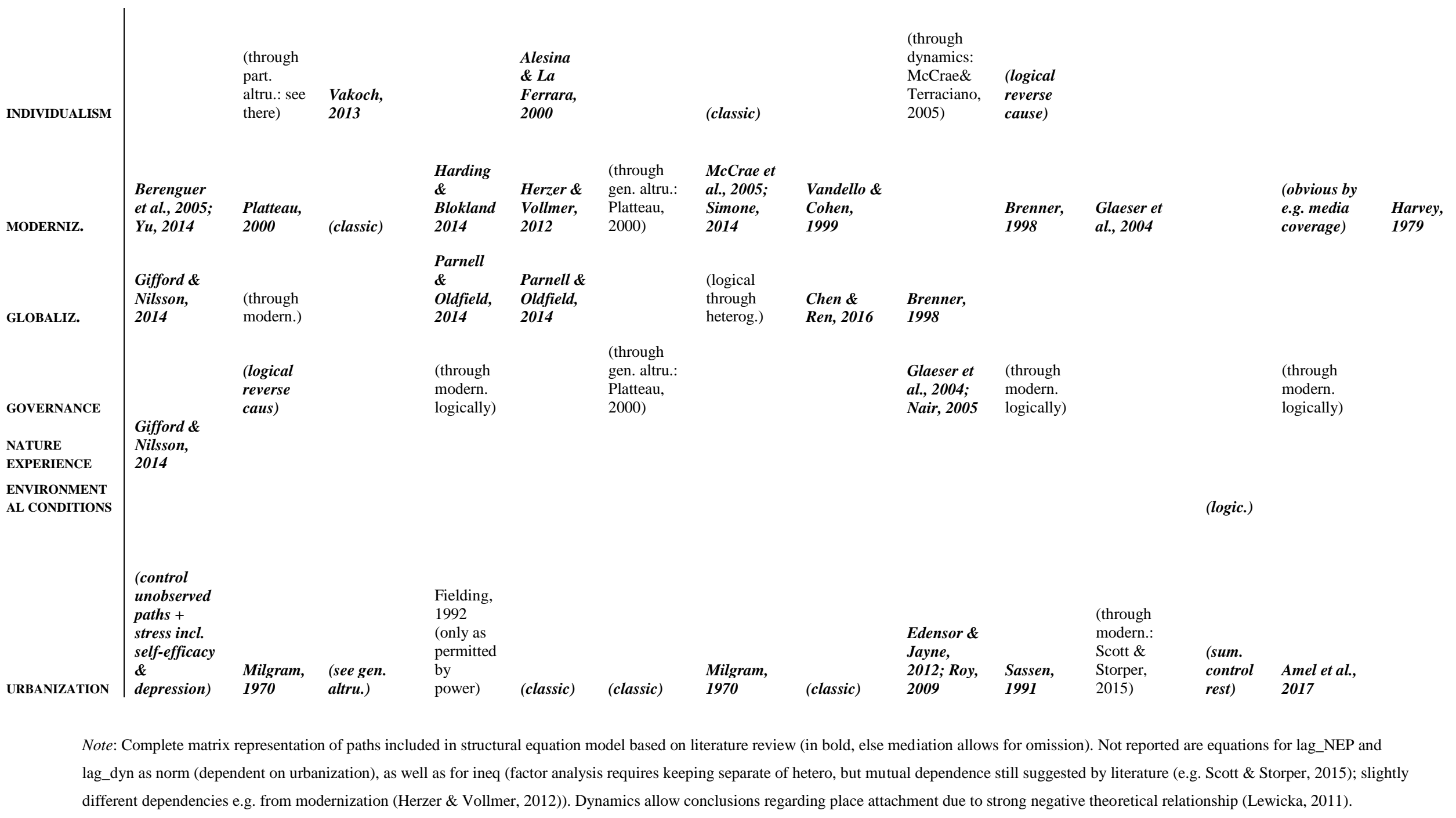




\section{Table A2. Item Statistics: Factor Analysis, Reliability and Descriptive Statistics}

\begin{tabular}{|c|c|c|c|c|c|c|c|c|c|c|c|}
\hline items & & $\begin{array}{l}\text { NEP (raw } \\
\text { data) }\end{array}$ & $\begin{array}{l}\text { NEP } \\
\text { (error } \\
\text { imputa- } \\
\text { tion) }\end{array}$ & $\begin{array}{l}\text { dynamics } \\
\text { (educ. } \\
\text { does not } \\
\text { enter) }\end{array}$ & $\begin{array}{l}\text { moderni- } \\
\text { zation }\end{array}$ & $\begin{array}{l}\text { urban } \\
\text { (distance } \\
\text { sep. } \\
\text { analyzed) }\end{array}$ & indiv & $\begin{array}{l}\text { altruism } \\
\text { (sep. } \\
\text { analyzed) }\end{array}$ & $\begin{array}{l}\text { gover- } \\
\text { nance }\end{array}$ & $\begin{array}{l}\text { globali- } \\
\text { zation }\end{array}$ & $\begin{array}{l}\text { (sep. } \\
\text { analyzed) }\end{array}$ \\
\hline & mean & 0.86 & 0.74 & 0.38 & 0.5 & 0.14 & 0.17 & & 0.13 & 0.60 & \\
\hline & $(s d)$ & $(0.20)$ & $(0.15)$ & $(0.14)$ & $(0.15)$ & $(0.14)$ & $(0.19)$ & & $(0.14)$ & $(0.28)$ & \\
\hline & reliability & 0.50 & 0.55 & 0.38 & 0.65 & 0.79 & 0.30 & & 0.98 & 0.43 & \\
\hline eco-crisis & Dunlap, et al. & & & & & & & & & & \\
\hline balance of nature & (2000); & 0.82 & 0.82 & & & & & & & & \\
\hline limits to growth & Khan et al.. & & 0.30 & & & & & & & & \\
\hline anti-anthropocentrism & & & 0.34 & & & & & & & & \\
\hline time in location (physical mobility, inverted) & & & & 0.44 & & & & & & & \\
\hline time in main occupation (social mobility, inverted) & & & & 0.56 & & & & & & & \\
\hline asset index & & & & & 0.61 & & & & & & \\
\hline global brand knowledge (Tu, Khare, \& Zhang, 2012) & & & & & 0.70 & & & & & & \\
\hline openness to experience & & & & & 0.33 & & & & & & \\
\hline education (years) & & & & 0.39 & 0.57 & & & & & & \\
\hline time preference & & & & & 0.20 & & & & & & \\
\hline distance to city center (inverted) & $0.55(0.26)$ & & & & & 0.64 & & & & & \\
\hline population size of agglomeration & & & & & & 0.63 & & & & & \\
\hline builtup area $\%$ & & & & & & 0.91 & & & & & \\
\hline anonymity (Hite, Voelker, \& Robertson, 2014) & $0.25(0.27)$ & & & & & & & & & & \\
\hline
\end{tabular}


heterogeneity (Piekut \& Valentine, 2016)

inequality (spatial lag of assets)

vertical individualism (Singelis, 1995)

horizontal individualism (")

generalized altruism (Berg et al., 1995)

situational altruism (")

$0.34(0.24)$

$0.48(0.25)$

public good availability

formal land titles

local tradition importance (Tu et al., 2012)

perceived impact international trade (")

power exposure (Nesler, Aguinis, Quigley, Lee, \& Tedeschi,

1999)

nature experience (Bögeholz, 2006)

(environmental conditions: water access)

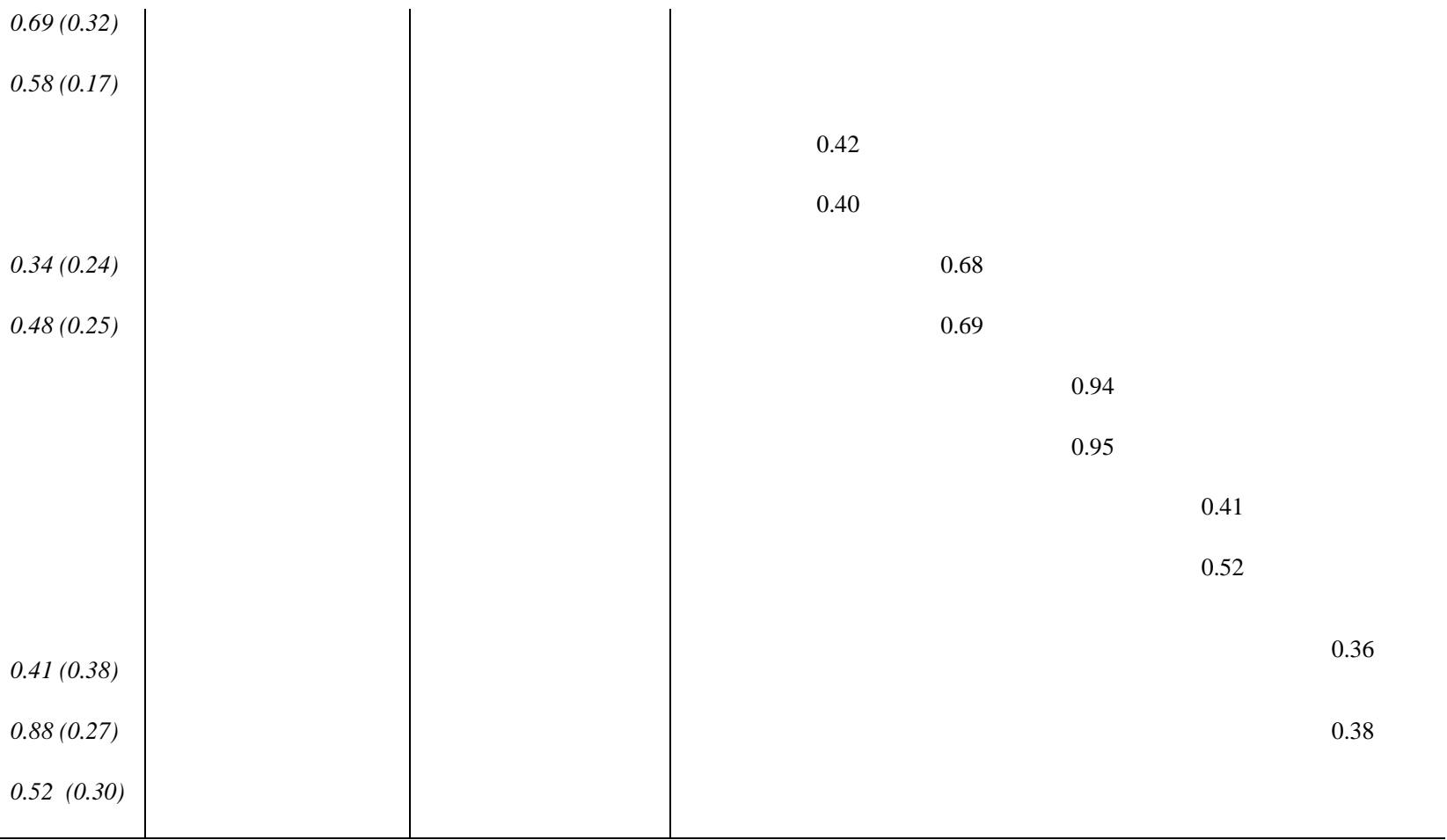

Note: Exploratory factor analysis of all measures entering path model demonstrating convergent and discriminant validity of constructs. Variables constructed from factor means if not indicated otherwise (i.e. single-item measures). Results sharpened by separate analysis for dynamics and modernization; dependent variable anyhow separate, and environmental conditions not included in factor analysis. Loadings from WLS factoring, using varimax rotation. Loadings $<0.3$ omitted from representation. Measurement is straightforward / manifest if not indicated otherwise. Split-half reliability reported for 2item factors, and omega-t for more items. For descriptive statistics variables are normalized between 0 and 1 ; statistics reported for individual variables (row) only, where not part of factors already (column). 


\section{Table A3. Regression Results for Pathmodel incl. Robustness}

\begin{tabular}{|c|c|c|c|c|c|c|c|c|c|c|c|c|c|c|c|c|}
\hline \multirow{2}{*}{$\begin{array}{l}\text { dependent lindependent variable } \\
N E P\end{array}$} & \multicolumn{3}{|c|}{$\begin{array}{l}\text { OLS (latent var model, } \\
\text { original data, face-valid } \\
\text { NEP) }\end{array}$} & \multicolumn{3}{|c|}{ OLS (parceled scales) } & \multicolumn{3}{|c|}{ OLS (sampling weights) } & \multicolumn{3}{|c|}{$\begin{array}{l}\text { OLS (full NEP, error } \\
\text { imputation data) }\end{array}$} & \multicolumn{3}{|c|}{$\begin{array}{l}\text { Spatial IV }(\text { Fuller(4) } \\
\text { estimator, original data, } \\
\text { face-valid NEP) }\end{array}$} & \multirow[t]{2}{*}{$\begin{array}{l}\text { AR } \\
\text { tes }\end{array}$} \\
\hline & & & & & & & & & & & & & & & & \\
\hline altruism (generalized) & -0.095 & $(0.033)$ & $* * *$ & -0.106 & $(0.027)$ & $* * *$ & -0.129 & $(0.024)$ & $* * *$ & -0.082 & $(0.021)$ & $* * *$ & -0.101 & $(0.026)$ & $* * *$ & \\
\hline altruism (situational) & 0.065 & $(0.033)$ & . & 0.080 & $(0.027)$ & ** & 0.094 & $(0.024)$ & $* * *$ & 0.058 & $(0.021)$ & ** & 0.078 & $(0.026)$ & $* *$ & \\
\hline nature experience & 0.081 & $(0.025)$ & $* * *$ & 0.083 & $(0.023)$ & $* * *$ & 0.103 & $(0.024)$ & $* * *$ & 0.039 & $(0.018)$ & * & 0.082 & $(0.023)$ & $* * *$ & \\
\hline environmental conditions & 0.044 & $(0.116)$ & & 0.064 & $(0.046)$ & & -0.037 & $(0.022)$ & . & 0.010 & $(0.036)$ & & 0.063 & $(0.079)$ & & \\
\hline urban & 0.099 & $(0.026)$ & $* * *$ & 0.070 & $(0.033)$ & $*$ & 0.037 & $(0.016)$ & $*$ & 0.075 & $(0.026)$ & $* *$ & 0.063 & $(0.035)$ & . & \\
\hline lag_NEP (norm) & & & & & & & & & & & & & -1.433 & $(1.895)$ & & \\
\hline modernization & 0.256 & $(0.066)$ & $* * *$ & 0.192 & $(0.042)$ & $* * *$ & 0.107 & $(0.035)$ & $* *$ & 0.130 & $(0.033)$ & $* * *$ & 0.189 & $(0.042)$ & $* * *$ & \\
\hline \multirow[t]{2}{*}{ globalization } & 0.343 & $(0.109)$ & $* * *$ & 0.131 & $(0.030)$ & $* * *$ & 0.021 & $(0.026)$ & & 0.101 & $(0.023)$ & **** & 0.121 & $(0.030)$ & $* * *$ & \\
\hline & 0.085 & 0.071 & & 0.095 & & & 0.076 & & & 0.078 & & & 0.104 & $(10.030)$ & $(0.51)$ & \\
\hline \multicolumn{17}{|l|}{ altruism (generalized) } \\
\hline urban & -0.152 & $(0.061)$ & $*$ & -0.103 & $(0.032)$ & $* *$ & -0.132 & $(0.019)$ & $* * *$ & & & & -0.215 & $(0.097)$ & $*$ & \\
\hline altruism (situational) & 0.500 & $(0.037)$ & $* * *$ & 0.500 & $(0.025)$ & $* * *$ & 0.561 & $(0.024)$ & $* * *$ & & & & 0.519 & $(0.031)$ & $* * *$ & \\
\hline heterogeneity & 0.029 & $(0.036)$ & & 0.033 & $(0.031)$ & & -0.007 & $(0.032)$ & & & & & -0.128 & $(0.112)$ & & \\
\hline modernization & 0.145 & $(0.070)$ & $*$ & 0.084 & $(0.043)$ & . & 0.160 & $(0.043)$ & $* * *$ & & & & 0.847 & $(0.510)$ & . & $*$ \\
\hline \multirow[t]{2}{*}{ governance } & -0.033 & $(0.042)$ & & -0.002 & $(0.033)$ & & 0.027 & $(0.022)$ & & & & & 0.094 & $(0.132)$ & & \\
\hline & 0.091 & 0.072 & & 0.257 & & & 0.345 & & & & & & 0.258 & $(0.164)$ & $(0.13)$ & \\
\hline \multicolumn{17}{|l|}{ altruism (situational) } \\
\hline heterogeneity & -0.047 & $(0.039)$ & & -0.045 & $(0.036)$ & & 0.030 & $(0.038)$ & & & & & -0.398 & $(0.165)$ & $*$ & \\
\hline
\end{tabular}




\begin{tabular}{|c|c|c|c|c|c|c|c|c|c|c|c|c|}
\hline inequality & -0.070 & $(0.029)$ & $*$ & -0.070 & $(0.029)$ & $*$ & -0.041 & $(0.032)$ & & -0.144 & $(0.091)$ & \\
\hline anonymity & -0.020 & $(0.030)$ & & -0.016 & $(0.030)$ & & 0.080 & $(0.029)$ & $* *$ & 0.135 & $(0.074)$ & . \\
\hline collectivism & 0.062 & $(0.152)$ & & 0.023 & $(0.039)$ & & 0.080 & $(0.041)$ & . & -0.090 & $(0.074)$ & \\
\hline modernization & -0.080 & $(0.060)$ & & -0.078 & $(0.051)$ & & 0.012 & $(0.051)$ & & 1.596 & $(0.749)$ & $*$ \\
\hline \multirow[t]{2}{*}{ urban } & -0.074 & $(0.043)$ & . & -0.021 & $(0.033)$ & & -0.123 & $(0.024)$ & $* * *$ & -0.177 & $(0.084)$ & $*$ \\
\hline & 0.106 & 0.072 & & 0.006 & & & 0.022 & & & 0.002 & (1.328) & $(0.28)$ \\
\hline \multicolumn{13}{|l|}{ dynamics } \\
\hline lag_dyn (social norm) & & & & & & & & & & 2.399 & $(0.914)$ & $* *$ \\
\hline power & 0.045 & $(0.029)$ & & -0.017 & $(0.028)$ & & -0.021 & $(0.031)$ & & -0.451 & $(0.239)$ & \\
\hline modernization & 0.939 & $(0.115)$ & $* * *$ & 0.123 & $(0.038)$ & $* *$ & 0.002 & $(0.042)$ & & 0.393 & $(0.230)$ & . \\
\hline globalization & -0.129 & $(0.118)$ & & -0.001 & $(0.029)$ & & 0.028 & $(0.034)$ & & 0.162 & $(0.331)$ & \\
\hline \multirow[t]{2}{*}{ heterogeneity } & 0.227 & $(0.033)$ & $* * *$ & 0.088 & $(0.028)$ & $* *$ & 0.131 & $(0.035)$ & $* * *$ & -0.013 & $(0.306)$ & \\
\hline & 0.112 & 0.092 & & 0.100 & & & 0.084 & & & 0.005 & $(0.918)$ & $(0.57)$ \\
\hline \multicolumn{13}{|l|}{ heterogeneity } \\
\hline urban & 0.019 & $(0.075)$ & & 0.121 & $(0.026)$ & $* * *$ & 0.096 & $(0.016)$ & $* * *$ & 0.039 & $(0.153)$ & \\
\hline globalization & 0.994 & $(0.165)$ & $* * *$ & 0.348 & $(0.028)$ & $* * *$ & 0.324 & $(0.026)$ & $* * *$ & 0.906 & $(0.383)$ & $*$ \\
\hline dynamics & 0.338 & $(0.170)$ & $*$ & 0.137 & $(0.030)$ & $* * *$ & 0.108 & $(0.024)$ & $* * *$ & 0.232 & $(0.440)$ & \\
\hline inequality & 0.002 & $(0.024)$ & & 0.003 & $(0.023)$ & & 0.034 & $(0.023)$ & & 0.083 & $(0.057)$ & \\
\hline \multirow[t]{2}{*}{ collectivism } & 0.478 & $(0.187)$ & $*$ & 0.113 & $(0.030)$ & $* * *$ & 0.131 & $(0.029)$ & $* * *$ & 0.624 & $(0.450)$ & \\
\hline & 0.035 & 0.030 & & 0.173 & & & 0.210 & & & 0.073 & $(0.806)$ & $(0.13)$ \\
\hline \multicolumn{13}{|l|}{ inequality } \\
\hline power & 0.027 & $(0.031)$ & & 0.034 & $(0.037)$ & & 0.074 & $(0.032)$ & $*$ & 1.264 & (1.037) & \\
\hline globalization & 0.129 & $(0.127)$ & & 0.018 & $(0.037)$ & & 0.005 & $(0.033)$ & & 0.061 & (1.101) & \\
\hline
\end{tabular}




\begin{tabular}{|c|c|c|c|c|c|c|c|c|c|c|c|c|}
\hline dynamics & 0.056 & $(0.044)$ & & 0.057 & $(0.037)$ & & -0.026 & $(0.029)$ & & 2.192 & $(0.633)$ & $* *$ \\
\hline modernization & $\begin{array}{l}-0.378 \\
0.060\end{array}$ & $\begin{array}{l}(0.112) \\
0.052\end{array}$ & ** & $\begin{array}{l}-0.216 \\
0.015\end{array}$ & $(0.049)$ & $* * *$ & $\begin{array}{l}-0.123 \\
0.010\end{array}$ & $(0.041)$ & $* *$ & $\begin{array}{l}\mathbf{- 3 . 0 1 1} \\
0.075\end{array}$ & $\begin{array}{l}(1.005) \\
(1.074)\end{array}$ & $\begin{array}{l}* * \\
(0.14)\end{array}$ \\
\hline \multicolumn{13}{|l|}{ power } \\
\hline anonymity & -0.061 & $(0.028)$ & $*$ & -0.010 & $(0.022)$ & & 0.091 & $(0.022)$ & $* * *$ & -0.290 & $(0.026)$ & \\
\hline altruism (generalized) & $\begin{array}{l}-0.040 \\
0.000\end{array}$ & $\begin{array}{l}(0.029) \\
0.000\end{array}$ & & $\begin{array}{l}-0.004 \\
(-0.001)\end{array}$ & $(0.022)$ & & $\begin{array}{l}0.026 \\
0.014\end{array}$ & $(0.023)$ & & $\begin{array}{l}\mathbf{0 . 4 5 2} \\
0.001\end{array}$ & $\begin{array}{l}(0.273) \\
(1.15)\end{array}$ & $\begin{array}{l}(0.74) \\
\end{array}$ \\
\hline \multicolumn{13}{|l|}{ anonymity } \\
\hline urban & 0.215 & $(0.064)$ & $* *$ & 0.111 & $(0.033)$ & $* * *$ & 0.242 & $(0.024)$ & $* * *$ & 0.214 & $(0.054)$ & $* * *$ \\
\hline dynamics & 0.235 & $(0.134)$ & . & 0.050 & $(0.038)$ & & 0.069 & $(0.033)$ & $*$ & 0.137 & $(0.058)$ & $*$ \\
\hline heterogeneity & 0.072 & $(0.034)$ & $*$ & 0.116 & $(0.035)$ & $* * *$ & 0.212 & $(0.039)$ & $* * *$ & 0.337 & $(0.107)$ & $* *$ \\
\hline collectivism & -0.735 & $(0.226)$ & $* *$ & -0.195 & $(0.037)$ & $* * *$ & -0.216 & $(0.040)$ & $* * *$ & -0.930 & $(0.456)$ & $*$ \\
\hline modernization & $\begin{array}{l}-0.485 \\
0.099\end{array}$ & $\begin{array}{l}(0.145) \\
0.082\end{array}$ & $* *$ & $\begin{array}{l}-0.257 \\
0.055\end{array}$ & $(0.049)$ & $* * *$ & $\begin{array}{l}-0.188 \\
0.140\end{array}$ & $(0.051)$ & $* * *$ & $\begin{array}{l}\mathbf{- 1 . 0 7 4} \\
0.026\end{array}$ & $\begin{array}{l}(0.557) \\
(1.362)\end{array}$ & $\begin{array}{l}\text { (0.18) } \\
\text { (1) }\end{array}$ \\
\hline \multicolumn{13}{|l|}{ collectivism } \\
\hline urban & 0.080 & $(0.026)$ & $* *$ & 0.080 & $(0.024)$ & $* *$ & 0.104 & $(0.017)$ & $* * *$ & 0.343 & $(0.090)$ & $* * *$ \\
\hline anonymity & -0.102 & $(0.024)$ & $* * *$ & -0.104 & $(0.022)$ & $* * *$ & -0.087 & $(0.020)$ & $* * *$ & -0.193 & $(0.181)$ & \\
\hline modernization & 0.285 & $(0.067)$ & $* * *$ & 0.167 & $(0.037)$ & $* * *$ & 0.074 & $(0.036)$ & $*$ & 0.269 & $(0.098)$ & $* *$ \\
\hline globalization & $\begin{array}{l}-0.211 \\
0.048\end{array}$ & $\begin{array}{l}(0.089) \\
0.045\end{array}$ & $*$ & $\begin{array}{l}-0.076 \\
0.051\end{array}$ & $(0.028)$ & $* *$ & $\begin{array}{l}-0.088 \\
0.060\end{array}$ & $(0.027)$ & $* * *$ & $\begin{array}{l}\mathbf{- 0 . 7 1 5} \\
0.038\end{array}$ & $\begin{array}{l}(0.298) \\
(1.711)\end{array}$ & $\begin{array}{l}* \\
(0.29)\end{array}$ \\
\hline \multicolumn{13}{|l|}{ modernization } \\
\hline globalization & 0.344 & $(0.059)$ & $* * *$ & 0.089 & $(0.021)$ & *** & 0.119 & $(0.020)$ & $* * *$ & 0.052 & $(0.282)$ & \\
\hline urban & 0.035 & $(0.032)$ & & 0.070 & $(0.023)$ & $* *$ & 0.209 & $(0.017)$ & $* * *$ & 0.217 & $(0.091)$ & $*$ \\
\hline
\end{tabular}




\begin{tabular}{|c|c|c|c|c|c|c|c|c|c|c|c|c|c|c|}
\hline governance & -0.049 & $(0.019)$ & $* *$ & -0.042 & $(0.021)$ & * & -0.059 & $(0.015)$ & $* * *$ & & & -0.064 & $(0.096)$ & \\
\hline dynamics & 0.305 & $(0.066)$ & **** & -0.046 & $(0.027)$ & . & -0.046 & $(0.023)$ & . & & & 0.380 & $(0.491)$ & \\
\hline heterogeneity & 0.124 & $(0.016)$ & $* * *$ & 0.154 & $(0.020)$ & $* * *$ & 0.157 & $(0.022)$ & $* * *$ & & & -0.113 & $(0.233)$ & \\
\hline \multirow[t]{2}{*}{ inequality } & -0.041 & $(0.011)$ & **** & -0.076 & $(0.016)$ & $* * *$ & -0.052 & $(0.018)$ & $* *$ & & & -0.010 & $(0.051)$ & \\
\hline & 0.116 & 0.108 & & 0.215 & & & 0.374 & & & & & 0.154 & $(0.864)$ & $(0.14)$ \\
\hline \multicolumn{15}{|l|}{ globalization } \\
\hline urban & 0.054 & $(0.020)$ & $* *$ & 0.041 & $(0.032)$ & & -0.003 & $(0.029)$ & & & & 0.335 & $(0.070)$ & $* *$ \\
\hline modernization & 0.365 & $(0.062)$ & $* * *$ & 0.306 & $(0.040)$ & $* * *$ & 0.360 & $(0.040)$ & $* * *$ & & & 0.294 & $(0.041)$ & $* *$ \\
\hline \multirow[t]{2}{*}{ collectivism } & -0.178 & $(0.079)$ & $*$ & -0.103 & $(0.030)$ & $* * *$ & -0.135 & $(0.031)$ & $* * *$ & & & -0.090 & $(0.031)$ & $* *$ \\
\hline & 0.108 & 0.099 & & 0.072 & & & 0.132 & & & & & 0.192 & - & - \\
\hline \multicolumn{15}{|l|}{ governance } \\
\hline modernization & 0.163 & $(0.037)$ & $* * *$ & -0.028 & $(0.044)$ & & -0.006 & $(0.051)$ & & & & -0.028 & $(0.043)$ & \\
\hline power & 0.005 & $(0.017)$ & & -0.063 & $(0.030)$ & * & -0.061 & $(0.035)$ & . & & & -0.063 & $(0.030)$ & $*$ \\
\hline heterogeneity & 0.012 & $(0.023)$ & & 0.018 & $(0.030)$ & & 0.009 & $(0.039)$ & & & & 0.018 & $(0.030)$ & \\
\hline \multirow[t]{2}{*}{ altruism (generalized) } & -0.029 & $(0.018)$ & & -0.029 & $(0.024)$ & & 0.014 & $(0.028)$ & & & & -0.029 & $(0.024)$ & \\
\hline & 0.107 & 0.083 & & 0.109 & & & 0.18 & & & & & 0.115 & - & - \\
\hline \multicolumn{15}{|l|}{ nature experience } \\
\hline urban & 0.099 & $(0.039)$ & $*$ & 0.073 & $(0.040)$ & . & 0.073 & $(0.040)$ & . & & & 0.073 & $(0.040)$ & . \\
\hline \multirow[t]{2}{*}{ environmental conditions } & 0.168 & $(0.149)$ & & 0.174 & $(0.057)$ & *** & 0.174 & $(0.057)$ & *** & & & 0.174 & $(0.057)$ & $* *$ \\
\hline & 0.236 & 0.145 & & 0.018 & & & 0.018 & & & & & 0.023 & - & - \\
\hline \multicolumn{15}{|l|}{ environmental conditions } \\
\hline NEP & -0.125 & $(0.080)$ & & 0.028 & $(0.018)$ & & 0.038 & $(0.021)$ & . & 0.027 & $(0.018)$ & 2.590 & (1.211) & * \\
\hline modernization & 0.179 & $(0.078)$ & $*$ & -0.014 & $(0.025)$ & & -0.061 & $(0.025)$ & $*$ & -0.013 & $(0.025)$ & -3.024 & (1.415) & $*$ \\
\hline
\end{tabular}




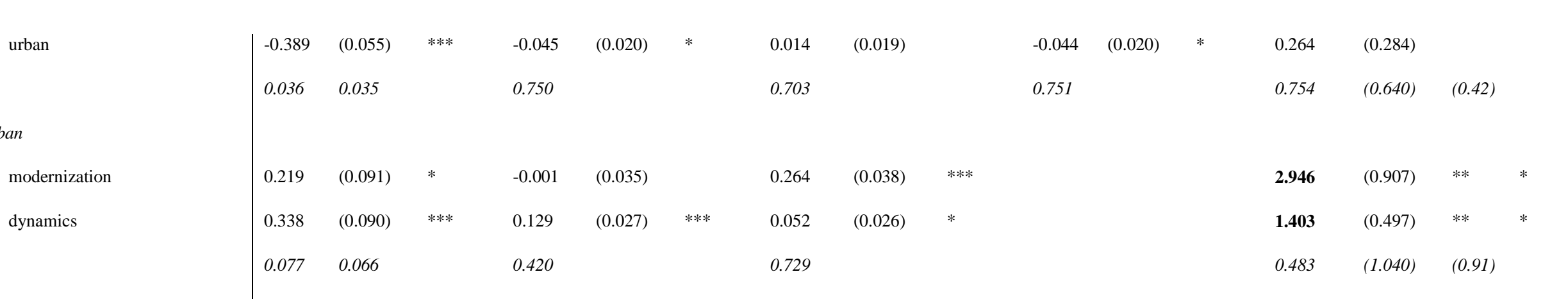

Note: Path structure theoretically informed by section 2, but also controls reverse causality. Coefficients finally aggregated for path model (Figure 6) in bold. Header displays changes from left to right. Lag equations omitted from representation (NEP and dynamics depend on their respective social norm significantly). Sample size > 1204 but varies with outlier correction and missingness in spatial information. Standard errors in parentheses. *** indicates p-value $<0.001, * *<0.01, *<0.05$ and.$<0.1$. Fit measures in italics below each equation: Std. $\mathrm{R}^{2}$ for OLS and generalized $\mathrm{R}^{2}$ for IV models, RMSEA and SRMR for latent variable models; Cragg-Donald statistic (weakness) and Sargan p-value (endogeneity) for weak-IV models in addition. In case of endogenous but weakly identified regressors (may concern only single coefficients, first-stage statistics not reported), robust Anderson-Rubin significance level behind coefficients. Insignificant coefficients may still be included in aggregation based on reasoning in section 3 . 


\title{
Chapter III. Environmental Concern, Income and Nature Experience in India ${ }^{20}$
}

\begin{abstract}
:
The relationship between income and environmental concern has only in some samples been found to mirror an Environmental Kuznets curve of pollution behavior by $U$-shaped preferences. Inconclusive aggregate findings may be due to differential presence of mechanisms causing a linear relationship, or a psychological equivalent to tunneling maximum pollution. We enquire into determinants of such a mechanism previously unrelated to income-concern literature, that could arise from persistent influence of environmentalism of the poor through economic development, until affluence and postmaterialist values become effective. It is captured empirically as influence of past nature experience on concern at critical intermediate income, retained by individuals that have abandoned farming and advanced to such income. The resultant moderated mediation model is calibrated on representative survey data from highly heterogeneous, urbanizing India. Our results explain pollution behavior within this middle-income country by a corresponding, $U$-shaped incomeconcern relationship. But in addition, differential obstruction of this relationship is predicted by conditionality of these findings upon controlling particularly pronounced influence of past nature experience at middle income for individuals that switched out of farming. Policy leverage may thus derive from reducing the gap to behavior in India, and fostering persistent positive nature experience elsewhere.
\end{abstract}

Keywords: Environmental Kuznets Curve; Tunneling; Environmentalism of the Poor; Nature Experience; Environmental Concern

\footnotetext{
${ }^{20}$ Authors' version of Bettin and Wollni (2019). Authors' contributions are as follows: Conceptualization, J. Bettin \& M. Wollni; Methodology, J. Bettin \& M. Wollni; Software, J. Bettin; Validation, J. Bettin \& M. Wollni; Formal Analysis, J. Bettin; Investigation, J. Bettin \& others (see acknowledgements); Resources, J.Bettin; Data Curation, J. Bettin, Monish Jose \& Johanna Gather; Writing - Original Draft Preparation, J. Bettin; Writing - Review \& Editing, J. Bettin \& M. Wollni; Visualization, J. Bettin; Supervision, M. Wollni; Project Administration, M. Wollni; Funding Acquisition, M. Wollni
} 


\section{Introduction}

The Environmental Kuznets Curve (EKC) hypothesis claims that environmental conditions deteriorate with economic development first, before they eventually improve again (Dinda, 2004). Evidence in favor of this hypothesis is particularly strong when considering belowaverage income countries and the case of carbon dioxide, as the perhaps most general and at the same time most relevant indicator (Murthy \& Bhasin, 2016). In the years to come, billions of poor are yet to embark on this path of development. Examining chances of bypassing maximum pollution or at least restraining the coupling of income and greenhouse gas emissions seem overdue. Such "tunneling" potential has been documented already for a variety of processes (Munasinghe, 1999).

This study proposes reaping underexplored tunneling potential within individual, psychological preferences for environmental protection (Roca, 2003). Such potential derives from, and may simultaneously shed some new light on, a persistently inconclusive link between income growth and environmental concern - a decisive ingredient to proenvironmental behavior (Gifford \& Nilsson, 2014): Both linear increases of concern in income within, and decreases between countries are found in some samples to tend toward a U-shape, mirroring the inverse U of a pollution-EKC (Fairbrother, 2013). One of the perhaps more parsimonious joint theoretical explanations is offered by the 'objective problems, subjective values' approach (Guha \& Martinez-Alier, 2013): Dependence on nature for livelihood sustenance is still widespread in the Global South and causes an often spiritual, affective attitude of environmental concern ("environmentalism of the poor", (Martinez-Alier, 2002)). With growing income, it is gradually replaced by affluence and postmaterialist value (Dunlap \& Mertig, 1995). We hypothesize that differential smoothness of these transitions may cause sample sensitivity of the U-pattern. Linear cases could then point to bridging mechanisms mirroring tunneling of a pollution EKC and constitute examples of potential use to policy-makers elsewhere, too.

Within and between decisive, economically less developed countries, preserving and asserting locally rooted environmentalism may be more interesting from a policy perspective than targeting differential onset of globalization-induced values, or concern that only follows degradation behavior (Koger, 2013). Our exploration of psychological tunneling potential therefore enquires into disparate determinants of persistence of environmentalism of the poor, hinted at by qualitative evidence already e.g. in India (Dwivedi, 2016). That is, we test for influence of environmentalism of the poor on environmental concern at critical, intermediate 
income. We thereby conceptualize environmentalism of the poor as nature experience (Nisbet, Zelenski, \& Murphy, 2008; Widdop Quinton \& Khatun, 2018) and allow for continued influence at intermediate income due to strong upward income dynamics within individuals' life courses (Diao et al., 2017). Because only certain individuals are likely to experience such dynamics, this approach amounts to linking nature experience -, and income-concern literature by three-way, moderated mediation analysis (Hayes, 2015).

We survey 1200 household heads at the rural-urban interface of Bangalore / India, where a large section of intertemporal income development is spread out in a cross-section (Nair, 2005). We show that a micro-level EKC of preferences as measured by the New Environmental Paradigm (NEP, (Dunlap et al., 2000)) would indeed obtain when bridging was absent. Our findings can hence explain pollution patterns at least within and between middle and low income countries as a consequence of preferences (Gambhir, 2017). Moreover, nature experience is also found to exhibit particularly pronounced influence at intermediate income for decisive individuals switching out of agriculture. Our results therefore also emphasize the need for policies reducing attitude-behavior gaps in Bangalore (Pisano \& Lubell, 2017), and in general suggest building on positive nature experiences for pro-environmental behavior instead of merely relying on degradation exposure.

We finally consider 'objective problems, subjective values' approaches to provide the most parsimonious explanation of our findings. If positive nature experience decreases between countries, this may point to this body of theory as the most parsimonious explanation even for income-concern patterns more generally; decreasing exposure to environmental degradation eventually outnumbering affluence and values would no longer be required in addition (Summers \& VanHeuvelen, 2017).

Section 2 develops the theoretical approach, section 3 introduces our models and survey, section 4 presents results, which are discussed in the concludingsection 5.

\section{Theoretical Background}

\subsection{An Indian EKC of Environmental Concern}

The relationship between income and environmental concern remains a controversial subject across environmental psychology and related disciplines: Increases of concern in income within, and decreases between countries may be perceived as a recent consensus (Summers 
\& VanHeuvelen, 2017). But whereas results are often considered largely invariant to measurement, sample dependence remains an issue [ibd.]. Even though mostly insignificant, a U-shaped relationship has thus equally been documented for both between and within country samples (Bravo \& Marelli, 2007; Duroy, 2008; Fairbrother, 2013). This sensitivity is exemplified by the case of India, where evidence for an initial and eventual maximum of concern interrupted by a gap (Lange, Meier. L., \& Anuradha, 2009; Mawdsley, 2004; Upadhya, 2009) is contradicted by other studies reporting monotonic increases in income (Chatterjee, 2008).

Explanations provided by extant theories even for linear, already contrasting findings are not easily integrated parsimoniously: Within-country economic development at any one point in time should mirror intertemporal income patterns, even between-countries (Diao et al., 2017; Plassmann \& Khanna, 2016). Affluence (Franzen \& Meyer, 2010) or postmaterialist values (Dunlap \& York, 2008) can explain within-country increases, and potentially fall in line with growing exposure to environmental degradation for poorer countries (Summers $\&$ VanHeuvelen, 2017). But between-country decreases in concern require assuming both degradation experiences, eventually outnumbering within country increases, and initially high, 'global' environmentalism 'of the poor' (Guha \& Gadgil, 2000; Martinez-Alier, 2002). Whereas the latter has been incorporated into so-called objective problems \& subjective values' theories together with affluence and values (Dunlap \& Mertig, 1995; Guha \& Martinez-Alier, 2013), degradation experience remains separate yet indispensable.

But even when considering all theories jointly, emergence of a $U$ pattern, instead of contrasting linear relationships, seems equally plausible: It remains unclear whether environmentalism of the poor is smoothly substituted by affluence and postmaterialist values (or exposure to environmental degradation), as individuals and countries become rich. What is more, affluence and values that persist within countries must then be assumed to become outnumbered by decreasing exposure to degradation equally smoothly between richer countries. Within and between poorer countries, transition from one driver of environmental concern to another could be interrupted by a gap. And degradation exposure between richer countries could reach saturation eventually, while affluence and postmaterialist values still exhibit upward influence on concern.

Such a U-shaped relationship would mirror real-world pollution behavior much better than currently dominant linear theorizing: At least both within and between poorer countries, decisive carbon dioxide emissions likely do exhibit the inverse U-shape put forward by the 
Environmental Kuznets Curve hypothesis (Murthy \& Bhasin, 2016; Pao \& Tsai, 2011). If preferences of environmental concern predict behavior despite a certain gap to some degree (Pisano \& Lubell, 2017; Roca, 2003), decreasing concern should lead to increasing pollution and vicus versa. But furthermore, global carbon dioxide - income patterns are now often assumed to best be described by a cubic- / N-shape (Murthy \& Bhasin, 2016). If behavior follows concern, U-shaped concern between countries toward the left of the income distribution could lend further support to the saddle of the cubic pattern. Within the example of India, U-shaped preferences would mirror an often reported EKC pattern of carbon dioxide emissions (Kanjilal \& Ghosh, 2013). But recent reports of a cubic pattern within this highly heterogeneous middle-income country also hint at representativeness of Indian economic development for more general, between country patterns (Gambhir, 2017). Livelihood dependence on an increasingly degraded nature coexists with westernized postmaterial middle classes here.

We finally derive theoretical potential for tunneling an EKC of pollution (Munasinghe, 1999), or bridging an EKC of concern, from (sample) sensitivity of the evidence for a U-pattern: Some mechanism apparently causes more or less linear, smooth transitions from environmentalism of the poor to affluence and values. As indicated by pollution behavior, this holds only within and between a minority of poorer countries. But while differential onset of affluence and values, or degradation exposure lagging behind EKC-shaped pollution behavior may explain examples of bridging, we investigate endurance of environmentalism of the poor. Local, positive roots of environmentalism seem a much more powerful motivation for pollution mitigation policies; enforcing extant attitudes is considered much less complicated and ethically questionable then changing them (Koger, 2013). Coexistence of a 'gap' with smooth, direct transitions from environmentalism of the poor to 'middle class environmentalism' (Mawdsley, 2004) are already supported by qualitative evidence for the case of India (Dwivedi, 2016).

Such a local, positive mechanism could even recede differentially between countries, and replace degradation exposure in explaining globally decreasing concern. This would allow for 'objective problems, subjective values' approaches to emerge as a unifying, parsimonious explanation of all empirical patterns. 


\subsection{Conceptual Framework}

This section formalizes one possible, idealized understanding of bridging that may explain sample sensitivity of a U-shaped Kuznets pattern of environmental concern. This allows for modeling differential concern at middle income as heterogeneity of an already established effect rooted in environmentalism of the poor (see next section). We show how certain theoretical assumptions lead to a concept of bridging independent of differential degradation experience. But we also allow for empirical departures from these, under which we still consider it meaningful, to then analyze influence of past environmentalism of the poor on such bridging.

For one thing, we assume that environmentalism of the poor is limited to farmers, because livelihood dependence on nature applies to them chiefly (Angelsen, Larsen, Lund, Smith-Hall, \& Wunder, 2011). It follows that farmers will always exhibit higher concern than nonfarmers: Concern monotonically increases in income for both groups because of educationinduced values, but farmers always benefit from dependence on nature in addition. The 'split' generating a potential minimum of concern at middle income then becomes possible only if farmers stop dominating aggregate concern for higher income. Non-farmers would then take over, with their initially lower concern due to absence of both types of environmentalism. This is ensured by the second assumption: According to recent confirmation of dual development theory, farmers cluster toward the left and non-farmers at the right of the income distribution (Figure 7, (Diao et al., 2017)). For bridging, we are hence interested in those nonfarmers clustering directly at the potential drop, at any one point in time.

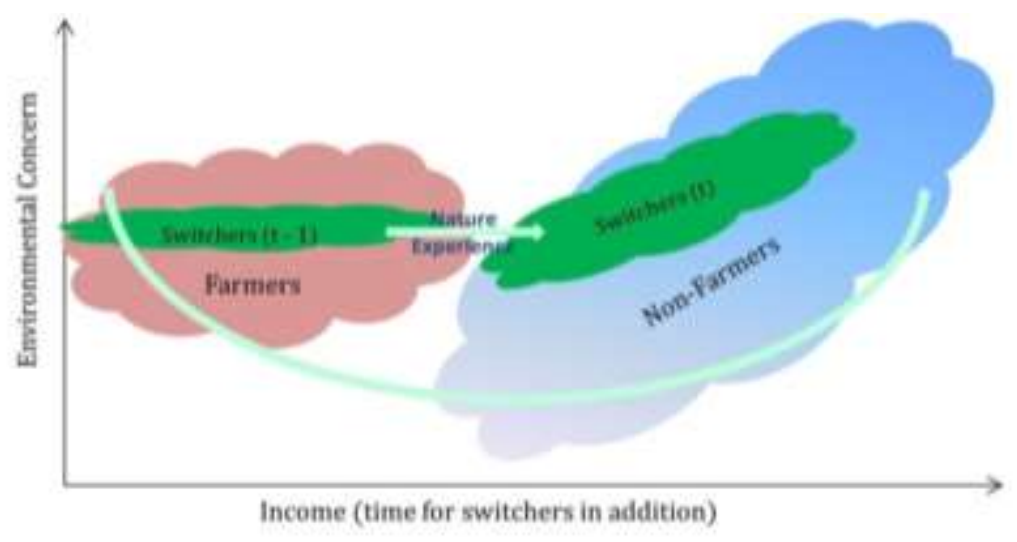

Figure 7. The Tunneling / Bridging Hypothesis in an EKC of Preferences

Since the minimum is generated in our understanding by absence of both kinds of environmentalism, there are two straightforward options to generate bridging: One consists in 
middle-class concern becoming effective early enough, before environmentalism of the poor loses influence. But a second option will be considered henceforth, as it appears more interesting in terms of local roots of environmentalism: Bridging will also be determined by the degree to which environmentalism of the poor endures, until middle class concern gains momentum.

We propose to study such endurance within individuals' life courses. Given current Indian growth dynamics, many of the non-farmers at the potential drop will likely have transitioned from the left to at least the middle of the income distribution within these life courses (World Bank). Because of dual development, such individuals are at the same time likely to have abandoned agriculture during that process. That is, they constitute a third group that we might call "switchers". Depending on the effect of earlier environmentalism of the poor from agriculture, this group may contribute to a split pattern just like other non-farmers, or to bridging.

One obvious way of explaining bridging would thus derive from the conditions under which past farming still affects otherwise minimum concern, at middle income. But the aggregate degree of bridging, i.e. environmental concern at critical income, could result from different types of bridging as well: Farmers might be present there for example, and their environmental concern could equally be affected by (past) environmentalism of the poor. The environmental concern for which we analyze the influence of past farming, at middle income, may hence in addition differ by group. In sum, we will thus aim to explain our understanding of bridging; that is, we test for the hypothesis of persistent influence of past farming on environmental concern at middle income, but for switchers only.

Note however that elements of this idealized framework may be relaxed in reality, while still allowing for such an explanation to be meaningful: In principle, all that we require for this type of bridging are some switchers at middle income, that positively influence aggregate environmental concern (assumption I: strong ordering w.r.t. concern). Furthermore, we can only speak about persistence of past environmentalism of the poor, if increased income for non-farmers hints at dynamics (assumption II: mild ordering w.r.t. to income), and if (poor) farmers exhibit some environmental concern (assumption III). But already a U-shape without the influence of past farming for switchers would correspond only to a literal understanding of bridging. We would consider conditions of lifting intermediate, but monotonically increasing environmental concern an equally valuable subject of enquiry. 


\subsection{Environmentalism of the Poor as Nature Experience}

Why should we theoretically expect livelihood environmentalism ("of the poor") to exert persistent influence on switchers' environmental concern when they enter the income section critical for bridging? In general, such a relationship is predicted by nature experience theory (Chawla, 1998; Nisbet et al., 2008). We argue that it is applicable here, because farming can be considered as a form of nature experience: Livelihood environmentalism is always rooted in direct, instrumental contact with nature (Angelsen et al., 2011; Widdop Quinton \& Khatun, 2018). But more than from exposure to environmental degradation, positive influence on concern is predicted by applying relationship theory to a context of environmental learning (Davis et al., 2009; Tam, 2013): Frequent enjoyable experiences with nature, more than bad ones, lead people to become emotionally attached to it (path 1 in Figure 8). Such an affective connection to nature can then lead people to care about it later on in life (path 2), either via concern for one's own well-being (egoistic investment, (Kaiser, Hartig, Brügger, \& Duvier, 2011)), or via altruistic empathy (Schultz, 2000). These mechanisms have been replicated separately in both non-western and farmers' samples (Corral-Verdugo, Carrus, Bonnes, Moser, \& Sinha, 2008). Bridging would then occur, if the overall experience-concern relationship replicated i) for the group of switchers better than for others, and ii) in particular so at middle income. In short, this would require switchers to be high on anxious attachment, altruism, time horizon and knowledge - and this even at reduced, middle income, that is expected to deflate all these traits (with unclear effects of abstract thinking).

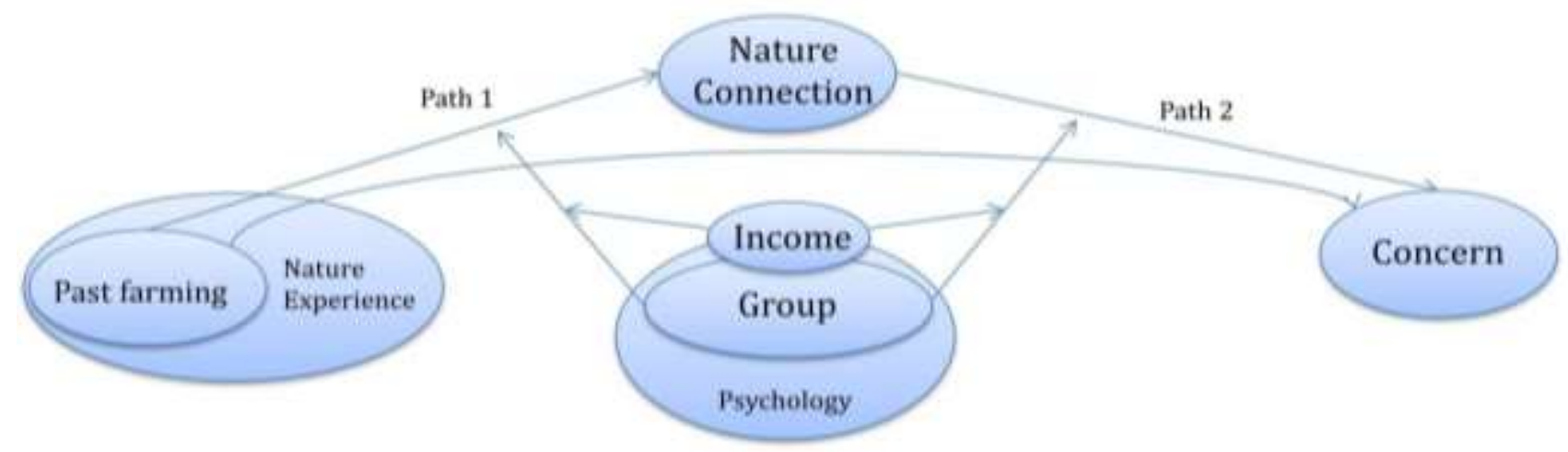

Figure 8. Theoretical Pathmodel. Some presumed relationships omitted from demonstration. No causal structure assumed between income, group and psychology.

We expect moderation of the experience-concern link by i) group within a nature experience framework because of psychological differences between groups. Farmers that are already closer to the traits of non-farmers are expected to select into switching (Shrapnel \& Davie, 
2001). Attachment style is often regarded as the most important predictor of individual difference (Shaver \& Brennan, 1992), in relationships but also beyond (Scannel \& Gifford, 2013). An anxiously attached group would facilitate bridging, because we hypothesize it to form relationships particularly easily (path 1), and be highly invested in such a relationship (path 2). The opposite would be true for avoidant attachment style on both paths (Mikulincer \& Shaver, 2003). Abstract thinking is also a likely moderator of both paths, albeit without clear requirements for bridging: Becoming attached is a form of conditioning (path1, (Giusti et al., 2014)), and that is prevented by abstraction (BARR \& MCCONAGHY, 1972). However, path 2 requires conversion of affective attitudes into more general ones, which is facilitated by abstraction (Gifford \& Nilsson, 2014). For bridging to emerge from reinforcement of path 2, switchers should also be high in altruism (see above), be patient (long time horizon) and knowledgeable about the environment (Gifford \& Nilsson, 2014).

Possibly in addition to, or even instead of the group moderation, bridging conditions are determined by the degree to which the overall relationship replicates ii) at middle income. Our framework allows for modeling this type of heterogeneity too, because income may affect the psychological constructs depicted further ${ }^{21}$. This becomes evident when observing relationships of both nature experience and income to risk behavior: Risk aversion is related to avoidant attachment (Yaghoobi, Mohammadzade, Chegini, Yarmohammadi Vasel, \& Zoghi Paidar, 2016), but relationship investment is risky (Mikulincer \& Shaver, 2003). At the same time, risk aversion is known to decrease in income (Haushofer \& Fehr, 2014). Middle income could therefore be already low enough to prevent bridging by reinforcing avoidance. Path 2 would furthermore be negatively affected by low income through a still shortened time horizon (Carvalho, 2010), through diminished altruism (Andreoni, 1990) and through inhibited abstract thinking (Mani, Mullainathan, Shafir, \& Zhao, 2013). The latter could on the other hand explain existence of bridging, if working mainly through path 1 (see above).

\section{Empirical Approach}

\subsection{Statistical Approach}

Our empirical strategy is a combination of graphical analysis and path modeling. Before explaining a particular type of bridging, we derive support for existence of both a psychological EKC and bridging thereof from graphical verification of the assumptions

21 Note that at the same time, income is affected by group according to dual development. 
behind our theoretical framework. This approach is facilitated by plotting locally weighted regression functions fitted to scatterplots of environmental concern over income ${ }^{22}$. Compared to a fully parametric approach, it allows for much more nuanced evaluation of hypotheses (see also (Plassmann \& Khanna, 2016)). With the aggregate curve, we evaluate overall presence of bridging (monotonic increase of concern in income), compared to an EKC pattern (U-shape). We then proceed by decomposing the graph by group to demonstrate how the type of bridging explained below contributes to any aggregate leveling of a potential $U$ shape: Verification of the clustering assumption with regard to income (and concern) is provided by groupwise scatterplots. Groupwise weighted regression curves facilitate verification of the hypothesis that farmers and non-farmers jointly exhibit an inverse U. If switchers' concern was elevated compared to these as well as to aggregate concern at critical income, this would point to added value from explaining their curve there. Influence of past farming would be suggested by differences especially to non-farmers. ${ }^{23}$

However as a second step, more in-depth inferential analysis is required to understand why switchers' concern-income relationship does exhibit the observed bridging potential - and if it indeed does so because of past environmentalism of the poor. To this end, we translate our theoretical approach, as outlined in the previous section, into a structural equations model. To each of the two implied paths of mediation, we introduce a 3-way interaction (Dawson \& Richter, 2006; Hayes, 2015). They make explicit the influence of past environmentalism of the poor, on current environmental concern, at the critical income section, and for the group of switchers:

$$
\begin{aligned}
& \text { I: Environmental concern }=\beta_{11} \cdot \text { Nature connection }+\beta_{12} \cdot \text { Income }+\beta_{13} \cdot \text { Group } \\
& +\gamma_{11} \cdot \text { Nature connection } * \text { Income }+\gamma_{12} \cdot \text { Nature connection } * \text { Group } \\
& \qquad \begin{array}{c}
\delta_{11} \cdot \text { Nature connect } * \text { Income } * \text { Group } \\
\text { II: Nature Connection }=\beta_{21} \cdot \text { Past farming }+\beta_{22} \cdot \text { Income }+\beta_{23} \cdot \text { Group } \\
+\gamma_{21} \cdot \text { Past farming } * \text { Income }+\gamma_{22} \cdot \text { Past farming } * \text { Group } \\
+\delta_{21} \cdot \text { Past farming } * \text { Income } * \text { Group }
\end{array}
\end{aligned}
$$

To explain these effects of income and group further, mediation of the two moderators by the hypothesized psychological constructs is then tested for in addition. Similarly, nature connection could be mediated by other types of nature experience. In each case, we decide

22 For interpretation we focus on the interval of 1 standard deviation around the median of the standardized data, because of known issues with weighted regression functions at the tails of the distribution.

23 As grouping cannot be assumed exogenous and non-farmers hence do not constitute the appropriate counterfactual, this should not be interpreted as an actual impact. For the same reason, estimation of the contribution of switchers' bridging toward total bridging does not constitute the focus of this study. 
about inclusion of further equations based on path analysis techniques, as well as feasibility in view of endogeneity issues: We will consider including a model to explain group by psychological constructs, because temporal antecedence seems plausible there. But we will model the influence of income on these constructs only as additional moderation of the group effect, because the relationships to psychology and group are explicitly two-way (see above). ${ }^{24}$ Theoretical identification of the main model is however ensured ex ante because of temporal antecedence of nature experience to both nature connection and environmental concern, and because the literature assumes one-way causality from nature connection to being concerned about it. Logically, moderators can become effective therein only if they pertain to the assumed directions of causality too. ${ }^{25}$

As a final step, we aggregate impact of nature connection across all paths, for the case of switchers, and as a function of income. This serves as a check of the relevance of the mechanisms studied, if total impact coincides with descriptively observed bridging, both on the income and concern axes. With switchers coded as 1 (see below), in the simplest case without any further mediation we have:

$$
\begin{aligned}
& \text { Environmental Concern (Income | Group = Switchers) } \\
& =\left(\beta_{21}+\left(\beta_{23}+\gamma_{22}\right) \cdot 1+\left(\beta_{22}+\gamma_{21}+\delta_{21} * 1\right) * \text { Income }\right) *\left(\beta_{11}+\left(\beta_{23}+\gamma_{22}\right) \cdot 1\right. \\
& \left.+\left(\beta_{12}+\gamma_{11}+\delta_{11} * 1\right) * \text { Income }\right)
\end{aligned}
$$

\subsection{Measurement}

We obtain our data from a standardized questionnaire that was implemented as part of a larger survey (see Supplementary Information 1 for full details). While this provided a host of manifest controls, it required us to systematically condense extant scales to very few items for measurement of latent variables (Raubenheimer, 2004). To still ensure measurement validity in such a culturally heterogeneous sample, we moreover followed standard protocols consisting of independent (re-)translation, reinforced by group discussions with local scientists and thinking aloud in a pretest sample (van de Vijver \& Tanzer, 2004). ${ }^{26}$

Our measure of environmental concern is a shortened version of the popular NEP scale (Dunlap et al., 2000). Cross-cultural validity even in low-income samples from the Global

\footnotetext{
24 The direction of causality between different types of nature experience can be concluded from empirical mediation only. 25 Our main results could be harmed if the two moderators were in fact mediators and i) in addition affected by reverse causality or ii) correlated to the same unobservables as the dependent variable. However, i) is unlikely given the sign of empirical coefficients (see results), and the potential for ii) is minimized by controlling all known covariates of environmental concern.

26 See robustness (section 4.3) for how we are able to address further sources of bias
} 
South suggests applicability to environmentalism of the poor (Hawcroft \& Milfont, 2010). This is even more true compared to income-sensitivity of willingness-to-pay items employed elsewhere (Summers \& VanHeuvelen, 2017).In case of India, a modified 4-factor structure has to be accounted for (Khan et al., 2012; Schultz et al., 2016), and reports of high overall reliability lead us to select 1 item each. For our baseline results, we however refrain to a narrowed, face-valid measure of environmental concern, which only consists of the items for Eco-Crisis and Balance of Nature. Only here do we obtain at least satisfactory split-half reliability (0.55) and measurement invariance across samples (the latter by construction). The latter thereby ensures applicability of our measure also to environmentalism of (poorer) farmers. Comparable item statistics for the full, 4-factor scale are only obtained after correcting for interviewer bias by imputation of $22 \%$ of the observations based on paradata ((Blackwell et al., 2015), Appendix A4). We test for generalization of our results to that sample as a robustness check. ${ }^{27}$

Next, we employ extant decompositions of nature experience in the Global North to operationalize past environmentalism of the poor (Bögeholz, 2006): An instrumental dimension seems most relevant, but conversion of it into aesthetic, recreational and educational/protective experiences too. Of particular theoretical importance to environmentalism of the poor is also a spiritual dimension (Witt, 2013). Known psychometric properties again allow for collapsing to one frequency item each (Pohl, D. \& Schrenk, M., 2005), especially since we assume experience to be quasi-manifest.

The mediator 'affective connection to nature' has been shown to be measurable by several constructs at equal validity across cultures (Tam, 2013). We argue that a single item from the unidimensional scale of Perkins (2010, (Perkins, 2010)) represents the emotional connotation in our theoretical framework well. In all these cases, predictive validity as the only test of psychometric properties available is largely given (see results).

Our first moderator, the group variable, derives from the respective nature experience: For example, switching would be indicated by no instrumental contact with animals and plants currently, but at least some in the past. For analytical convenience, we propose treating this variable as ordered, with farmers coded lowest and non-farmers highest. This may be justified based on the expectation that switchers will exhibit intermediate levels for most constructs of interest (see above). Further, deviation from farmers' mechanisms seems more interesting 
than from non-farmers', where there is no influence of past farming at all. Each time however, we will additionally verify effects against dummy results from subgroup regressions of switchers against the other two groups separately.

We operationalize the second moderator, income by the asset index "NEW SEC" (MRSI, Indian Market Research Society of India., 2011). True income measures are difficult to obtain in the Global South because of subsistence activities. But this index has been calibrated for the case of India to proxy not only for total asset ownership, but various income measures in additon (Howe et al., 2012). The main psychological driver of such moderation, attachment style, is proxied here by a shortened version of the Big Five Inventory (Gosling, Rentfrow, \& Swann, 2003). The varieties of insecure attachment, avoidant and anxious style, are known correlates of low agreeableness and high neuroticism, respectively (Noftle \& Shaver, 2006). While the constraints imposed by overall survey logistics were the main reason behind choosing this measurement instrument, it benefits from well-established cross-cultural validity (McCrae, Kurtz, Yamagata, \& Terracciano, 2011).

As is common (see above), we further include numeracy questions to proxy abstract thinking, the other overarching psychological moderator. ${ }^{28}$

Note in addition that these moderators are correlated to the most important potential sources of respondent bias (Podsakoff et al., 2003), such that they are not controlled for separately: Social desirability should reinforce correlations between any two latent variables, and is proxied here by agreeableness. Understanding of item content should decrease such correlations, and is proxied by abstract thinking.

\subsection{Data}

We randomly sampled 1200 individuals from two rural-urban transects in Bangalore / India (see introduction). The rural-urban interface of this mega city can be expected to represent the stages of development spread out in space in middle income countries of the Global South: It is known to exhibit high heterogeneity both in terms of economic structure and social norms (Kraas \& Mertins, 2014; Simon, 2008). By stratifying for urbanization at village cluster level, we thus ensure representativeness with regard to the desired variation (Hoffmann et al., 2017). As a consequence, however, we introduce household-level weights as an additional robustness

28 Manifest measures are also available for moderators of path 2 only, for knowledge about environmental issues, time preference Frederick (2003) and altruism R. O. Murphy, Ackermann, and Handgraaf (2011). Village fixed effects are employed to control for proximity to environmental problems. 
check to correct for potential underrepresentation of densely-populated modern districts and resulting overrepresentation of agrarian mechanisms (Solon, Haider, \& Wooldridge, 2013). ${ }^{29}$ Within households we sample at simple random from decision-makers, the most relevant unit for pro-environmental behavior in Indian society.

\section{Results}

\subsection{Graphical and Descriptive Analysis}

By verifying the theoretical assumptions behind our framework graphically and through mean comparisons, we now demonstrate support for both the existence of a modified psychological $\mathrm{EKC}$, and for the added value from further analyzing our type of bridging to understand aggregate environmental concern. See section 4.2 and 5 for further descriptive statistics and verification of more involved, statistical assumptions.

Table 1. Normalized + weighted group means (raw data).

\begin{tabular}{|c|c|c|c|c|c|c|}
\hline \multirow{2}{*}{$\frac{\text { group size (weighted) }}{\text { New Environmental Paradigm }}$} & \multicolumn{2}{|c|}{$\begin{array}{c}\text { Farmers } \\
\mathrm{N}=754(491)\end{array}$} & \multicolumn{2}{|c|}{$\begin{array}{c}\text { Switchers } \\
\mathrm{N}=359(567)\end{array}$} & \multicolumn{2}{|c|}{$\begin{array}{l}\text { Nonfarmers } \\
\mathrm{N}=97(152)\end{array}$} \\
\hline & 0.738 & $(0.163)$ & 0.775 & $(0.133)$ & 0.796 & $(0.145)$ \\
\hline Past farming & 0.822 & $(0.340)$ & 0.911 & $(0.207)$ & 0.000 & $(0.000)$ \\
\hline Nature connection & 0.785 & $(0.222)$ & 0.809 & $(0.252)$ & 0.726 & $(0.275)$ \\
\hline Religious nature experience & 0.565 & $(0.383)$ & 0.619 & $(0.363)$ & 0.643 & $(0.399)$ \\
\hline Recreational nature experience & 0.636 & $(0.450)$ & 0.706 & $(0.435)$ & 0.419 & $(0.475)$ \\
\hline Aesthetic nature experience & 0.561 & $(0.433)$ & 0.639 & $(0.416)$ & 0.317 & $(0.436)$ \\
\hline Educational nature experience & 0.343 & $(0.338)$ & 0.479 & $(0.352)$ & 0.308 & $(0.279)$ \\
\hline Knowledge & 0.297 & $(0.458)$ & 0.219 & $(0.416)$ & 0.262 & $(0.450)$ \\
\hline Abstraction & 0.199 & $(0.400)$ & 0.098 & $(0.299)$ & 0.110 & $(0.320)$ \\
\hline Agreeableness & 0.367 & $(0.282)$ & 0.350 & $(0.288)$ & 0.308 & $(0.281)$ \\
\hline Intraversion & 0.624 & $(0.379)$ & 0.634 & $(0.367)$ & 0.664 & $(0.388)$ \\
\hline Openness & 0.407 & $(0.368)$ & 0.433 & $(0.390)$ & 0.490 & $(0.425)$ \\
\hline Conscientousness & 0.625 & $(0.365)$ & 0.575 & $(0.406)$ & 0.497 & $(0.369)$ \\
\hline Neuroticism & 0.413 & $(0.367)$ & 0.395 & $(0.390)$ & 0.471 & $(0.412)$ \\
\hline Social Value Orientation & 0.261 & $(0.193)$ & 0.157 & $(0.166)$ & 0.220 & $(0.196)$ \\
\hline Time preference (impatient $=0$ ) & 0.355 & $(0.375)$ & 0.313 & $(0.311)$ & 0.428 & $(0.392)$ \\
\hline Age $(0=03,1=94)$ & 0.497 & $(0.146)$ & 0.436 & $(0.153)$ & 0.425 & $(0.162)$ \\
\hline Gender $($ female $=0)$ & 0.767 & $(0.424)$ & 0.566 & $(0.498)$ & 0.598 & $(0.502)$ \\
\hline Caste (highest $=0$, lowest $=7$ ) & 0.203 & $(0.225)$ & 0.190 & $(0.220)$ & 0.203 & $(0.242)$ \\
\hline Education (years, highest $=12$ ) & 0.127 & $(0.105)$ & 0.189 & $(0.125)$ & 0.166 & $(0.113)$ \\
\hline Assets & 0.518 & $(0.163)$ & 0.611 & $(0.233)$ & 0.573 & $(0.228)$ \\
\hline
\end{tabular}

Note: Group means of normalized variables (between 0 and 1), standard deviations in parentheses, observations weighted by sampling probability (stratification for urbanization, clustering at village level). Green shading indicates above-average value for switchers, yellow intermediate and red below-average values respectively.

29 On the other hand, if groups are spread over the rural-urban gradient as hypothesized, than group-wise mechanisms should not be biased in means but only lack internal heterogeneity for farmers. 
As measured by assets, we first observe increased mean income of non-farmers compared to farmers (Table 1). This confirms our assumption II about dual development (mild ordering w.r.t. income), and thus facilitates influence of past environmentalism of the poor on switchers under upward income dynamics.

Graphical results confirm existence of such bridging: Aggregate environmental concern monotonically increases throughout the income distribution, despite intermediate mean environmental concern for switchers as the group with highest income (Figure 9). But in addition, decomposition of the curve by group reveals elevated environmental concern of switchers compared to both other groups, and aggregate concern at critical intermediate income (assumption I: strong ordering of concern). Without switchers' still substantial representation there as indicated also by the scatterplot, aggregate concern would likely be lower at critical income. Farmers' concern at low income is not high enough to cause a maximum, but past farming may affect concern differently in case of switchers and still cause bridging (assumption III).

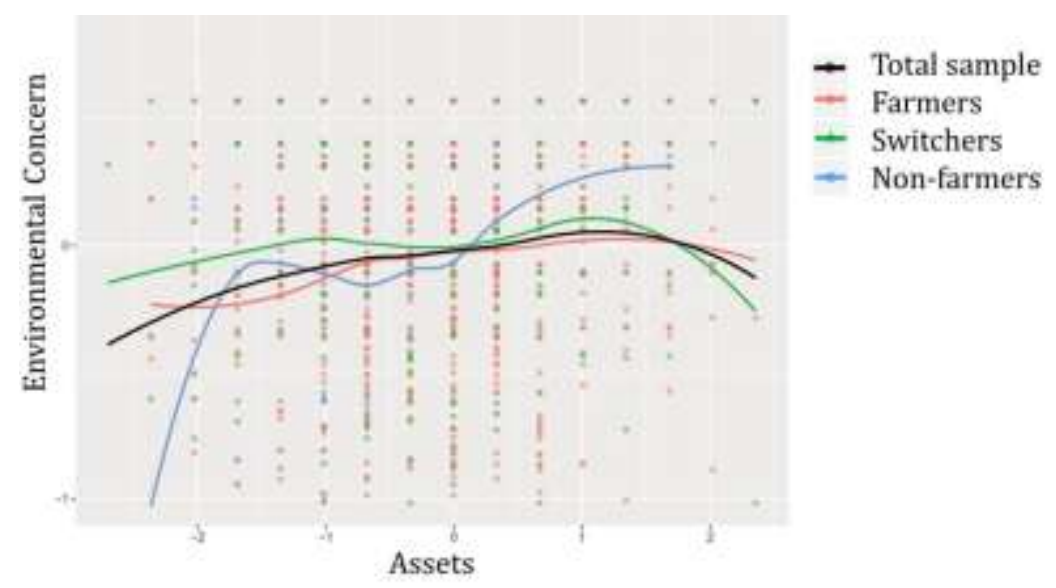

Figure 9. Environmental Concern by Group and Income. Local regression functions. Error-imputed variables standardized around median for emphasis in demonstration.

Beyond these minimum assumptions for meaningful analysis of our type of bridging, we also find evidence for a modified U-shape. It arises due to considerable within-group income heterogeneity, rather than due to income clustering of groups: Non-farmers are found to exhibit a maximum not only at high, but also at low income - generating a gap in between. This again hints at confirmation of our bridging hypothesis, given absence of past farming experience for non-farmers. 
While finally farmers' pattern does not help establishing an EKC in Bangalore, it contributes to an additional, straightforward bridge across non-farmers U-shape: Like the other two groups but in addition to current nature experience compared to non-farmers, farmers exhibit monotonic increases of concern in income as hypothesized. But like the other two, farmers also turn out to be highly heterogeneous internally with regard to income, which justifies examination of group-specific influence when analyzing our type of bridging below.

\subsection{Path Model}

The large influence of past nature experience in explaining the lifting of switchers' environmental concern then emerges from the inferential path model: Aggregating over all paths from nature connection to concern for switchers as a function of income, we find positive influence of earlier environmentalism of the poor particularly at low income, but still at the middle of the distribution (see also black line, Figure 10):

$$
\begin{aligned}
& \text { Environmental concern (assets } \mid \text { group=switch) } \\
= & 0.009 \times \text { assets }^{2}-0.019 \times \text { assets }+0.085
\end{aligned}
$$

Graphically, it can be shown how absence of such past nature experience generates a similar pattern as the one obtained for non-farmers in Figure 9 above; that is, how that group comes close to mimicking a counterfactual with regard to the impact of switchers' past nature experience, despite no truly exogenous grouping. Note here the substantial explanatory power of our framework for the degree of bridging present in our data: Just 1 unit of aggregate nature connection lifts switchers' concern around 0.1 units at critical income (Figure 10). This roughly corresponds to switchers' elevation above aggregate concern at non-farmers minimum in Figure 9. 


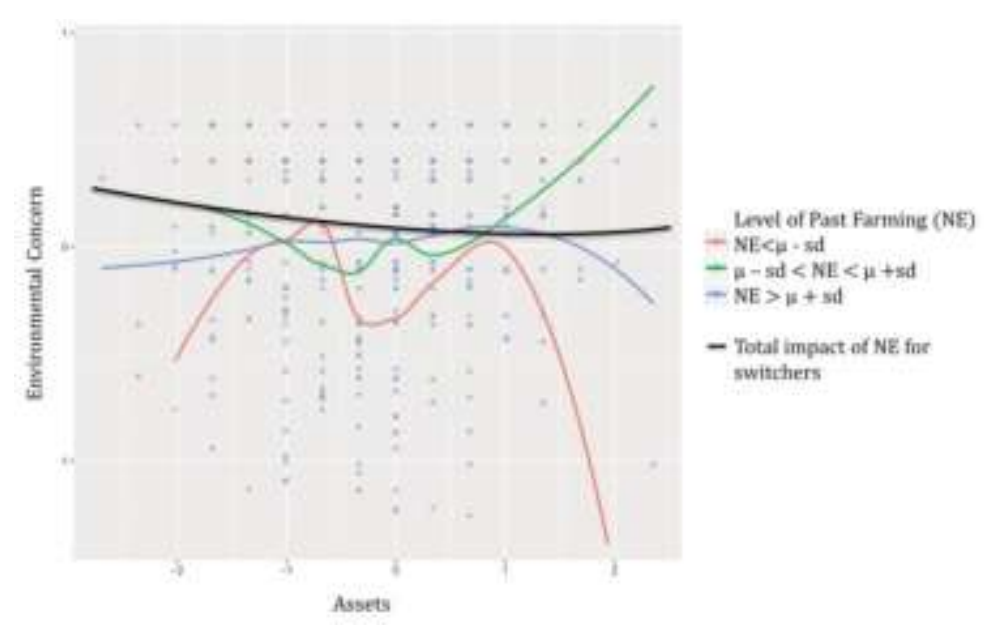

Figure 10. Environmental Concern for Switchers by Level of Past Farming. Note: Level functions from local regression. Errorimputed variables standardized around median for sharpened demonstration. Total impact from parametric path model (original data, [16]).

The model generates this effect, for one thing, because switchers benefit from above-average levels of nature connection: Our data confirm the overall applicability of our theoretical approach by allowing for replication of a positive relationship between past nature experience and environmental concern (Figure 11). Previous findings are also confirmed with regard to mediation of this relationship by nature connection. But on top of this, switchers also benefit from underproportional conversion of nature connection into concern (path 2), but dominant overproportional conversion of past nature experience into nature connection (path 1).

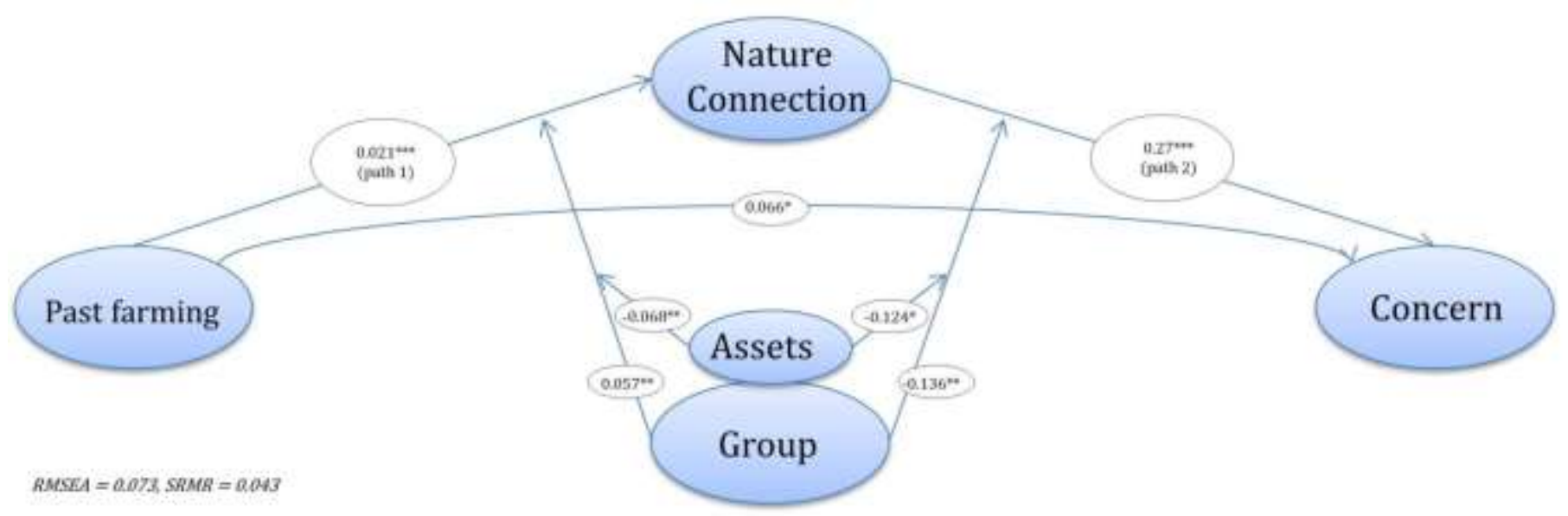

Figure 11. Environmental Concern caused by past Nature Experience. Coefficient estimates and significance level selected from latent variable model with raw data and reduced dependent (moderated mediation; Table 2). Paths aggregated for path 1 [16]. Causal structure is theoretical. 
At equation level (Table 2), our results back these findings by a first attempt at moderation analysis of nature experiences' influence on environmental concern: In case of path 2, a negative and quite sizeable 3-way interaction between nature connection, group and income (0.124 ) indicates that switchers' impact of nature connection onto concern is in fact below average, but less so at lower income (Figure 11). ${ }^{30}$ Assuming that our proxies capture psychological constructs behind these two moderators to some degree, we find indication for confirmation of hypotheses regarding what drives the negative group moderation (see robustness for how these results emerge as valid simplifications from dummy regression): It is explained by the group model through comparatively low levels of agreeableness (increased avoidance) and abstract thinking for switchers (with non-farmers even lower), and lowest scores for switchers on knowledge and time preference (Table 2). But contrary to our hypothesis, the resultant underproportional conversion of switchers is partially mitigated at low income: Mentioned 3-way interaction mediates the negative 2-way one between nature connection and income. Note also the implication that group moderation is indeed required in addition to individuals' location on the income distribution to explain the empirical degree ${ }^{31}$.

30 Interpretation of 3-way interactions is only feasible from 2-way ones Dawson and Richter (2006). Again, 'sizeable' refers to maximum group difference at median income of about 0.2 (Figure 10).

31 Full mediation additionally means that income moderation indeed operates through the same (psychological) mechanisms as group. 
Table 2. Baseline structural equation regression (selective).

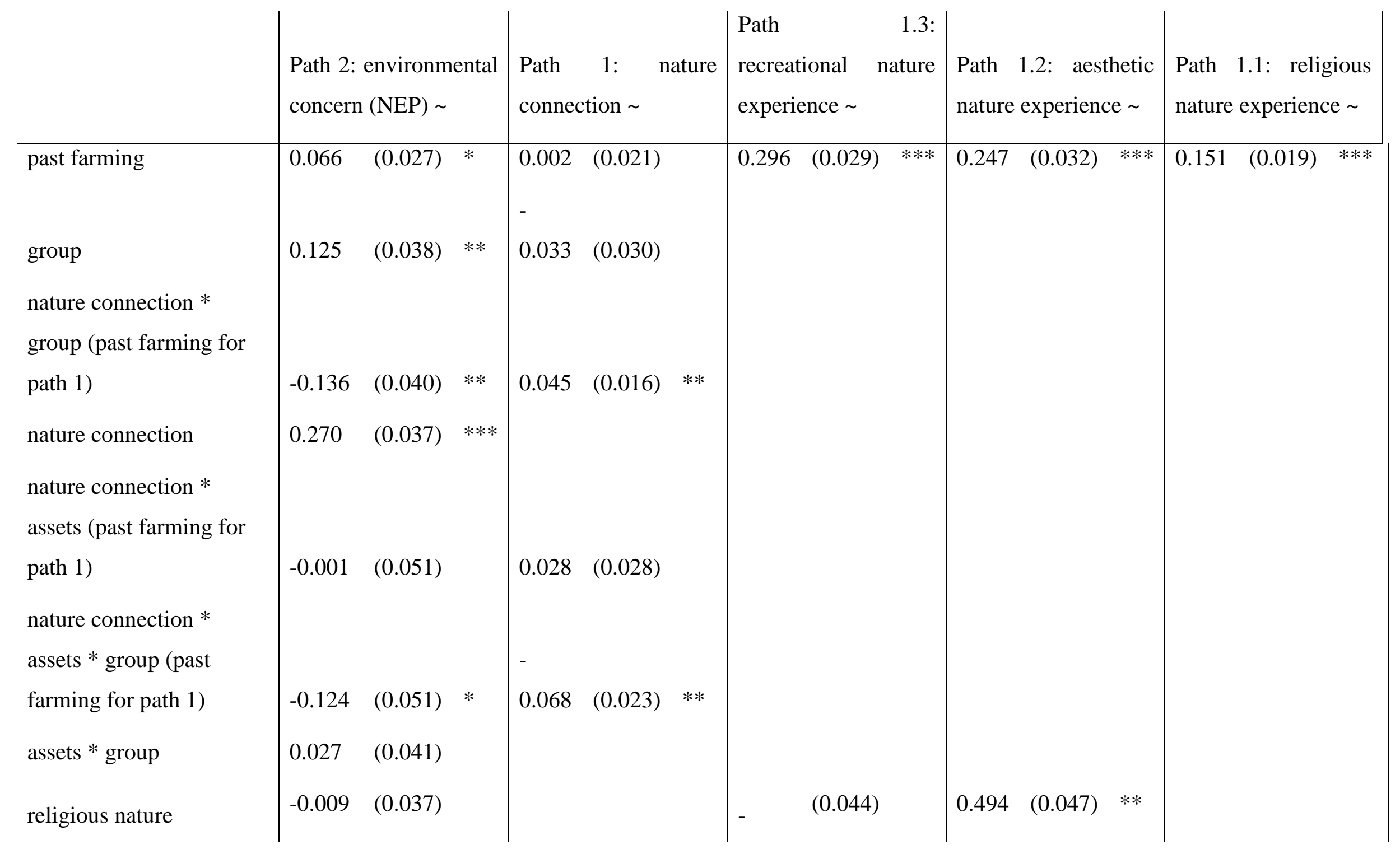


experience

religious nature

experience * group

religious nature

experience $*$ assets

recreational nature

experience

aesthetic nature

experience

aesthetic nature

experience $*$ group

abstract thinking

time preference

knowledge

altruism

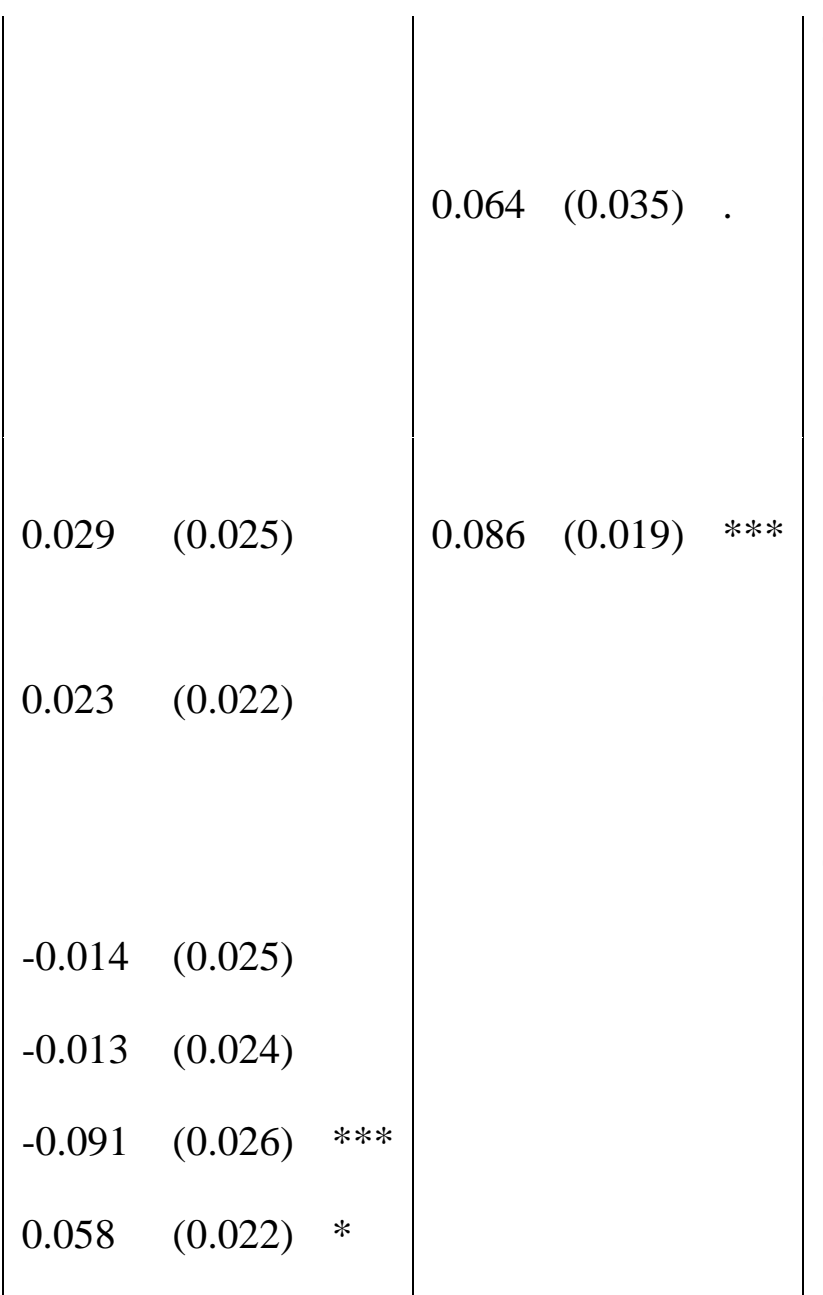

0.057

$(0.026)$

0.062

$(0.025) *$

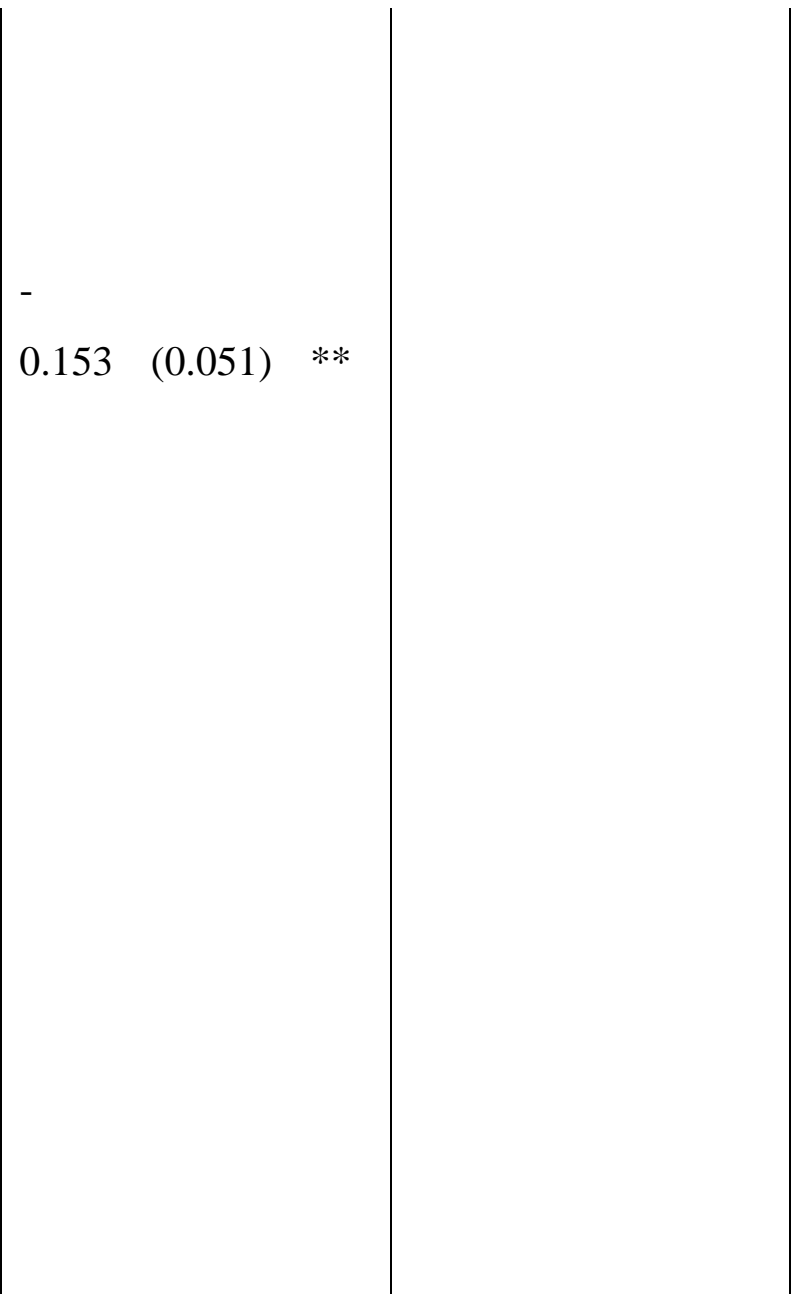

Note: Standardized coefficients, as well as equations selected from baseline structural equations model for demonstration purpose (see Appendix A5 for full model estimated, group and mediation-ofmoderation equations omitted here). Nature connection interactions replaced by past farming interactions in path 1 and submodels. RMSEA $=0.073$, SRMR $=0.043$. Standard errors in parentheses, sign codes: '***' $<0.001^{\prime * *}$ ' $<0.01^{\text {' }}$ ' $<0.05^{\prime}$ '? $<0.1$ 
In contrast, path 1 explains bridging also by above-average benefits from past environmentalism of the poor in case of switchers: Nature connection only translates into nature connection positively for switchers (positive group moderation), and even more so at lower income (negative 3-way interaction in Table 2). This effect is reinforced by several mediations through other types of nature experience, which results in an aggregate group coefficient of +0.057 on path 1 (Figure 11): Only switchers convert nature connection into aesthetic and spiritual nature experiences. While decreased income does reinforce group moderation and is hence in line with theory, our proxies for the psychological mechanisms behind the positive group moderation only partially point toward confirmation of hypotheses: Switchers benefit from low abstract thinking, which seems to indeed favor becoming conditioned to nature. But counterintuitively, positive moderation is also driven by (switchers') increased avoidant attachment.

\subsection{Robustness}

By and large, we regard our results as quite robust despite the many obstacles psychometric survey research is faced with in the Global South. ${ }^{32}$

First of all, this is true for measurement of the dependent variable: Our main results generalize to error-imputation data, and then to regressing on the full NEP in addition (Appendix A5). Both path 1 and path 2 even exhibit more main effects, and added value from heterogeneity is equally retained. The 3-way interaction in path 2 changes sign, but total group effects are not put into question by this: For switchers, they still decrease in income, while remaining larger than farmers' throughout the bridging section of income. ${ }^{33}$

Whereas this also indicates robustness to controlling interviewer bias, in case of respondent bias we ultimately have to rely on standard precautions that were taken when constructing the questionnaire. In addition, replication of the most important effects does obtain under weighting by population size. If urbanization in India does represent stages of modernization in a cross-section, then our results generalize to economic development. Note however that convergence is conditional upon parceling the NEP scale, and that the group model does not replicate at all.

32 Note that this also justifies interpretation of various data sources interchangeably in figures and descriptive statistics. 33 Switchers concern function becomes $-0.002 y^{2}-0.019 y+0.076$, which intersects with farmers linear impact at $y=1.78$ ( $\mathrm{y}=$ income). Similar analysis is possible for population weights and subsample / dummy regressions. 
Finally, we are also able to demonstrate that our ordered group variable can be interpreted as a just simplification of dummy effects: With the exception of additional mediation of path 1 by switchers, both signs and significances of the most important effects replicate in both subsamples alike; that is, when comparing switchers to both farmers and non-farmers. This seems intuitive in case of path 1: Here the baseline already compares to farmers only effectively, as non-farmers do not exhibit any influence of nature connection. In case of path 2, it becomes straightforward given minimum altruism, time horizon and abstract thinking means of switchers compared to the other two groups (Table 1). Technically, the baseline coefficient thus represents a conservative estimate on switchers' moderation compared to farmers', since it is additionally mitigated by non-farmers' one. As opposed to all these, avoidant attachment does exhibit the hypothesized ordering. But since the comparison between non-farmers and switchers would contradict the ordering, we again interpret the group coefficient as the effect of switchers compared to farmers only.

\section{Discussion and Conclusion}

We discuss our findings in light of recent advances in income-concern, nature experience and pollution-EKC literature, while suggesting possible extensions in future research alongside.

\subsection{General Implications for Income-Concern Theory}

In sum, our results confirm a positive income-concern relationship within a middle-income country (Summers \& VanHeuvelen, 2017). However, in our Indian case, aggregate patterns hide an underlying U-shape for some individuals (confirming (Upadhya, 2009)), bridged by others (simultaneously allowing for (Chatterjee, 2008)). This would explain previous failure to find significant quadratic terms in the relationship more generally (Fairbrother, 2013), if some type of bridging was present in many of the cases modeled.

With regard to income-concern theories, our findings can be explained by a 'objective problems, subjective values' approach, that incorporates global environmentalism and affluence and values, but holds without recourse to degradation exposure (Guha \& MartinezAlier, 2013). This becomes evident, first, by the drivers of a U-shaped Kuznets pattern in Bangalore, as demonstrated by our graphical analysis (Figure 9): Concern increases toward higher income for all groups, which could point to affluence and values. Degradation seems a 
less plausible explanation, given that rich Indians are usually able to shield themselves from exposure to pollution (Nair, 2005). Secondly, non-farmers' concern exhibits a maximum at low income and then decreases with income to cause the Kuznets pattern as hypothesized in our sample. This can only be accounted for by environmentalism of the poor, as contained in 'objective problems, subjective values' theory: Urban poor may exhibit persistent dependence on the environment for livelihoods (Nijman, 2015). Evidence of differential bridging in Bangalore equally reinforces global environmentalism at least in addition to degradation: Increases of concern with income are to a large part explained by positive nature experience in case of switchers particularly up to intermediate income, and to a constant degree in case of farmers.

Absence of maximum concern for farmers at low income must not invalidate these claims, but could point to limitations of our study regarding measurement: We conveyed the psychological constructs modeled as far as the survey context allowed. But even if future studies replicated Northern item statistics in a Southern sample like ours, we would consider explorative studies of what really describes how farming translates into environmentalism would be highly valuable (van de Vijver \& Tanzer, 2004).

In future studies, external validity of this argument could however be strengthened: One could imagine situations where pull urbanization, as in Bangalore, is replaced by push urbanization (Sridhar, Reddy, \& Srinath, 2010). Switching then happens out of necessity rather than as a conscious decision, once resources permit. Strong income ordering of groups could then allow for more clear-cut verification of our hypotheses. But on the other hand, especially memories of past nature experience might not be as positive there. Relative contributions of the type of bridging focused here should thereby also become clearer and complement internal validity of our study, even if more systematic remedies for potential endogeneity were again lacking.

\subsection{Details of Nature Experience's Influence}

A closer look at our regression results relates these findings to recent applications of nature experience theory to Southern samples (Widdop Quinton \& Khatun, 2018): As hypothesized, bridging is explained to a large degree by overproportional influence of switchers' nature experience at critical income. But whereas one driver of this influence, robust negative income moderation, equally confirms our theoretical approach, personality-related moderators cancel out. If found robust (see above), these findings would amount to almost zero 
moderation effect, if generalized to rich, Western samples. We however favor an interpretation of limited generalizability of nature experience mechanisms between Southern and Northern studies, and hence emphasize the need for future moderation studies in different cultural contexts. This claim is supported by sensitivity of the group-model to population weights: Psychological heterogeneity is known to increase with economic development, and could result in more complex yet not inexistent moderation (Cross, Hardin, \& Gercek-Swing, 2011). Moreover, brevity of our rather exploratory personality scale could again mask true relationships.

At more detail, the path model carries further implications: Lower income mitigates negative group effects in case of path 2, and reinforces positive group effects of path 1 . Regarding income moderation, the latter confirms expectations, whereas the former may again point to urban poor's remaining dependence on nature. Switchers' psychological traits, on the other hand, are conducive to becoming attached to nature, but prevent conversion into abstract concern. High discount rates and low knowledge unambiguously cause the latter, and reduced abstract thinking moderation of both paths. Low investments and involvement in 'relationships', as predicted by avoidant attachment, were hypothesized to negatively moderate path 2. However, note alternative explanations of these findings related to respondent bias. ${ }^{34}$ The unexpected finding for path 1 may be due to nature being different from social relationships, such that suppressed needs of avoidant individuals surface. At least they would be particularly susceptible to counter-depressive effects of nature experience (Bratman, Hamilton, Hahn, Daily, \& Gross, 2015). Yet another alternative explanation for path 1 could more generally be nostalgic bias (Morewedge, 2013): The more time has passed since the experience, the more switchers would remember only positive nature experience. Affect for nature then comes easy, while actual consequences like worrying are not required in their everyday lives anymore.

Note finally how these psychological traits moreover point to explanations for selection into groups: Successful farming under adverse climatic conditions like in Bangalore seems hard to manage for impatient nature lovers lacking knowledge and abstract thinking (Shrapnel \& Davie, 2001).

\footnotetext{
${ }^{34}$ In case of path 2, social desirability could bias results by artificially increasing correlations: It is known to increase in agreeableness, and that had been found to positively moderate correlations here. Affirmative bias resulting in artificially high correlations could additionally result from lack of understanding. Again, understanding should increase in abstract thinking, and that had been found to positively moderate path 2 . Path 1 would not be subject to these biases, once one is willing to assume that past nature experience is manifest and as such not affected.
} 


\subsection{Pollution behavior and bridging policies}

For policymakers in Bangalore, our results may be considered to open up considerable leverage: Monotonic increases of environmental concern with growing income are to a large degree not just driven by linear degradation experience (Gambhir, 2017), and they also do not simply lag behind an EKC-shaped pollution scenario (Murthy \& Bhasin, 2016). But U-shaped preferences neither cause inverse U-shaped polluting behavior unequivocally, at least not without pointing to dominant preferences for environmental protection even at critical intermediate income. Future research would need to explore ways of reducing the attitudebehavior gap further, but then preferences of a sufficient number of individuals seem to provide a leverage on contemporaneous environmental problems (Koger, 2013; Pisano \& Lubell, 2017).

Besides such a gap, we however consider a number of alternative explanations to be likely causes of the income-concern relationship documented: Our sample could be contradicted by less positive memories and absence of bridging elsewhere (e.g. under push urbanization). It could further fail to cover the higher part of the income distribution of the between-country but possibly also within-India case, such that both U-shape of concern and bridging end where growth relinks to pollution (Gambhir, 2017). Toward higher income, increasing saturation of affluence and postmaterialist values could then be coupled with receding memories of nature experience. At least for within-country patterns previously explained by decreasing degradation exposure, we found nature experience to be an at least equally valid theoretical underpinning. For all these cases however, politically induced preference change could build on prolonging influence of the bridging mechanisms outlined here (Amel et al., 2017). 


\section{Appendix}

\section{Table A4. Item Statistics for Full NEP (Error-Imputed Data)}

reliability (omega-t): 0.55

\begin{tabular}{l|lccc} 
& full sample & farmers & switchers & non-farmers \\
\hline eco-crisis & 0.79 & 0.80 & 0.71 & 0.71 \\
balance of nature & 0.82 & 0.84 & 0.79 & 0.76 \\
limits to growth & 0.30 & 0.24 & 0.33 & 0.68 \\
anti-anthropocentrism & 0.34 & 0.37 & 0.40 &
\end{tabular}

Note: Loadings from confirmatory, principal axis factoring, using varimax rotation. Loadings $<0.2$ omitted from representation. Groupwise analysis proves configural measurement invariance. 


\section{Table A5. Structural Equation Regressions Including Robustness (selected controls)}

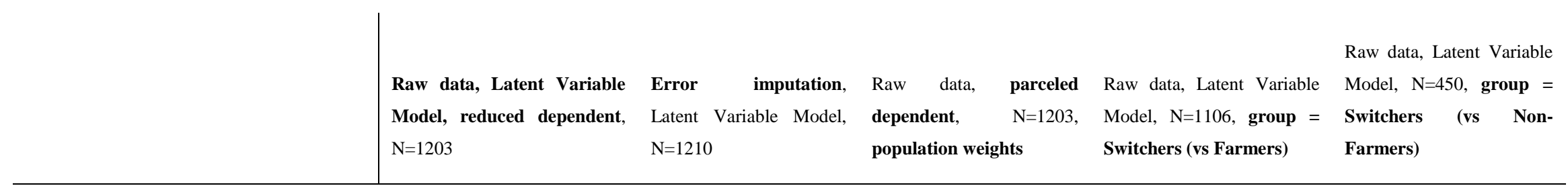

Path 2: environmental concern (NEP)

\begin{tabular}{|c|c|c|c|c|c|c|c|c|c|c|c|c|c|c|c|}
\hline past farming & 0.066 & $(0.027)$ & $*$ & 0.029 & $(0.008)$ & $* * *$ & 0.084 & $(0.044)$ & . & 0.082 & $(0.035)$ & * & & & \\
\hline group & 0.125 & $(0.038)$ & $* *$ & 0.013 & $(0.009)$ & & 0.196 & $(0.058)$ & $* *$ & 0.084 & $(0.025)$ & $* *$ & -0.029 & $(0.041)$ & \\
\hline nature connection * group & -0.136 & $(0.040)$ & $* *$ & -0.026 & $(0.009)$ & $* *$ & -0.094 & $(0.053)$ & . & -0.317 & $(0.072)$ & $* * *$ & -0.266 & $(0.064)$ & *** \\
\hline nature connection & 0.270 & $(0.037)$ & $* * *$ & 0.031 & $(0.009)$ & $* *$ & 0.246 & $(0.055)$ & $* * *$ & 0.330 & $(0.041)$ & $* * *$ & 0.299 & $(0.053)$ & $* * *$ \\
\hline nature connection $*$ assets & -0.001 & $(0.051)$ & & -0.021 & $(0.010)$ & $*$ & 0.137 & $(0.104)$ & & & & & & & \\
\hline nature connection $*$ assets $*$ group & -0.124 & $(0.051)$ & $*$ & 0.035 & $(0.012)$ & $* *$ & -0.168 & $(0.072)$ & $*$ & -0.173 & $(0.079)$ & $*$ & -0.142 & & $*$ \\
\hline assets * group & 0.027 & $(0.041)$ & & -0.008 & $(0.010)$ & & 0.005 & $(0.051)$ & & & & & & & \\
\hline religious nature experience & -0.009 & $(0.037)$ & & -0.003 & $(0.009)$ & & 0.062 & $(0.043)$ & & -0.037 & $(0.041)$ & & 0.076 & $(0.059)$ & \\
\hline recreational nature experience & 0.029 & $(0.025)$ & & 0.016 & $(0.006)$ & $*$ & 0.030 & $(0.030)$ & & 0.028 & $(0.027)$ & & -0.009 & $(0.035)$ & \\
\hline aesthetic nature experience & 0.023 & $(0.022)$ & & 0.014 & $(0.006)$ & $*$ & -0.014 & $(0.027)$ & & 0.030 & $(0.024)$ & & 0.014 & $(0.033)$ & \\
\hline educational nature experience & 0.019 & $(0.031)$ & & -0.010 & $(0.011)$ & & 0.016 & $(0.042)$ & & 0.016 & $(0.033)$ & & 0.075 & $(0.046)$ & \\
\hline abstract thinking & -0.014 & $(0.025)$ & & -0.008 & $(0.006)$ & & 0.008 & $(0.043)$ & & -0.010 & $(0.027)$ & & 0.044 & $(0.039)$ & \\
\hline time preference & -0.013 & $(0.024)$ & & -0.005 & $(0.006)$ & & 0.024 & $(0.032)$ & & -0.023 & $(0.026)$ & & 0.014 & $(0.038)$ & \\
\hline knowledge & -0.091 & $(0.026)$ & $* * *$ & -0.042 & $(0.010)$ & $* * *$ & -0.151 & $(0.050)$ & $* *$ & -0.105 & $(0.029)$ & $* * *$ & -0.032 & $(0.038)$ & \\
\hline altruism & 0.058 & $(0.022)$ & $*$ & 0.006 & $(0.005)$ & & 0.063 & $(0.029)$ & $*$ & 0.060 & $(0.025)$ & $*$ & 0.054 & $(0.033)$ & \\
\hline extraversion (inverted) & -0.010 & $(0.026)$ & & 0.028 & $(0.008)$ & $* * *$ & -0.027 & $(0.038)$ & & -0.004 & $(0.029)$ & & -0.008 & $(0.037)$ & \\
\hline
\end{tabular}


Chapter III. Environmental Concern, Income and Nature Experience in India

\begin{tabular}{|c|c|c|c|c|c|c|c|c|c|c|c|c|c|c|c|}
\hline agreeableness & -0.055 & $(0.030)$ & · & -0.014 & $(0.007)$ & & -0.110 & $(0.060)$ & & -0.053 & $(0.033)$ & & -0.050 & $(0.044)$ & \\
\hline conscientousness & 0.005 & $(0.025)$ & & 0.015 & $(0.006)$ & $*$ & -0.015 & $(0.028)$ & & 0.008 & $(0.027)$ & & 0.012 & $(0.036)$ & \\
\hline openness & -0.091 & $(0.024)$ & $* * *$ & 0.008 & $(0.006)$ & & -0.103 & $(0.026)$ & $* * *$ & -0.104 & $(0.026)$ & $* * *$ & -0.117 & $(0.034)$ & $* *$ \\
\hline neuroticism & 0.013 & $(0.023)$ & & 0.017 & $(0.006)$ & $* *$ & 0.041 & $(0.033)$ & & 0.009 & $(0.025)$ & & 0.048 & $(0.033)$ & \\
\hline age & 0.039 & $(0.029)$ & & 0.006 & $(0.007)$ & & 0.046 & $(0.036)$ & & 0.044 & $(0.031)$ & & 0.026 & $(0.043)$ & \\
\hline sex & -0.090 & $(0.027)$ & $* *$ & -0.017 & $(0.007)$ & $*$ & -0.013 & $(0.027)$ & & -0.101 & $(0.029)$ & $* *$ & -0.016 & $(0.037)$ & \\
\hline caste (inverted) & 0.018 & $(0.027)$ & & -0.008 & $(0.007)$ & & 0.050 & $(0.036)$ & & 0.002 & $(0.030)$ & & -0.060 & $(0.040)$ & \\
\hline education & 0.131 & $(0.049)$ & $* *$ & 0.038 & $(0.014)$ & $* *$ & 0.071 & $(0.067)$ & & 0.136 & $(0.053)$ & $*$ & 0.079 & $(0.078)$ & \\
\hline assets & -0.030 & $(0.044)$ & & -0.007 & $(0.010)$ & & -0.023 & $(0.069)$ & & -0.012 & $(0.047)$ & & -0.091 & $(0.123)$ & \\
\hline & & & & & & & & & & (only & & & (only & & \\
\hline village + religious FE & ON & & & ON & & & OFF & & & rel) & & & rel) & & \\
\hline \multicolumn{16}{|l|}{ Path 1: nature connection } \\
\hline past farming & 0.002 & $(0.021)$ & & -0.047 & $(0.025)$ & . & -0.001 & $(0.035)$ & & -0.009 & $(0.026)$ & & & & \\
\hline group & -0.033 & $(0.030)$ & & -0.027 & $(0.035)$ & & -0.030 & $(0.066)$ & & -0.007 & $(0.019)$ & & & & \\
\hline past farming * group & 0.045 & $(0.016)$ & $* *$ & 0.092 & $(0.019)$ & $* * *$ & 0.041 & $(0.033)$ & & 0.251 & $(0.101)$ & $*$ & & & \\
\hline religious nature experience $*$ group & 0.064 & $(0.035)$ & . & 0.155 & $(0.042)$ & $* * *$ & 0.125 & $(0.052)$ & $*$ & -0.071 & $(0.055)$ & & & & \\
\hline past farming $*$ assets & 0.028 & $(0.028)$ & & -0.011 & $(0.034)$ & & 0.027 & $(0.042)$ & & -0.002 & $(0.026)$ & & & & \\
\hline past farming $*$ assets $*$ group & -0.068 & $(0.023)$ & $* *$ & -0.045 & $(0.028)$ & . & -0.053 & $(0.029)$ & . & -0.055 & $(0.028)$ & $*$ & & & \\
\hline recreational nature experience & 0.086 & $(0.019)$ & $* * *$ & 0.094 & $(0.023)$ & $* * *$ & 0.079 & $(0.035)$ & $*$ & 0.095 & $(0.020)$ & $* * *$ & & & \\
\hline \multicolumn{16}{|l|}{ Path 1.3: recreational nature experience $~$} \\
\hline religious nature experience & -0.057 & $(0.044)$ & & -0.016 & $(0.043)$ & & -0.037 & $(0.082)$ & & -0.044 & $(0.046)$ & & & & \\
\hline
\end{tabular}




\begin{tabular}{|c|c|c|c|c|c|c|c|c|c|c|c|c|c|c|c|}
\hline past farming & 0.296 & $(0.029)$ & $* * *$ & 0.287 & $(0.029)$ & $* * *$ & 0.287 & $(0.051)$ & $\begin{array}{l}* * \\
*\end{array}$ & 0.308 & $(0.036)$ & $* * *$ & & & \\
\hline aesthetic nature experience & 0.030 & $(0.026)$ & & 0.073 & $(0.025)$ & $* *$ & -0.028 & $(0.044)$ & & 0.034 & $(0.027)$ & & & & \\
\hline aesthetic nature experience * group & 0.062 & $(0.025)$ & $*$ & 0.026 & $(0.025)$ & & 0.083 & $(0.045)$ & . & 0.018 & $(0.044)$ & & & & \\
\hline & & & & & & & & & & $\sim$ & & & & & \\
\hline \multicolumn{16}{|l|}{ Path 1.2: aesthetic nature experience } \\
\hline past farming & 0.247 & $(0.032)$ & $* * *$ & 0.253 & $(0.033)$ & $* * *$ & 0.312 & $(0.077)$ & $* * *$ & 0.193 & $(0.040)$ & $* * *$ & & & \\
\hline religious nature experience & 0.494 & $(0.047)$ & $* *$ & 0.390 & $(0.049)$ & $* * *$ & 0.565 & $(0.068)$ & $* * *$ & 0.519 & $(0.050)$ & $* * *$ & & & \\
\hline religious nature experience * assets & -0.153 & $(0.051)$ & $* *$ & -0.095 & $(0.051)$ & & -0.115 & $(0.095)$ & & -0.157 & $(0.054)$ & $* *$ & & & \\
\hline \multicolumn{16}{|l|}{ Path 1.1: religious nature experience } \\
\hline past farming & 0.151 & $(0.019)$ & $* * *$ & 0.150 & $(0.019)$ & $* * *$ & 0.066 & $(0.057)$ & & 0.196 & $(0.023)$ & $* * *$ & & & \\
\hline & & & & & & & & & & $\sim$ & & & $\sim$ & & \\
\hline \multicolumn{16}{|l|}{ group } \\
\hline abstract thinking & -0.037 & $(0.019)$ & $*$ & -0.033 & $(0.019)$ & & & & & -0.016 & $(0.031)$ & & 0.074 & $(0.046)$ & \\
\hline time preference & -0.062 & $(0.018)$ & $* *$ & -0.056 & $(0.018)$ & $* *$ & & & & -0.118 & $(0.030)$ & $* * *$ & -0.027 & $(0.046)$ & \\
\hline agreeableness & -0.073 & $(0.023)$ & $* *$ & -0.083 & $(0.022)$ & $* * *$ & & & & -0.089 & $(0.038)$ & $*$ & 0.065 & $(0.053)$ & \\
\hline knowledge & 0.050 & $(0.019)$ & $*$ & 0.050 & $(0.019)$ & $*$ & & & & 0.027 & $(0.032)$ & & -0.093 & $(0.046)$ & * \\
\hline education & 0.068 & $(0.027)$ & $*$ & 0.069 & $(0.027)$ & $*$ & & & & 0.183 & $(0.044)$ & $* * *$ & 0.111 & $(0.063)$ & . \\
\hline \multicolumn{16}{|l|}{ nature connection $*$ assets $*$ group } \\
\hline nature connection $*$ assets & 0.640 & $(0.024)$ & $* * *$ & 0.571 & $(0.024)$ & $* * *$ & 0.922 & $(0.050)$ & $* * *$ & & & & & & \\
\hline
\end{tabular}


Chapter III. Environmental Concern, Income and Nature Experience in India

\begin{tabular}{l|lllll}
\hline RMSEA & 0.073 & 0.069 & 0.092 & 0.204 & 0.141 \\
SRMR & 0.043 & 0.045 & 0.037 & 0.042 \\
\hline
\end{tabular}

Note: For demonstration purpose only theoretically meaningful controls included. Non-meaningful model parts omitted from subgroup estimation (last 2 columns). Coefficients from standardized variables. Standard errors in parentheses, sign. codes: ' $* * *$ ' $<0.001^{\prime} * *$ ' $<0.01^{\prime} *$ ' $<0.05^{\prime}$. ' $<0.1$. RMSEA and SRMR $<0.08$ required for acceptable fit, where SRMR does not penalize additional variables. Sample size varies with outlier correction (after imputation). 


\title{
Chapter IV. Trust, Collectivism and Causality
}

\begin{abstract}
:
Especially vertical, hierarchical collectivism has been suggested to affect generalized social trust negatively because of allegedly enhanced ingroup bias. But such accounts may suffer from various sources of statistical confounding: Horizontal, distance-based preferences of relationally constructed selfs in collectivist societies could even generalize particularly well. They could imply negative mediation by trustworthiness (generalized morality), which may also facilitate reverse causality. Vertical structures could equally prove beneficial given voluntary cross-group experiences as a moderator. This study aims at revealing causal influence by embedding both roles of the trust game in a representative survey conducted in Bangalore / India $(N=1200)$. Urbanization introduces variation spatially and provides instrumental variables. Negative main effects of both dimensions of collectivism on trust replicate here, but turn positive under experiences of high morality (moderation), and are partially obstructed by reverse causality. These results point to fostering social exchange as the way toward desirable norm equilibria.
\end{abstract}

Keywords: generalized social trust, collectivism, self construal, generalized morality 


\section{Introduction}

Cultural norms coevolve historically, such that true causal relationships are often well hidden in the "bowl of well-tossed spaghetti" that one usually observes (Bowles, 2010; Putnam, 1993). This applies to generalized social trust, the willingness to engage in interdependence with another individual involving uncertainty but potential mutual gains (Robbins, 2016). Understanding underlying causes may prove particularly useful here, because "trust matters" as the central lubricant across disciplines for beneficial outcomes in social interactions - not the least of them being economic growth (Alesina \& Giuliano, 2015).

But extant attempts at isolating causal cultural influence on generalized trust even just from the most important confounders, such as omitted variable bias or reverse causality, remain unsatisfactory (Bjørnskov, 2007; James, 2015; Letki, 2006): Cultural dynamics unfold only in the very long run, depending on common causes such as the subsistence base of societies (Witkin \& Berry, 1975). Even where all such confounders are controlled, endogeneity still remains a threat to most of the common instrumental variables; even cross-country panels would miss the variation of interest, while experimental manipulation is hardly available.

We study collectivism, potentially subject to confounding in extant studies, but a decisive and politically relevant preference for trust: Besides beliefs, preferences constitute one group of cultural norms suggested to influence trust (Fehr, 2009). Individualism-collectivism and its psychological roots in self-construal arguably form the most basic cultural dimension that all other preference differences trace back to (Gorodnichenko \& Roland, 2011). Collectivism has reliably been associated to generalized trust negatively; this has been attributed to ingroup bias, and been interpreted as more or less deterministic evidence that some cultural environments are simply not conducive to modern economic exchange (Fukuyama, 1996; Putnam, 1993; van Hoorn, 2014).

Reliably positive correlations of trust to agreeableness however hint at the need to control for confounding before such conclusions are drawn (Dinesen \& Bekkers, 2015): Collectivists also tend to score very high on agreeableness due to relational preferences that generalize to outgroups readily (Cross et al., 2011; Triandis, 2001). This study therefore tests for some of the more obvious, but so far neglected alternative explanations of observed negative collectivism-trust correlations: Omitted variable bias indicative of mediation or moderation, reverse causality and multidimensionality of the construct.

We conduct incentivized trust games in India (both roles; Johnson \& Mislin, 2011). It could be considered a critical case, as persistently low economic development in large parts of the 
country is often attributed to particularly strong collectivism keeping generalized trust very low (Platteau, 1994). Our representative sample from the rural-urban gradient of globalizing Bangalore $(\mathrm{N}=1200)$ exploits continuous variation in space introduced to constructs of interest by urbanization (Nair, 2005). The speed of associated social change may yield advantages compared to extant approaches here (Chen \& Ren, 2016); we tackle reverse causality by a spatial instrumental variable approach (Drukker et al., 2013).

Our data provide first evidence toward a more nuanced picture of collectivism - one compatible to (multiple) modernities (Eisenstadt, 2000): We reveal positive influence of both dimensions of collectivism on generalized social trust, but only at high generalized morality and once reverse causality is taken into account. Confounding chiefly arises from moderation: Absence of cross-group interaction experience leads to previously observed negative effects and explains lock-in of the Indian society at low a low trust equilibrium, because horizontal categorization then gains momentum over closeness orientation of cooperative relational selves, and scaling disadvantages of vertical duties prevail over structuralism conducive to recategorization. Policies conducive to cross-cutting experiences are expected to foster generalized trust in other collectivist societies too, but absence of Indian caste-based categorizing could even lead to unconditionally positive influence of collectivism there.

Section 2 derives the theoretical framework, section 3 introduces our empirical approach, section 4 discusses results and section 5 concludes with an outlook to future research.

\section{Theoretical background}

\subsection{Collectivist Preferences, Dimensionality Confounding and Ingroup Bias}

We outline first how collectivism implies horizontal social preferences for relational selves that may affect generalized trust positively once properly differentiated from vertical collectivism. There is now widespread consensus that generalized social trust originates in relatively stable individual differences that one may call preferences: If one is willing to assume that generalized social trust is best defined as the $1^{\text {st }}$-mover decision in a trust game, then this decision is irrational to a certain degree; it is not merely determined by expectations of trustworthiness (Dunning, Anderson, Schlösser, Ehlebracht, \& Fetchenhauer, 2014). Rather, it is predicted by predispositions to take social risks ('betrayal aversion'), correlates but is not identical to certain varieties of altruism, and has even been found to be partially heritable (Fehr, 2009). Even though the direction of causality is far from clear and besides 
openness to experience, agreeableness has proven to be one of the most consistent predictors across samples for this preference (Dinesen \& Bekkers, 2015).

Collectivism relates to preferences for generalized social trust here, because relational selves tend to be agreeable and emphasize cooperation in social interaction (Triandis, 2001). A widely acknowledged definition of collectivism consists of an interdependent self construal, as well as priority of relationships, group goals and norms over self enhancement as defining elements (Triandis \& Gelfand, 1998). Amongst these, self construal may arguably be interpreted as the most fundamental psychological difference between cultures (Gorodnichenko \& Roland, 2011). The relational rather than the collective self construal has lately been found to describe collectivist culture best (Brewer \& Chen, 2007; Yuki, 2003): Rather than by depersonalization within common identities or categories shared by close others, which is also observed in individualist culture in some situations, it is characterized by common bonds of close distance. In social interaction, relational selves strive not so much for similarity but for harmony and cooperation. Across a variety of studies and situations, such a tendency has been documented to result in particularly pronounced prosocial preferences even including betrayal aversion as the most direct predictor of generalized trust (Bohnet, Greig, Herrmann, \& Zeckhauser, 2008; Cross et al., 2011; Romano et al., 2017).

Even though a specific preference for trust remains to be demonstrated in case of India, prosocial preferences point towards it here, too: Unconditional altruism in the form of helping strangers is considered a social norm (Vakoch, 2013). Indians enjoy socializing (Robinson, 2014); cooperation across social strata has always been an essential part of traditional Indian subsistence (Krishna, 2007).

The difference between horizontal and vertical dimensions of collectivism is one of the most common frameworks of analysis for the cultural preference of interest here. At the same time it helps understand the potential caveat in its link to generalized social trust (Singelis, Triandis, Bhawuk, \& Gelfand, 1995): Implications of the relational self construal covered so far largely refer to the horizontal dimension. They rely on low interpersonal distance, and apply to collective selves experienced by individualists in common identity groups to a certain degree, too. The vertical dimension of collectivism, on the other hand, is implied only by relational selves' common bonds in addition. It describes where preferences are expected to be articulated. Relational selves occupy well defined positions in structured networks of close bonds mirroring a hierarchy between group norms and individual duties (Yuki, 2003). 
It is by and large this vertical dimension of collectivism that has been hold accountable for the discrepancy between social preferences and generalized trust in these cultures (Shin \& Park, 2004). Extant literature failing to differentiate between the two dimensions may have obfuscated partially positive influence, because structured networks have been linked to exacerbated ingroup bias in cultures like the Indian one. Essentially this is due to the fact that they are assumed to restrict the targets of horizontal preferences (Figure 12; (Yamagishi, 2011; Yuki, Maddux, Brewer, \& Takemura, 2005)). This is mirrored by especially vertical collectivists repeatedly scoring low on openness to experience; besides agreeableness, this constitutes the other reliable individual preference consistently predicting generalize trust (see above).

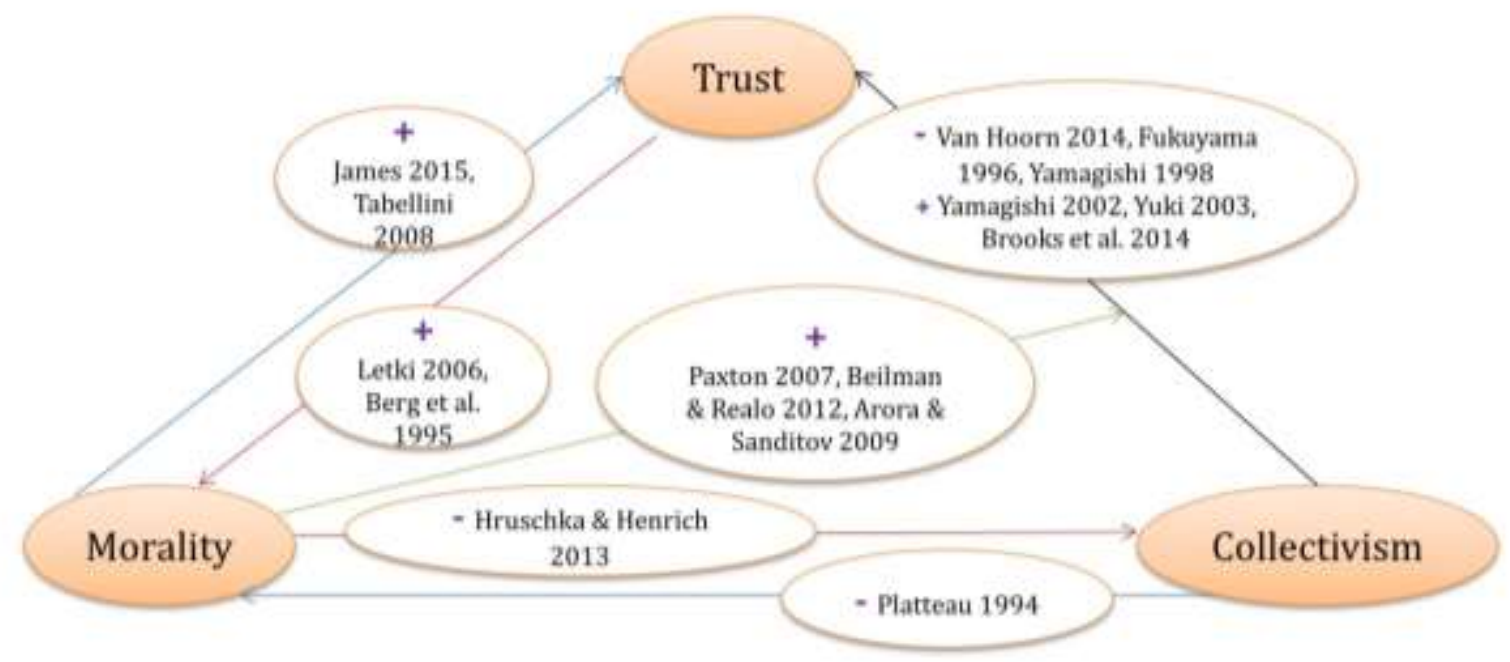

Figure 12. Theoretical framework. Confounding of collectivism-trust link (black) by mediation (blue), moderation (green) and reverse causality (red). Dimensionality omitted for readability. Supportive literature exemplary.

Such ingroup bias is manifest across cultures (Balliet, Wu, \& Dreu, 2014), but collectivists are said to have even more trouble widening the circle of relationships. Instead of structural common bonds, independent selves form groups based on shared categories. Allegedly, such common identities scale up faster than relational selves' personalized bonds, since strangers can be incorporated under a common ingroup identity and do not need to acquire a spot in the network structure one by one (Lee, Adair, Mannix, \& Kim, 2012).

And indeed, infamous 'cellularity' of the Indian society reflecting strong primacy of family and caste ingroups, particularly when it comes to trust (Saberwal, 1996), is mirrored by a dominant vertical dimension of collectivism (Verma \& Triandis, 1999). However, India is in addition known for its long tradition of categorizing groups hierarchically based on caste (Dunham, Srinivasan, Dotsch, \& Barner, 2013). This ambiguity is mirrored by prevalence of 
autonomously-related selves: Close but hierarchical relationship structures dominate inside groups, and categoric competition outside (Sinha, 2014). Thus far, the net effect of this combination on the unconfounded collectivism-trust relationship remains equally ambiguous.

\subsection{Collectivist Trustworthiness, Mediation Confounding and the Social Dilemma}

To see how actual causalities might deviate from these observations beyond but in combination with dimensionality issues, it warrants exploring belief-related drivers of generalized social trust. We describe next how they mediate relational collectivists' horizontal and vertical social preferences negatively (Figure 12). As opposed to this, positive direct influence of distance-based horizontal relations on generalized trust may obtain due to reduced ingroup bias especially compared to individualists. Such counterbalancing could however be obstructed in India, if category-based horizontal relations obtain there, too.

Expectations of trustworthiness constitute a somewhat more 'rational', reliably positive predictor of trusting strangers (James, 2015; Manapat, Nowak, \& Rand, 2013). They are formed based on experiences, such that more than preferences, they are malleable (Paxton $\&$ Glanville, 2015). The degree to which any given society is conducive to such experiences is assumed to be one of the major causes of the emergence of cooperation in human evolution, and it has alternatively been named reciprocity, conditional cooperation or generalized morality (Nowak, 2006; Platteau, 1994). It relies on a pro-social transformation of the zerozum dilemma of the $2^{\text {nd }}$ mover in the one-shot trust game with a stranger, into an assurance game yielding additional pay-off from joint gains (Guth \& Kliemt, 1994).

Proximal causes of such 'strong reciprocity' have so far hardly been separated from the social preferences also affecting trust. Under collectivism they are hence likely to be equally augmented, but suffer from enhanced ingroup bias as well (Letki, 2006). Static inequality aversion or procedural fairness concerns constitute highly culturally relative norms internalized through education or enforced by manifest institutions (Tabellini, 2008). They may also be evolutionary adaptive due to group selection (Fehr, Fischbacher, \& Gächter, 2002).

However, there is evidence suggesting that enhanced ingroup bias of collectivists may to a much larger part be a problem of morality, and not of direct preferences for trust. This amounts to negative mediation and might dominate observed correlations in extant literature. One such hint derives from overproportional benefits of collectivists from particularized morality but not trust, and implied positive discrimination: Indirect reciprocity driven by 
reputation may motivate cooperation, given that information on players is available at some cost (Platteau, 1994). Moreover, morality may be indicative of reciprocal altruism in situations where players derive direct benefits from a repeated dilemma with the same person. Dense, vertical collectivist networks with high mutual obligations more readily lend themselves to these particularized experiences of trustworthiness. This increases the opportunity cost of investing in systems of generalized morality (Yamagishi, Cook, \& Watabe, 1998).

But in collectivist societies, strong reciprocity may also be affected by augmented ingroup bias, or negative outgroup discrimination. Enhanced ingroup bias from vertical collectivism is counterbalanced here by reduced ingroup bias from horizontal, distance-based sociability of relational selves. This becomes evident from the sequential nature of trust game - like situations, which creates an incentive differential between $1^{\text {st }}$ and $2^{\text {nd }}$ mover: Whereas the $1^{\text {st }}$ mover stands to gain from cooperation, the $2^{\text {nd }}$ mover faces a zerozum-tradeoff between his (untransformed) pay-offs and the ones of the $1^{\text {st }}$ mover (Fehr et al., 2002). Then, individualists playing with an outgroup or a stranger may tend to defect even in the $1^{\text {st }}$ mover situation, as it maximizes the pay-off difference between ingroup and outgroup. Individualists experience self enhancement from collective depersonalization in groups, and that depends on the groups' category's relative standing; seemingly high horizontal sociability thus stops at group boundaries. Horizontal cooperativeness of collectivists, to the contrary, has been found to extend to outgroups as long as this does not negatively affect the ingroup. They may not incorporate outgroups under a common identity, but they care for vertical network obligations more than for self-enhancement; collectivists may thus be as likely to defect as individualists only in the $2^{\text {nd }}$ mover situation, with a tradeoff between ingroup and outgroup (Yuki, 2003).

In support of these two arguments, ingroup bias in collectivist samples has been documented to even disappear completely once expectations of reciprocity are controlled (Yamagishi, 2003). Even though expectations have not actually been controlled in India, the best available evidence remains mixed and could point to a 'double burden' - i.e. horizontal category-based outgroup discrimination in addition to limits to common identity generalization imposed by vertical collectivist structures ${ }^{35}$ : Cross-caste cooperation has consistently been observed to be enhanced in cooperative compared to competitive tasks (Brooks, Hoff, \& Pandey, 2014; Chakravarty, Fonseca, Ghosh, \& Marjit, 2016), and monitoring options as in village economies or business networks largely eliminate outgroup discrimination (Harriss, 2003).

\footnotetext{
${ }^{35}$ Recall that we assume category-based horizontal preferences never to reduce ingroup bias more than distance-based ones under presence of vertical collectivism, because the latter prevents common identity generalization (Lee et al., 2012).
} 
But some studies also report at least equally high preference or $1^{\text {st }}$ mover bias, perhaps indicating that presumed distance-based horizontal collectivism does not prevail in India (Chuah, Fahoum, \& Hoffmann, 2013). To some degree, empirical testing of conditionally positive influence of especially horizontal collectivism on trust may hence be perceived as a simultaneous evaluation of which group concept prevails in India.

\subsection{Collectivist Tightness, Common Causes and Generalization}

Yet, there is at least one further reason why both experiences of trustworthiness and generalized trust may historically have been lower than they could have been under both horizontal and vertical collectivism even in India, so that a potential double burden is converted into a double dividend: Cultural tightness is the basis of collectivist, relational self construal, but it may also have prevented emergence of voluntary cross-cutting groups decisive for generalization of preferences (Figure 12 still).

Convincing evidence now documents that ingroup bias can be reduced through converting 'bonding' social capital into 'bridging' social capital (Paxton, 2007): All experiences are necessarily personal and take place within a certain group first. Before one expects strangers to be trustworthy, one has probably found many of them to be so in concrete encounters. Societies that feature overlapping, rather than exclusive groups, are able to facilitate personal encounters with strangers. This may help reduce ingroup bias by generalization beyond immediate encounters; this time however not by a common ingroup identity, but by decategorizing outgroups through personal ties and then recategorizing jointly with them into cross-cutting groups. Indirect reciprocity could thus lead to expectations of strong reciprocity, but potentially particularistic prosocial preferences could even generalize directly, too (Gaertner et al., 2000). The latter may build on, but is not limited to the incentive differential outlined in section 2.2 .

Many collectivist societies have not historically benefited from this mechanism, because they likely originated from cultural tightness required for subsistence in uncertain climates (Thomson et al., 2018). Whereas overlap of groups depends on voluntariness of relationship uptake, such tightness limits relational mobility, and that has historically often been equal to voluntariness. However, both horizontal bonds and vertical obligations of relational selves have sometimes proven beneficial to both prosocial preferences and experiences with strangers when close, longterm obligations were a matter of choice (Beilmann \& Realo, 2012). The prime example for this distinction is Japanese peer collectivism rooted in 
voluntary 'iemoto' business groups, as opposed to Chinese family collectivism based on kin (Fukuyama, 1996).

In particular and besides higher cooperative preferences, relationals' distance rather than similarity-based sociability may facilitate decategorization compared to independent selves here. In addition, vertical collectivism could more than counterbalance its difficulties in relating to strangers based on generalizing identities here, because interaction should more easily result in recategorization into new structural networks (Yuki, 2003). Controlling outgroup interaction could therefore reveal a 'double dividend' of collectivism: Positive influence of distance- rather than category-based horizontal, as well as recategorizing rather than generalization limiting vertical collectivism on both generalized morality and trust once again.

Beyond actual trust and reciprocity, Indian collectivism has traditionally been considered to prevent cross-cutting association by emphasizing non-voluntary, stable and exclusive group membership based on caste and family (Verma, 1985). However, ample evidence now illustrates how Indian collectivism may benefit from unique synergies that could render controlling mere possibilities of interacting with outgroups redundant: Starting with directly reciprocal and hence trustworthy, personalized relationships, reputational networks featuring personal affinity with different families and caste are common in India (Arora \& Sanditov, 2009; Krishna, 2007). But not only distance- rather than category-based horizontal, but also vertical structures have been documented to exert integrative influence in India: In analogy to Japanese peer groups, authority exerted by 'strong men' recurrently reunites cross-caste groups - especially in business relations (Harriss, 2009). As trustworthiness is controlled, such groups likely even benefit generalized preferences directly: In India, power has recently been found to foster trust directly according to the encapsulated interest hypothesis (Friedman et al., 2018).

\subsection{Further Confounding: Moderation and Reverse Causality}

The outlined mediation by experiences finally hints at two additional potential confounders of collectivism's true influence. They point to the fact that preferences like collectivism do not only influence (latent) institutions like generalized social trust or morality. On the other hand, these confounders may themselves be interpreted as social norms indicative of evolutionary equilibria and hence subject to influence from other cultural norms (Bowles, 2010). 
For one thing, trustworthy experiences may moderate the collectivism-trust link in addition to or even instead of mediating it, so that the main effect becomes at best insignificant under all controls. It makes intuitive sense not to fully act upon preferences if beliefs make this too costly. This is pointed to explicitly for example when generalization of preferences is often assumed to depend on conducive institutional environments (Farrell \& Knight, 2016; Tabellini, 2008). Indian levels of generalized trust have also been attributed qualitatively to an interaction of institutional weakness and familist preferences (Harriss, 2009). But moderation may in fact be hidden in much of the mediation literature. Reinforcement of preference generalization by outgroup experience appears particularly susceptible to it (section 2.3). As a consequence, moderation by morality also proxying for mere interaction would point to explanatory value of the common cause in addition to the mediation hypothesis (section 2.2).

Last but not least, reverse causality appears unlikely to affect the collectivism-trust link directly. However, negative mediation for such a relationship by generalized morality features prominently in the literature. For one thing, the very definition of reciprocity implies that it is positively influenced by trust; this has received manifold empirical (Berg, Dickhaut, \& McCabe, 1995). Furthermore, experiences created by manifest institutions are known to render collectivistic, strong ties increasingly unnecessary; such substitution effects are hinted at by positive discrimination in section 2.2 (Hruschka \& Henrich, 2013). In a similar fashion, betrayal is equally known to reinforce agreeableness (Jones, Couch, \& Scott, 1997). Note that as compared to mediation and hence also moderation reasoning above, we do not entertain explicit hypotheses about dimensionality here.

\section{Empirical Approach}

\subsection{Model}

Our theoretical discussion readily translates into 5 testable hypotheses: 0. Main effects of aggregate collectivism on generalized trust in OLS without further controls are negative and replicate extant literature (confounding). 1. Decomposing collectivism by dimension reveals positive influence of horizontal collectivism even in India, whereas the vertical dimension remains negative. 2. Only conditional upon controlling generalized morality, counterbalancing of negative vertical collectivism by positive horizontal collectivism effects emerges even in India (i.e. no double burden). Mediation through generalized morality remains negative because of adverse effects of collectivism on it, but positive influence of good experiences on generalization of trust. 3. Positive interaction between both dimensions 
of collectivism and generalized morality as an indicator for outgroup interaction hints at a double dividend. 4. Controlling for negative reverse causality from generalized trust to both dimensions of collectivism through generalized morality further increases net positive contributions in 2 and 3.

With social norms represented by spatially lagged variables (see below), hypotheses 1, 2 and 3 can be tested within an SLX (Spatial Lag of X) specification estimable via OLS (LeSage \& Pace, 2009). Differentially aggregated scales of collectivis are included alongside with generalized morality (mediation) or the interaction of the two (moderation) as follows:

Trust $=\beta_{11} \times W \times$ Morality $+\beta_{12} \times$ Collectivism $+\beta_{13} \times \mathrm{W} \times$ Morality $\times$ Collectivism

... where $\mathrm{W}$ is an nxn spatial weights matrix.

Differentiating within hypothesis 3 between generalization of good experiences and mere exposure to outgroup interaction is facilitated by multiple experience measures tapping the two meanings differentially, that are than aggregated by factor analysis. Alternatively, factor analysis yields robustness checks for convergent validity of belief and preference influence.

As opposed to a variety of, in our view, less convincing attempts in extant literature, we approach hypothesis 4 by means of spatial instruments (Drukker et al., 2013): Available exogenous variables are lagged in space to inflate the matrix of orthogonality conditions available in spatial two stage least squares estimation. Validity of such instruments is now generally assumed (Halleck Vega \& Elhorst, 2015). Standard instrument testing is available and e.g. allows for tackling weak instrument bias by applying the Fuller estimator (Stock, Wright, \& Yogo, 2002). All of this allows for including an autoregressive spatial lag of the depenent variable and estimate influence of the social norm of trust within a SDM specification (Spatial Durbin, henceforth spatial IV model) as follows:

$$
\begin{aligned}
\text { Trust }=\beta_{20} \times W & \times \text { Trust }+\beta_{21} \times W \times \text { Morality }+\beta_{22} \times \text { Collectivism } \\
& +\beta_{23} \times \mathrm{W} \times \text { Morality } \times \text { Collectivism }
\end{aligned}
$$

\subsection{Measurement}

We conducted trust games embedded into a standardized questionnaire as part of a larger survey. Measurement validity might be affected by strong educational heterogeneity in our sample, so we subjected abridging of scales to a number of established procedures - e.g. 
multiple translation rounds, independent counsel by several Indian experts, and extensive pretesting (van de Vijver \& Tanzer, 2004). Further, we subjected our data to overimputation based on paradata regarding interviewer bias as well as respondent understanding (Blackwell et al., 2015). Social desirability as the other most important source of measurement bias especially in collectivist culture is considered controlled by model variables already (Podsakoff et al., 2003).

The $1^{\text {st }}$ mover decision of the trust game is well established as one of the most valid measures of generalized social trust (Glaeser, Laibson, Scheinkman, \& Soutter, 2000), and the $2^{\text {nd }}$ mover decision therein has been discussed as the best aggregate measure for experience-based beliefs above. The spatial nature of our data allows to model experiences with relevant norms by neighbors' trustworthiness weighted by inverse distances (LeSage \& Pace, 2009).

A standard experimental protocol was followed to a maximum feasible degree given Southern context and survey logistics (Johansson-Stenman, Mahmud, \& Martinsson, 2013; Johnson \& Mislin, 2011): After thorough explanations in the local language, respondents played both roles against a computer primed to be connected to unknown real persons different in both situations. We endowed senders with INR 100, which is equivalent to the opportunity cost of time required to conduct the interview for skilled labor ( 2 hours). According to common practice, the rate of return was set to 3 , but receivers were not initially endowed (we control altruism motives). Respondents could hence earn real money paid as mobile credit independently from both situations.

Collectivism is measured by a narrowed version of the Singelis et al. scale (1995). Essentially, it taps into a 2-dimensional self construal as the basis of more derived cultural features. Here we sacrifice context sensitivity for comparability to other studies: The scale cannot differentiate between category- and distance-based horizontal collectivism, even though we feel it leans toward the latter. The vertical dimension focuses on goal hierarchy, which however implies structured relationships (see section 2.1). Because of being administered as part of a larger survey, we moreover had to condense the instrument to the maximum amount possible (Raubenheimer, 2004). Given multiple accounts of unidimensionality and high reliability for each of the 4 factors, we consider 1 face-valid item each feasible - if feasible clearly only for a first exploration of the issue. Moderate to low item statistics for aggregate collectivism lead us to rely on decomposition by dimensionality where possible (Table 3).

We operationalize further important covariates of generalized trust that can be grouped into preferences and beliefs as well (Table 3; Dinesen \& Bekkers, 2015). Given bandwidth of 
personality facets and experiences of interest, multidimensionality obtained from exploratory factor analysis hardly surprises: Only agreeableness loads on collectivism, but on both dimensions at the same time. Rather than modeling in particular an aggregate experience factor, we therefore employ alternative measures for robustness checks of main findings obtained with trust game decisions.

Table 3. Descriptive and item statistics.

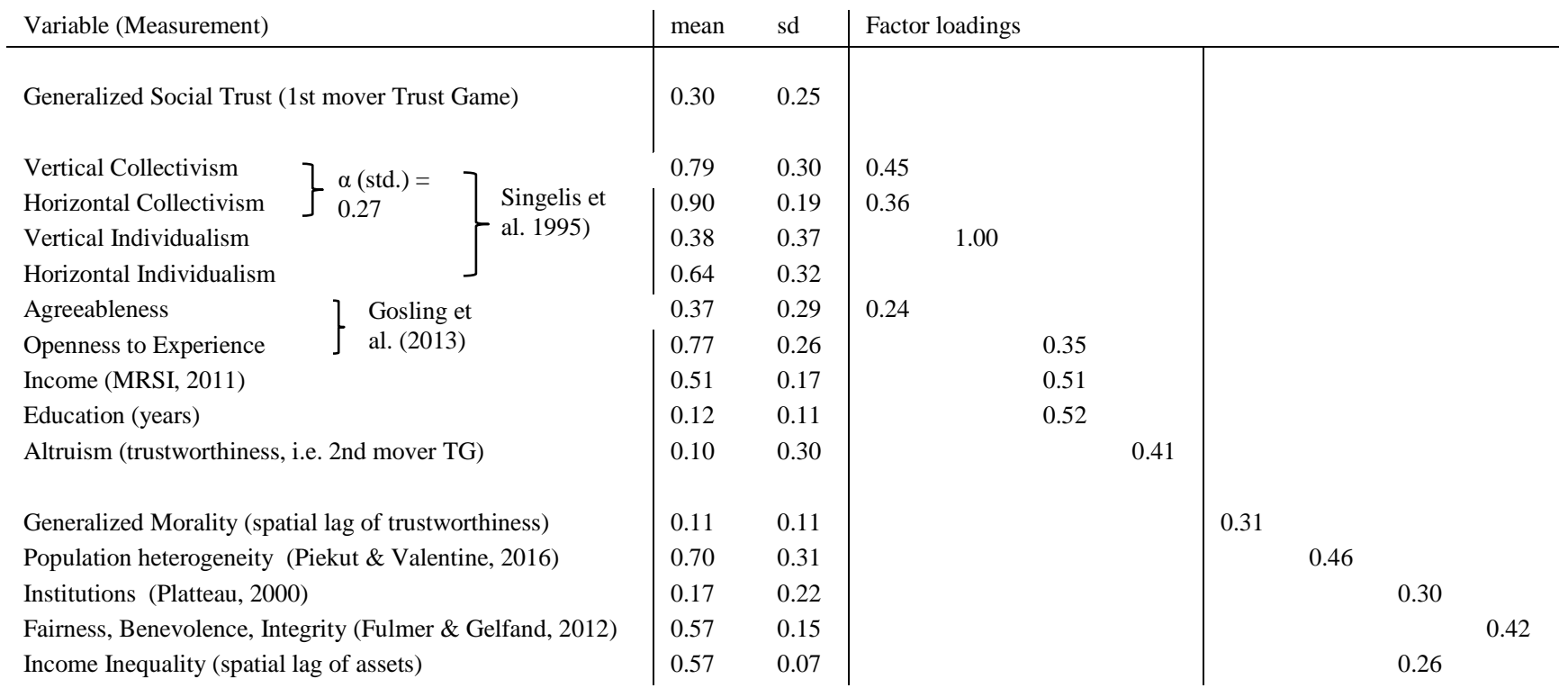

\footnotetext{
Note: Descriptive statistics of selected model variables (= items here), from data normalized between 0 and 1. Loadings from exploratory factor analysis using minres factoring using oblimin rotation. Loadings $<0.21$ omitted for emphasis in demonstration. Predispositions and experiences from separate analyses. For further controls see Table 4.
}

\subsection{Data}

We obtain a representative sample of 1204 decision makers along the rural-urban gradient of Bangalore (see introduction). Comparatively low generalized trust (.32 average in the World Value Survey (Inglehart et al., 2018) but high collectivism (.71 on Hofestede's scale (Hofstede, 2013)) deem India a critical case: This pattern appears like particularly stable lockin at a negative equilibrum, yet it also constitutes a typical example for potential confounding. Descriptive statistics demonstrate representativeness of our sample for this pattern overall, (Table 3), but an inverted ordering of horizontal and vertical collectivism compared to Verma \& Triandis (1999) could point to dynamics.

Urbanization introduces continuous variation in space to a number of social norms, so that we can observe an intertemporal, evolutionary stable equilibrium in the sense of Bowles in a 
cross-section (LeSage \& Pace, 2009) ${ }^{36}$. The variation observable in Southern megacities is known to span a few generations of socio-cultural development in time (Chen \& Ren, 2016). Bangalore's particularly fast urbanization pushed by hyperglobalization again constitutes a good example: Correlations to modernization likely affect at least collectivism and generalized morality strongly, and intergroup exchange is facilitated by increseases in population heterogeneity (Harriss, 2003; Nair, 2005; Sinha, Sinha, Verma, \& Sinha, 2001). In spite of Indian particularities (section 2), our approach may thus reveal dynamics leading to high trust equilibria in collectivist societies more generally.

We stratify at village cluster level to ensure representativeness of these spatial dynamics, and sample at simple random from decisiomakers within households as the most relevant economic unit (Hoffmann et al., 2017). High variation but insignificant correlation to urbanization in case of generalized trust may point to confounding in our sample (Figure 13), especially considering positive correlations for generalized morality (.11***) and both dimensions of collectivism $\left(.16^{* * *}\right)$. The latter may seem counterintuitive at first, especially considering equally positive correlations of urbanization to individualism $\left(.085^{* * *}\right.$ and $.065^{* *}$ for horizontal and vertical dimensions respectively). But rather than to measurement error (see below for robustness), an at least equally plausible interpretation would attribute this to multiple modernities (Eisenstadt, 2000) and confounding: Collectivism could even thrive alongside socio-economic development, if some of its historical covariates opposed modernization, but not collectivsm itself.

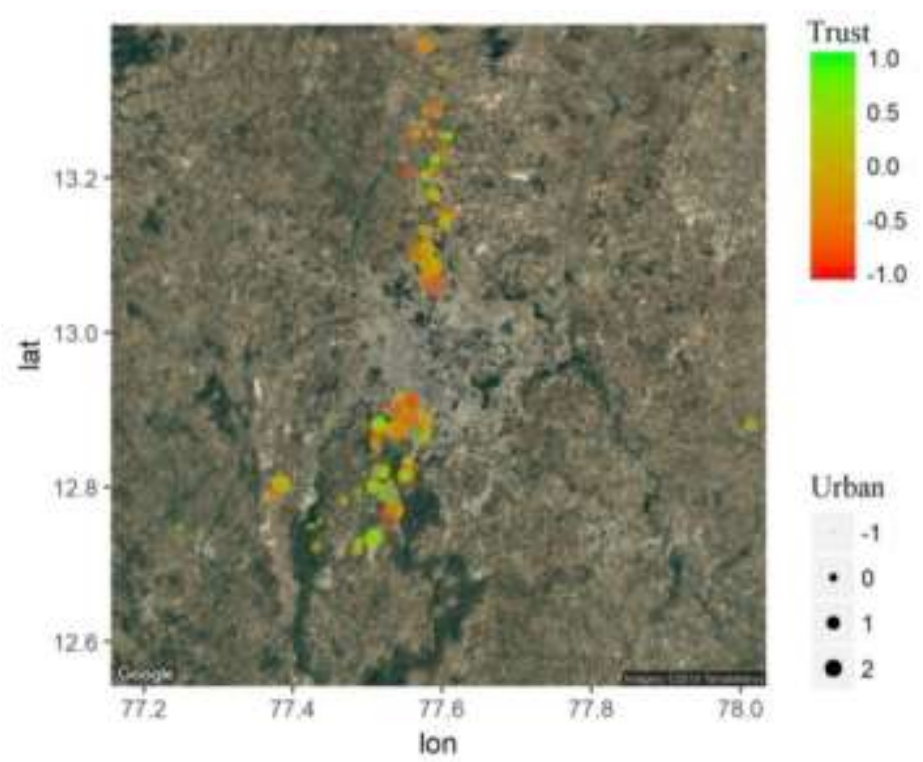

Figure 13. Generalized social trust as a function of urbanization in Bangalore. Standardized variables plotted by location in rural-urban transects.

\footnotetext{
${ }^{36}$ Even though exogeneity of this variation seems plausible at least to a large degree, it is not a requirement for spatial instruments (Drukker et al. 2013).
} 


\section{Results and Discussion}

Our data reveal positive influence of both dimensions of collectivism on generalized trust (double dividend), but only at high generalized morality and once reverse causality is taken into account. This is equivalent to unconditional confirmation of hypothesis 3 , as well as partial verification of hypotheses 0,1 and 4 .

At more detail, these findings emerge from an interlinkage of confounding that confirms extant literature only to some degree. This is demonstrated, first, by a contradiction between correct predictions of previously reported effects regarding the true influence of collectivism on generalized trust, but additional presence of confounding on the other hand (hypothesis 0 ). In our baseline specification we do not encounter any significant effect for collectivism. Eventually and ceteris paribus however, a negative main effect of collectivism on generalized social trust will replicate previous findings in our sample (Table 4). ${ }^{37}$ However, we specify below how this finding is conditional upon introducing multiple controls missed by extant literature (moderation implying also mediation and either dimensionality or reverse causality).

Table 4. Regression results (generalized social trust dependent).

\begin{tabular}{|c|c|c|c|c|c|c|c|c|c|}
\hline \multirow{3}{*}{$\begin{array}{l}\text { Generalized Morality } \\
\text { Generalized Morality } * \text { Collectivism }\end{array}$} & \multicolumn{3}{|c|}{$\begin{array}{l}\text { Dimensions } \\
\text { collectivism, of } \\
\text { interaction effect (OLS / }\end{array}$} & \multicolumn{3}{|c|}{$\begin{array}{l}\text { Interaction effect and } \\
\text { dimensions of collectivism } \\
(\text { OLS / SLX, N=1204) }\end{array}$} & \multicolumn{3}{|c|}{$\begin{array}{l}\text { Aggregate collectivism and } \\
\text { interaction effect (Spatial } \\
\text { IV / SDM, N=1176) }\end{array}$} \\
\hline & -0.272 & $(0.244)$ & & -0.324 & $(0.245)$ & & -1.446 & $(0.507)$ & $* * *$ \\
\hline & & & & 0.549 & $(0.283)$ & $*$ & 1.860 & $(0.679)$ & $* * *$ \\
\hline $\begin{array}{l}\text { Collectivism } \quad \text { (Horizontal } \\
\text { aggregate) }\end{array}$ & -0.022 & $(0.024)$ & & -0.023 & $(0.024)$ & & -0.734 & $(0.390)$ & $*$ \\
\hline Vertical Collectivism & 0.027 & $(0.024)$ & & -0.183 & $(0.111)$ & $*$ & & & \\
\hline $\begin{array}{l}\text { Individualism (Horizontal or } \\
\text { aggregate) }\end{array}$ & 0.001 & $(0.024)$ & & 0.001 & $(0.024)$ & & 0.008 & $(0.029)$ & \\
\hline Vertical Individualism & -0.004 & $(0.024)$ & & -0.004 & $(0.024)$ & & & & \\
\hline Agreeableness & 0.066 & $(0.024)$ & $* * *$ & 0.065 & $(0.024)$ & $* * *$ & 0.088 & $(0.029)$ & $* * *$ \\
\hline Openness to Experience & -0.003 & $(0.024)$ & & -0.001 & $(0.024)$ & & 0.004 & $(0.030)$ & \\
\hline Altruism & 1.336 & $(0.081)$ & $* * *$ & 1.332 & $(0.081)$ & $* * *$ & 1.233 & $(0.112)$ & $* * *$ \\
\hline Population Heterogeneity & 0.069 & $(0.025)$ & $* * *$ & 0.071 & $(0.025)$ & $* * *$ & 0.044 & $(0.039)$ & \\
\hline Institutions & -0.060 & $(0.023)$ & $* *$ & -0.060 & $(0.023)$ & $* * *$ & -0.043 & $(0.033)$ & \\
\hline Fairness, Benevolence, Integrity & -0.028 & $(0.024)$ & & -0.029 & $(0.024)$ & & -0.033 & $(0.032)$ & \\
\hline Income Inequality & -1.037 & $(0.234)$ & $* * *$ & -1.043 & $(0.234)$ & $* * *$ & -0.824 & $(0.394)$ & $* *$ \\
\hline Norm / Lag of Generalized Trust & & & & & & & 0.571 & $(0.208)$ & $* * *$ \\
\hline$R^{2}(s t d)$ & 0.206 & & & 0.208 & & & 0.247 & & \\
\hline
\end{tabular}

Note: OLS controls not reported: education, income, caste, gender, time preference and extraversion. Additional controls not reported in IV model: risk preferences, age and religion. Standard errors in parentheses, $* * * \mathrm{p}<0.01, * * \mathrm{p}<0.05, * \mathrm{p}<0.1$. Reduced $\mathrm{N}$ in IV specification due to missingness in spatial information. Here, generalized R squared reported. SLX ... Spatial Lag of X and SDM ... Spatial Durbin specifications.

\footnotetext{
${ }^{37}$ Robust insignificance of individualism could be due to Indian individualism simply mirroring collectivism in interaction with strangers, rather than the Western trait with corresponding properties (section 2.1).
} 
Dimensionality constitutes a further example for such divergence between confounding and evidence for hypothesized relationships: Effects vary between horizontal and vertical collectivism, but this only contributes to revealing the true influence of collectivism under certain conditions (hypothesis 1). In the baseline specification, only vertical collectivism exhibits a negative main effect. Such vertical, structural bounds on horizontal sociability would underscore extant findings by further explanations and should generalize readily. However, openness to experience remains insignificant across specifications and thus does not confirm this hypothesis by itself. ${ }^{38}$ Rather, dimensionality seems to interact with other sources of confounding: It would itself be confounded if not controlling moderation in addition (and hence implicitly mediation as well). Furthermore, once reverse causality is included in the model, the negative main effect generalizes to horizontal collectivism, and dimensionality can be ignored.

As already implied by all of the above, our data allow for partially rejecting the relationships underlying hypothesis 2: None of the controls, including mediation, reveal positive main effects of any dimension of collectivism onto generalized trust. We thus regard horizontal relationalism to unlikely be obstructed in extant literature, and to not counterbalance vertical limits to cross-group identities in Bangalore. Instead it completes the picture of a double burden in contemporary India and may indicate prevalence of category- rather over distancebased horizontal preferences. Such a bias may not generalize to other, caste-less collecivist societies. But robust positive influence of agreeableness on generalized trust also points to further conditionallity in our sample.

Mediation may nonetheless have obstructed this true, negative main effect, since we expect it to likely be positive in our sample. This is because, for one thing, morality actually affects trust negatively once reverse causality is instrumented. Even given good experiences, generalization is hence still not straightforward. Culture-specific interpretations of strong reciprocity as a signal of not being trustworthy may explain this counterintuitive effect unlikely to replicate elsewhere (Johansson-Stenman et al., 2013). For another, we theoretically expect negative influence of collectivism on generalized morality across samples. Elsewhere, this would reduce the confounding potential of then overall negative mediation. In our data however, we are not able to actually test this second part of hypothesis 2 related to confounding by, rather than influence of collectivism. This is because one cannot model moderation without mediation.

\footnotetext{
${ }^{38}$ Reverse causality of these alternative measures is ruled out by testing for instrument exogeneity.
} 
We find moderation to be the principal confounder of collectivisms' main effect. None of the controls reveals collectivism's effect without including an interaction term in the model. At the same time, moderation emerges as the chief reason to reject extant findings based on underlying relationships, because it allows for conditionally positive influence of collectivism (hypothesis 3): At high generalized morality, vertical collectivism exhibits positive effects on generalized social trust in Bangalore (cross-over effect, Figure 14). Instrumenting leads to generalization of this effect to horizontal collectivism, so that the moderation effect itself is confounded by either dimensionality or reverse causality.

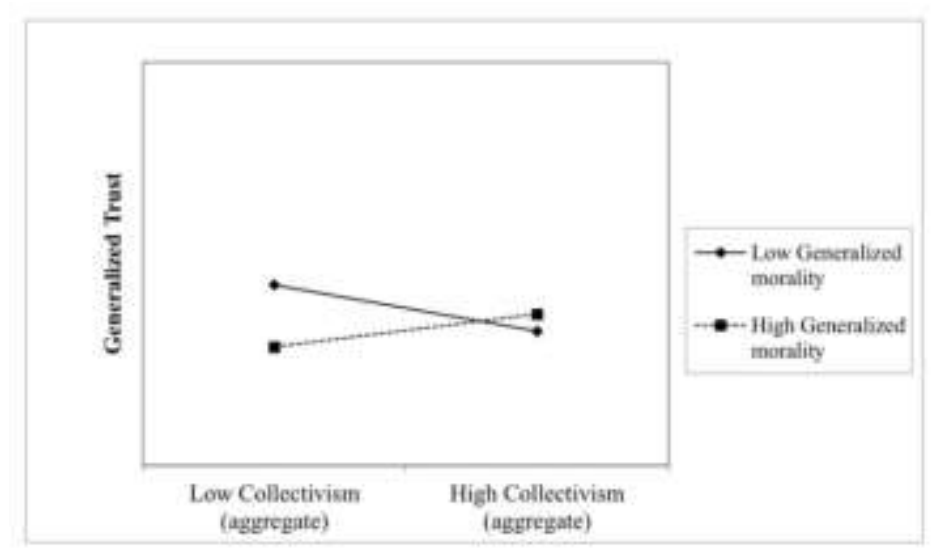

Figure 14. Cross-over effect of collectivism on generalized trust depending on generalized morality. Spatial two-stage-least squares coefficients, aggregate collectivism.

Conversion of a double burden into a double dividend is hence conditional upon good experienes in Bangalore. We interpret this as facilitation of distance-based cooperative horizontal sociability of relationals to vertically recategorize strangers into shared networks (recall our assumption about inexistence of common identity generalization under vertical collectivism in section 2.1). Confounding of this effect hints at absence of good outgroup experiences in India. For example, urbanization may not lead to encounters with strangers if accompanied by segregation (Bettin \& Wollni). Fostering such a conversion especially regarding vertical collectivism may yield additional benefits in other collectivist societies where horizontal relations are already distance- instead of category-based, and potentially result in incentive differentials (hypothesis 2).

We consider these findings to point to benefits of social interaction for direct generalization of preferences, rather than to a detour via generalization of moral experiences; negative influence of generalized morality on trust does not allow for the latter in our sample. Alternative measures of experiences (of generalized morality) reinforce this claim: The main (but not moderation) effects generalize to institutional quality, but not fairness-benevolence- 
integrity, heterogeneity or inequality (positive influence in the latter two cases). While measurement issues may play a role for all of these latent constructs, heterogeneity and inequality moreover describe contact with strangers more than actual trustworthiness. Note also that the statistical interaction could equally indicate moderation of the morality-trust link by collectivism. This however seems unlikely given that high collectivism in our sample should lead to a positive (main) effect of generalized morality on trust.

Finally, we interpret differences between OLS and IV models in case of horizontal and to a lesser degree also vertical collectivism as evidence of mainly positive reverse causality (significance vs. magnitude of effect, hypothesis 4). ${ }^{39}$ In particular, this is evident from negative main and positive moderation effects of vertical collectivism emerging only after instrumenting them. With appropriate controls (dimensionality and moderation / mediation) reverse causality hence does not necessarily obstruct collectivism's true influence on generalized trust. Given that morality's influence on trust only becomes significantly negative once instrumenting it too, we moreover conclude positive influence of trust on morality as hypothesized.

All of this then implies one further, confounded mechanism of overcoming a double burden in India: Morality only affects horizontal collectivism negatively when it is high, but positively otherwise. When generalized trust was low, it should therefore result in low morality deflating collectivism, which would in turn help lift trust under still low morality. Such positive reverse causality is opposed to our hypotheses. But it could have been missed by linear effects in extant literature (Thomson et al., 2018) and become plausible even beyond India, if very bad experiences crowd out relational closeness with particularized others (Jones et al., 1997).

Finally note that both main and moderation effects' sensitivity to controlling risk and some other demographics like urbanization disappears with instrumentation. This may be explained by the fact that all of these constitute common causes with unclear direction of causality. Risk may for example proxy uncertainty reduction, which not only drives both trust and collectivism, but also mediates the relationship from experiences with low morality to the latter (Thomson et al., 2018). Urbanization is equally known to affect both collectivism and trust; however it additionally benefits from modern economic exchange facilitated by trust, and urbanization itself is also conducive to experiences with strangers inducing reciprocity (Bettin \& Wollni). ${ }^{40}$

\footnotetext{
${ }^{39}$ Tests for instrument validity all hold except in case of weakness, which we tackle by Fuller estimation (section 3.1).

${ }^{40}$ As an addendum, it may be interesting to observe positive influence of the social norm of trusting on trust, which is indicated by a significant spatial autoregression coefficient (Table 3).
} 


\section{Conclusion}

Our results underscore the leverage at least some societies may have on selection of cultural norm equilibria: Low beliefs arising from absence of generalized morality in India, perhaps indicative of negative influence from its strong collectivism, explain current lock-in of the society at a low preference - low trust equilibrium that may indeed impede economic development. Even net positive mediation and reverse causality are not able to counterbalance morality's negative moderation of the collectivism-trust link. Low trustworthiness leads to categorizing rather than cooperative horizontal, and generalization-preventing rather than recategorizing vertical structures.

But our data also point to pathways for transitioning to a second basin of attraction previusly hidden by confounding, at least in India: High generalized trust may turn out to be evolutionary stable under collectivist preferences, too. Decisively, it appears all that would be required were cross-cutting experiences, irrespective of whether they are being accompanied by generalized morality. Depending on the right political choices, collectivism could simply constitute an alternative approach to high trust and 'modern' social exchange.

Previously encountered, negative influence of collectivism on trust is explained by our analysis for samples where generalized morality is low throughout, and where vertical collectivism prevails or reverse causality and mediation behave negatively as theoretically expected. This is because generalization of these findings to other collectivist societies seems plausible with regard to dimensionality and moderation, as they conform to general theoretical expectations ceteris paribus. Mediation by generalized morality on the other hand deserves further, explicit scrutiny. Like reverse causality and even if found robust, positive effects encountered should remain specific to India; elsewhere they could still lead to confounding and threaten existence of a positive equilibrium. In cultures with less outgroup categorization and positive main effects of collectivism on trust, they could even become the main reason for observing negative correlations.

Other possible extensions of our analysis relate to the measurement dimension of our approach: Arguably our collectivism scale should only be taken as a first hint toward sounder exploration of the issue. Perhaps a thorough measure would then allow for analytic rather than interpretative differentiation between morality and mere cross-cutting interaction. Finally, emphasis of distance- rather than category-based horizontal collectivism across societies, and its implications for learning from cross-cutting interaction, do constitute a viable subject of experimental enquiry. 


\section{Chapter V. Conclusion}

\section{Findings and Their Comparative Contributions}

Environmental degradation associated with current high rates of urbanization especially in the Global South requires policy intervention (UN, 2018). SES models of urbanization are needed for enhanced understanding of such complex systems, and could contribute to identifying leverage (Frank et al., 2017). But so far they have been characterized by undercomplex representation of particularly critical, social mechanisms (Schlüter et al., 2017). Yet, simply adding up previously reported psychological detail is likely to introduce bias due to confounding through system feedback, and due to mechanisms being altered in Southern urban contexts. Against the empirical background of the rural-urban interface of Bangalore / India and through (latent variable) structural equations models identified by spatial instrumental variables, this thesis aimed at adequate quantification of three exemplary psychological mechanisms.

\section{Chapter II}

A first essay investigated under which conditions alleged loss of nature experience would be substituted by alternative drivers of environmental concern, that could be absent from SES models predicting red-loop transitions from urbanization on path i (Figure 1). Psychological effects of urbanization have so far been reported separately mainly in case of the global North (Thomas et al., 2005), but simply adding them up cannot explain aggregate increases of environmental concern with urbanization (Berenguer et al., 2005). This could hint at a bias that a joint model of culturally relative interaction of urban features could help mitigate. The first essay aimed at such quantification.

Previous positive aggregate findings were confirmed for the case of Bangalore. However, this result is driven by unique adaptation of known mechanisms in this Southern urban context (first problem in chapter I, section 1.4): Especially globalization, and probably as a consequence also modernization contribute the largest shares of the overall effect (Chen \& Ren, 2016). Compared to this, some mediators investigated by traditional urban psychology and likely more prominent in many Northern cities, e.g. heterogeneity and hence altruism, inhibit positive substitution (Milgram, 1970). In case of some other constructs depicted as negative mediators by extant literature, the Southern urbanization captured in this essay contradicts previous findings: E.g. anonymity or individualism work differently in the Indian 
context and acquire positive substitution potential in Bangalore. Finally, these results only emerged after controlling feedback (third and hence second problem in chapter I, section 1.4).

The first essay hence implies the need for controlling general equilibrium effects when working toward quantification of a comprehensive urban SES model. Despite some weak instrument problems, the model proposed is therefore considered a substantial improvement over extant literature. Note however that the implied equilibrium effects contradict empirical realities and point to a need for adding detail also with regard to path ii or environmental variables (Lele et al., 2013): Overall positive effects of urbanization on environmental concern are complemented by positive feedback, so that improved environmental conditions rather than the empirically obvious degradation are predicted as an attractor by the first essay.

The model nonetheless points to a number of particularly Southern urban features which already help, and could further be leveraged to avoid red-loop transitions in case of path i (Figure 1). For instance, affluence and values are even more conducive to pro-environmental attitudes than low physical distance to nature in farming (Meyfroidt, 2013). Extant urban SES models completely neglect such substitution and should hence be expected to predict environmental repercussions of urbanization-induced preference change incorrectly (Cumming \& Cramon-Taubadel, 2018).

\section{Chapter III}

The second essay questioned the central assumption behind urban environmental degradation, i.e. loss of nature experience. Extant SES models much like income-concern literature rely on increasing physical distance to degradation experiences to explain decreasing environmental preferences under urbanization (Summers \& VanHeuvelen, 2017). But a separate field has attributed at least equal importance to positive emotional connections to nature, which may originate in farming as well but would likely exhibit different loss patterns under urbanization (Nisbet et al., 2008). This research aimed at identifying psychological drivers of such persistent memories that could help facilitate bridging of potentially U-shaped environmental concern (Fairbrother, 2013; Munasinghe, 1999).

Memories of positive nature experience were found to explain increasing environmental concern throughout the income growth associated to the rural-urban gradient in Bangalore to a large degree. This was true in particular at otherwise minimum concern at intermediate income. In contradiction of extant claims, positive nature experience does hence not decrease when switching out of farming (Meyfroidt, 2013). Rather, it translates into environmental 
concern conditional upon abstraction level and avoidant attachment style. These characteristics were found to be more prominent amongst intermediately rich individuals with increased distance to nature.

These results underscored how adding uniquely Southern and complementing detail to societal relationships contributes to yet more nuanced predictions about red-loop transitions on path i (first and third problem in chapter I, section 1.4). Differential presence of psychological bridging explains sample sensitivity of a Kuznets pattern in previous literature (Fairbrother, 2013) and could be leveraged by policymakers elsewhere. In addition, such persistent positive memories, until substitution by wealth and values become effective (Guha $\&$ Martinez-Alier, 2013), lend further support to focusing on path ii in explaining real-world red-loop transitions at least in Bangalore. However, control over this path had to be sacrificed for specification and cultural complexity in this essay.

\section{Chapter IV}

The third essay focused on moderation of path ii. Real-world red loops could be explained by cultural relativity of positive moderation exerted by urbanization onto the link from preferences to the environment. Urbanization has been found to reduce collectivism (Sørensen 2015); as a result, generalized social trust would be assumed to increase (Fukuyama, 1996), which is known to help translate environmental attitudes into behavior (Van Lange et al., 2015). The reported negative association between collectivism and generalized trust may however suffer from confounding (Putnam, 1993), so that urbanization-induced individualism in fact harms indigenous bases of collective environmental action. Trading generality for complex psychological detail further, the third essay tested for such confounding.

The research confirmed a complex interplay of statistical confounding to drive previous, correlational findings (Van Hoorn, 2014). Negative main effects of collectivism on generalized trust only replicated when controlling moderation by cross-cutting experiences, and either reverse causality through generalized morality, or dimensionality of collectivism in addition. Positive effects of collectivism on generalized trust hence obtain whenever voluntary interaction across societal groups facilitates distance-based horizontal sociability and vertical recategorization of strangers into common ingroups (Yuki, 2003).

At least for the case of Bangalore, this however still does not explain red-loop transitions or point to a need to go against the rise of individualism. Chiefly, this is because collectivism actually increases in urbanization in Indian culture (chapter II). As cross-cutting experiences 
of generalized morality however increase in urbanization as well (chapter IV), high generalized trust becomes the equilibrium attractor under high urbanization ${ }^{41}$; environmental degradation at the city center does however not reflect this, groundwater overextraction is amongst the highest here (Sudhira \& Nagendra, 2013).

This attempt at clarifying problem one through adressing problem two from chapter I (section 1.4) should nonetheless be integrated into more general urban SES models: In cultures where urbanization indeed reduces collectivism (Tönnies, 1887), the mechanisms encountered would explain negative moderation of path ii.

\section{General Implications for Modeling and Governing Urban SES}

Taken together, all three essays underscore the need for theoretically and specificationwise complex, as well as culturally and contextually sensitive representation of societal processes in models of the specific human environment interactions dynamically altered by urbanization (Schlüter et al., 2017; overarching research question). SES models are arguable best equipped for such quantifications (Frank et al., 2017), yet considerable scope for improvement of extant attempts has been demonstrated (Grimm et al., 2015; Grove et al., 2013). For example, moderation of path ii (Figure 1) depends on so many more factors than income growth or population density; even just moderation by generalized social trust already appears highly sensitive to cultural context (first problem in chapter I, section 1.4). In turn, focusing only on preference change through e.g. income growth would miss such feedback entirely (path i, second and third problem). Note also how these findings limit external validity of relationships in fields like conventional economics (Costanza, 1992).

However, this thesis can only constitute a first step towards more profound understanding of society in urbanizing SES. For the moment, prediction of urban environmental effects has rather been complicated by this analysis: While non-linear and culturally sensitive complexity in individual relationships was found essential in essays two and three, the thesis also demonstrated in essay one that neither of these can be analyzed in isolation. On the other hand, real-world effects are still not explained satisfyingly (Bettencourt et al., 2007): Whereas essays one and two raise serious doubts about a red-loop transition with regard to path i, disruptions would then have to arise from negative moderation of path ii, and essay three can

\footnotetext{
${ }^{41}$ Implications for general equilibrium rely on a number of assumptions. Most importantly, the positive moderation could be outweighed by negative direct effects from urbanization on water quantity and quality (chapter II), that transmit onto generalized trust via a positive causal effect (author's analysis, unpublished). See chapter I for further potential confounders untested here.
} 
only constitute a very preliminary attempt at understanding such drivers of an attitudebehavior gap (Pisano \& Lubell, 2017).

This research, on the other hand, clearly demonstrated that red-loop transitions are far from automatic (Cumming \& Cramon-Taubadel, 2018). A number of viable leverage mechanisms for policymakers stand out as multipliers affecting both path i and ii: Most directly, potential influence of governance on the whole system has been demonstrated in the first essay (Roy, 2009); positive repercussions on generalized morality in particular would not only benefit path i directly, but also relate to the third essay - i.e. reinforce path ii through trust. Multiple positive feedback effects from nature experience (first essay), but especially direct bridging of an environmental concern minimum at middle income reinforce previous calls for strengthening urbanites connection to nature; in addition though, they also point to indigenous roots of such a connection as a point of departure (Amel et al., 2017). Strong spatial dependence in all models tested finally suggests social marketing approaches of progressive norms as a viable alternative despite fractionalization of Indian society (Jackson, 2005).

\section{Limitations and Suggestions for Future Research}

Working toward yet more complex calibration of a complete urban SES model still featuring system feedback, especially with regard to explaining the attitude behavior gap in case of path ii, constitutes the most obvious extension of this research (Schlüter et al., 2017). However, some more specific limitations of all three essays jointly also apply:

First, limited correspondence of equilibrium implications of findings to urban realities could stem from low external validity: Critical variation for all variables of interest was indeed encountered in globalized, economically quite developed Bangalore. But similarly, urban features will also differ in other Southern cities equally critical from a practical point of view related to global environmental change. Some prominent examples include push urbanization and negative nature experiences, differentially distributed (i.e. lower) income, or collectivist dynamics under distance rather than category based horizontal sociability (Yuki, 2003).

Further, alternative explanations for limited explanatory power even for the case at hand might also arise from qualifications to internal validity. Mechanisms documented by Southern urban studies are still incomplete, scattered and hard to quantify; especially the first essay could only be a first attempt at integration here (Parnell \& Oldfield, 2014). Internal validity would also be increased by including environmental variables beyond water: It may not be very representative given that the water urbanites depend on may indeed improve with urban 
infrastructure (Lele et al., 2013). To some extent, focusing on society has within the scope of this thesis required simplification of natural science aspects. Statistically, one might also want to consider more traditional approaches to causality: Spatial instruments have been found here to almost always suffer from a certain degree of weakness. Panel data would also allow for more systematically focusing on decisive feedback from the environment to urbanization, which has only been touched upon in essay one (Groeneveld et al., 2017).

Finally but perhaps most importantly, measurement of societal constructs in empirically relevant, Southern contexts, where WEIRD results (Henrich et al., 2010) may not apply, would deserve more systematic attention: Despite statistical cross-cultural validity of the scales employed, respondent bias might still vary with education-related 'westernization'; it could thus increase in urbanization and provide an alternative explanation for somewhat counterintuitive results in case of path i (first two essays; van de Vijver \& Tanzer, 2004).

Future research could go beyond employing 'longer' versions of established scales with more items here; despite being still harder to quantify, true representation of complex societal context could mean qualitatively exploring which dimensions of collectivism really describe caste society best (Sinha, 2014), or which understanding of nature connection really predicts pro-environmental behavior in spiritually rich cultures like India (Kent, 2013). Alternatively, decomposed games may constitute measures less prone to such bias (Schultz, 2002). 


\section{References}

Agarwal, B. (1992). The gender and environment debate: lessons from India. Feminist Studies, 18(1), $119-158$.

Alesina, A., \& Giuliano, P. (2015). Culture and Institutions. Journal of Economic Literature, 53, 898944.

Alesina, A., \& La Ferrara, E. (2000). Participation in Heterogeneous Communities Quarterly Journal of Economics, 115, 847-904.

Amel, E., Manning, C., Scott, B., \& Koger, S. (2017). Beyond the roots of human inaction: Fostering collective effort toward ecosystem conservation. Science, 356, 275-279.

Amin, A., \& Graham, S. (1997). The ordinary city. Transactions of the Institute of British Geographers, 22(4), 411-429.

Anderson, L. R., Mellor, J. M., \& Milyo, J. (2008). Inequality and public good provision: An experimental analysis. The Journal of Socio-Economics, 37, 1010-1028.

Andersson, E., Barthel, S., Borgström, S., Colding, J., Elmqvist, T., Folke, C., \& Gren, Å. (2014). Reconnecting Cities to the Biosphere: Stewardship of Green Infrastructure and Urban Ecosystem Services. AMBIO, 43, 445-453.

Andreoni, J. (1990). Impure Altruism and Donations to Public Goods: A Theory of Warm-Glow Giving. The Economic Journal, 100, 464.

Angelsen, A., Larsen, H. O., Lund, J. F., Smith-Hall, C., \& Wunder, S. (Eds.). (2011). Measuring Livelihoods and Environmental Dependence: Methods for Research and Fieldwork: Routledge.

Arora, S., \& Sanditov, B. (2009). Caste as Community? Networks of social affinity in a South Indian village. UNU-MERIT Working Papers. (37), 1871-9872.

Balliet, D., Wu, J., \& Dreu, C. K. W. de. (2014). Ingroup Favoritism in Cooperation: A MetaAnalysis. Psychological Bulletin, 140, 1556-1581.

BARR, R. F., \& MCCONAGHY, N. (1972). Conditioning in Relation to Conceptual Thinking. The British Journal of Psychiatry, 121, 299-310.

Beilmann, M., \& Realo, A. (2012). Individualism-Collectivism and Social Capital at the Individual Level. Trames. Journal of the Humanities and Social Sciences, 16, 205.

Berenguer, J., Corraliza, J. A., \& Martín, R. (2005). Rural-Urban Differences in Environmental Concern, Attitudes, and Actions. European Journal of Psychological Assessment, 21, 128-138.

Berg, J., Dickhaut, J., \& McCabe, K. (1995). Trust, Reciprocity and Social History. Games and Economic Behavior, 10, 122-142.

Bettencourt, L., \& West, G. (2010). A unified theory of urban living. Nature, 467, 912-913. 
Bettencourt, L. M. A., Lobo, J., Helbing, D., Kühnert, C., \& West, G. B. (2007). Growth, innovation, scaling, and the pace of life in cities. Proceedings of the National Academy of Sciences of the United States of America, 104, 7301-7306.

Bettin, J., \& Wollni, M. Decomposing the experience of living in cities: The example of environmental concern. Under Review.

Bettin, J., \& Wollni, M. (2019). Environmental Concern, Income, and Nature Experience in India. Sustainability, 11, 346.

Bhowmik, S. K. (2009). Urban Sociology. In Y. Atal (Ed.), Sociology and Social Anthropology in India (237-263). Delhi: Longman.

Bjørnskov, C. (2007). Determinants of generalized trust: A cross-country comparison. Public Choice, $130,1-21$.

Blackwell, M., Honaker, J., \& King, G. (2015). A Unified Approach to Measurement Error and Missing Data: Overview and Applications. Sociological Methods \& Research, 46, 303-341.

Bögeholz, S. (2006). Nature experience and its importance for environmental knowledge, values and action: Recent German empirical contributions. Environmental Education Research, 12, 65-84.

Bohnet, I., Greig, F., Herrmann, B., \& Zeckhauser, R. (2008). Betrayal Aversion: Evidence from Brazil, China, Oman, Switzerland, Turkey, and the United States. The American Economic Review, 98(1), 294-310.

Bollen, K. A. (1987). Total, Direct, and Indirect Effects in Structural Equation Models. Sociological Methodology, 17, 37.

Bowles, S. (2010). The coevolution of institutions and preferences: history and theory. In N. Salvadori (Ed.), Institutional and Social Dynamics of Growth and Distribution. Edward Elgar Publishing.

Bratman, G. N., Hamilton, J. P., Hahn, K. S., Daily, G. C., \& Gross, J. J. (2015). Nature experience reduces rumination and subgenual prefrontal cortex activation. Proceedings of the National Academy of Sciences of the United States of America, 112, 8567-8572.

Bravo, G., \& Marelli, B. (2007). Micro-foundations of the Environmental Kuznets Curve hypothesis: an empirical analysis. Int. J. Innovation and Sustainable Development, 2(1), 36-62.

Brenner, N. (1998). Global Cities, Glocal States: Global City Formation and State Territorial Restructuring in Contemporary Europe. Review of International Political Economy, 5(1), 1-37.

Brenner, N., \& Schmid, C. (2014). The 'Urban Age' in Question. International Journal of Urban and Regional Research, 38, 731-755.

Brewer, M. B., \& Chen, Y.-R. (2007). Where (Who) Are Collectives in Collectivism? Toward Conceptual Clarification of Individualism and Collectivism. Psychological Review, 114, 133-151.

Brooks, B. A., Hoff, K., \& Pandey, P. (2014). Insult versus Accident: Caste Culture and the Efficiency of Coordination. 
Brosig, J., Riechmann, T., \& Weimann, J. (2007). Selfish in the End?: An Investigation of Consistency and Stability of individual Behavior. MPRA. (2035).

Burger, P., BezenÃ§on, V., Bornemann, B., Brosch, T., Carabias-HÃ¹/4tter, V., Farsi, M., .. . Volland, B. (2015). Advances in Understanding Energy Consumption Behavior and the Governance of Its Change â€" Outline of an Integrated Framework. Frontiers in Energy Research, 3, 711.

Carvalho, L. S. (2010). Poverty and Time Preference. RAND Working Paper Series. (WR 759).

Census of India. (2016). SRS Statistical Report. Retrieved from http://www.censusindia.gov.in/vital_statistics/SRS_Reports_2016.html

Chakravarty, S., Fonseca, M. A., Ghosh, S., \& Marjit, S. (2016). Religious fragmentation, social identity and cooperation: Evidence from an artefactual field experiment in India. European Economic Review, 90, 265-279.

Chatterjee, D. P. (2008). Oriental Disadvantage versus Occidental Exuberance. International Sociology, 23, 5-33.

Chawla, L. (1998). Significant Life Experiences Revisited: A review of research on sources of environmental sensitivity. Environmental Education Research, 4, 369-382.

Chen, X., \& Ren, Y. (2016). Modernity and Globalization: The Local and Global Sources of Individualistic and Materialistic Values in Shanghai. Globalizations, 13(1), 16-31.

Chuah, S.-H., Fahoum, R., \& Hoffmann, R. (2013). Fractionalization and trust in India: A fieldexperiment. Economics Letters, 119, 191-194.

Coller, M., \& Williams, M. B. (1999). Eliciting individual discount rates. Experimental Economics, 2, $107-127$.

Corral-Verdugo, V., Carrus, G., Bonnes, M., Moser, G., \& Sinha, J. B. P. (2008). Environmental Beliefs and Endorsement of Sustainable Development Principles in Water Conservation. Environment and Behavior, 40, 703-725.

Cosier, M., \& Shen, D. (2009). Urban Water Management in China. International Journal of Water Resources Development, 25, 249-268.

Costanza, R. (1992). Ecological economics: the science and management of sustainability: Columbia University Press.

Cross, S. E., Hardin, E. E., \& Gercek-Swing, B. (2011). The What, How, Why, and Where of SelfConstrual. Personality and Social Psychology Review, 15, 142-179.

Cumming, G. S., Buerkert, A., Hoffmann, E. M., Schlecht, E., Cramon-Taubadel, S. von, \& Tscharntke, T. (2014). Implications of agricultural transitions and urbanization for ecosystem services. Nature, 515, 50-57. 
Cumming, G. S., \& Cramon-Taubadel, S. von. (2018). Linking economic growth pathways and environmental sustainability by understanding development as alternate social-ecological regimes. Proceedings of the National Academy of Sciences of the United States of America, 115, 9533-9538.

Davis, J. L., Green, J. D., \& Reed, A. (2009). Interdependence with the environment: Commitment, interconnectedness, and environmental behavior. Journal of Environmental Psychology, 29, 173 180.

Dawson, J. F., \& Richter, A. W. (2006). Probing three-way interactions in moderated multiple regression: Development and application of a slope difference test. Journal of Applied Psychology, 91, 917-926.

Dear, M. J. (2000). The postmodern urban condition. Oxford: Blackwell.

Dhakal, S. (2009). Urban energy use and carbon emissions from cities in China and policy implications. Energy Policy, 37(11), 4208-4219.

Diao, X., McMillan, M., \& Rodrik, D. (2017). The Recent Growth Boom in Developing Economies: A Structural Change Perspective. Advance online publication.

Dinda, S. (2004). Environmental Kuznets Curve Hypothesis: A Survey. Ecological Economics, 49, $431-455$.

Dinesen, P. T., \& Bekkers, R. (2015). The Foundations of Individuals' Generalized Social Trust: A Review. In P.A.M. van Lange, B. Rockenbach, \& T. Yamagishi (Eds.), Series in Human Cooperation: Vol. 2. Trust in Social Dilemmas. Oxford: Oxford University Press.

Drukker, D. M., Egger, P., \& Prucha, I. R. (2013). On Two-Step Estimation of a Spatial Autoregressive Model with Autoregressive Disturbances and Endogenous Regressors. Econometric Reviews, 32, 686-733.

Dunham, Y., Srinivasan, M., Dotsch, R., \& Barner, D. (2013). Religion insulates ingroup evaluations: the development of intergroup attitudes in India. Developmental Science, 1-9.

Dunlap, R. E., \& Mertig, A. G. (1995). Global Concern for the Environment: Is Affluence a Prerequisite? Journal of Social Issues, 51, 121-137.

Dunlap, R. E., van Liere, K. D., Mertig, A. G., \& Jones, R. E. (2000). Measuring Endorsement of the New Ecological Paradigm: A Revised NEP Scale. Journal of Social Issues, 56, 425-442.

Dunlap, R. E., \& York, R. (2008). The Globalization of Environmental Concern and The Limits of The Postmaterialist Values Explanation: Evidence from Four Multinational Surveys. The Sociological Quarterly, 49, 529-563.

Dunning, D., Anderson, J. E., Schlösser, T., Ehlebracht, D., \& Fetchenhauer, D. (2014). Trust at zero acquaintance: More a matter of respect than expectation of reward. Journal of Personality and Social Psychology, 107, 122-141. 
Duroy, Q. M.H. (2008). Testing the affluence hypothesis: A cross-cultural analysis of the determinants of environmental action. The Social Science Journal, 45, 419-439.

Dwivedi, R. (2016). Environmental Movements in the Global South. International Sociology, 16, 1131.

Edensor, T., \& Jayne, M. (2012). Introduction. In T. Edensor \& M. Jayne (Eds.), Urban Theory Beyond the West: A World of Cities. Routledge.

Eisenstadt, S. N. (2000). Multiple modernities. Daedalus, 129(1), 1-29.

Evans, G. W. (2003). The built environment and mental health. Journal of Urban Health : Bulletin of the New York Academy of Medicine, 80, 536-555.

Evans, G. W., Lepore, S. J., \& Allen, K. M. (2000). Cross-cultural differences in tolerance for crowding: Fact or fiction? Journal of Personality and Social Psychology, 79, 204-210.

Fairbrother, M. (2013). Rich People, Poor People, and Environmental Concern: Evidence across Nations and Time. European Sociological Review, 29, 910-922.

Farrell, H., \& Knight, J. (2016). Trust, Institutions, and Institutional Change: Industrial Districts and the Social Capital Hypothesis. Politics \& Society, 31, 537-566.

Fehr, E. (2009). On the Economics and Biology of Trust. Journal of the European Economic Association, 7, 235-266.

Fehr, E., Fischbacher, U., \& Gächter, S. (2002). Strong reciprocity, human cooperation, and the enforcement of social norms. Human Nature, 13, 1-25.

Fielding, A. J. (1992). Migration and social mobility: South East England as an escalator region. Regional Studies, 26(1), 1-15.

Franco, S., Mandla, V. R., \& Ram Mohan Rao, K. (2017). Urbanization, energy consumption and emissions in the Indian context A review. Renewable and Sustainable Energy Reviews, 71, 898907.

Frank, B., Delano, D., \& Schaefer Caniglia, B. (2017). Urban systems: a socio-ecological system perspective. Sociology International Journal, 1(1), 1-8.

Franzen, A., \& Meyer, R. (2010). Environmental Attitudes in Cross-National Perspective: A Multilevel Analysis of the ISSP 1993 and 2000. European Sociological Review, 26, 219-234.

Frederick, S. (2003). Time preference and personal identity. In Loewenstein, G., Read, D. and Baumeister, R.F. (Ed.), Time and Decision: Economic and Psychological Perspectives on Intertemporal Choice (pp. 89-113). New York: Russell Sage Foundation.

Friedman, R., Hong, Y.-Y., Simons, T., Chi, S.-C., Oh, S.-H., \& Lachowicz, M. (2018). The Impact of Culture on Reactions to Promise Breaches: Differences Between East and West in Behavioral Integrity Perceptions. Group \& Organization Management, 43, 273-315. 
Fukuyama, F. (1996). Trust: The social virtues and the creation of prosperity (1. Free Press paperback ed.). New York, NY: Free Press.

Fulmer, C. A., \& Gelfand, M. J. (2012). At What Level (and in Whom) We Trust. Journal of Management, 38, 1167-1230.

Gaertner, S. L., Dovidio, J. F., Banker, B. S., Houlette, M., Johnson, K. M., \& McGlynn, E. A. (2000). Reducing Intergroup Conflict: From Superordinate Goals to Decategorization, Recategorization, and Mutual Differentiation. Group Dynamics: Theory, Research and Practice, 4, 98-114.

Gambhir, S. (2017). Environmental Kuznets Curve: An Empirical Analysis in the Indian Context. PRAGATI: Journal of Indian Economy, 4(2), 44-77.

Gaston, K. J. (2010). Urban ecology: Cambridge University Press.

Gifford, R., \& Nilsson, A. (2014). Personal and social factors that influence pro-environmental concern and behaviour: A review. International Journal of Psychology : Journal International De Psychologie, 49, 141-157.

Giusti, M., Barthel, S., \& Marcus, L. (2014). Nature Routines and Affinity with the Biosphere: A Case Study of Preschool Children in Stockholm. Children, Youth and Environments, 24, 16.

Glaeser, E. L., La Porta, R., Lopez-de-Silanes, F., \& Shleifer, A. (2004). Do institutions cause growth? Journal of Economic Growth, 9(3), 271-303.

Glaeser, E. L., Laibson, D. I., Scheinkman, J. A., \& Soutter, C. L. (2000). Measuring Trust Quarterly Journal of Economics, 115, 811-846.

Gorodnichenko, Y., \& Roland, G. (2011). Which Dimensions of Culture Matter for Long-Run Growth? American Economic Review, 101, 492-498.

Gosling, S. D., Rentfrow, P. J., \& Swann, W. B. (2003). A very brief measure of the Big-Five personality domains. Journal of Research in Personality, 37, 504-528.

Grimm, N. B., Cook, E. B., Hale, R. L., \& Iwaniec, D. M. (2015). A broader framing of ecosystem services in cities: Benefits and challenges of built, natural or hybrid system function. In K. C. Seto (Ed.), Routledge International Handbooks. The Routledge Handbook of Urbanization and Global Environmental Change. Florence: Taylor and Francis.

Groeneveld, J., Müller, B., Buchmann, C. M., Dressler, G., Guo, C., Hase, N., . . Schwarz, N. (2017). Theoretical foundations of human decision-making in agent-based land use models - A review. Environmental Modelling \& Software, 87, 39-48.

Grove, J. M., Pickett, S. T. A., Whitmer, A., \& Cadenasso, M. L. (2013). Building an Urban LTSER: The Case of the Baltimore Ecosystem Study and the D.C./B.C. ULTRA-Ex Project. In S. J. Singh, H. Haberl, M. Chertow, M. Mirtl, \& M. Schmid (Eds.), Human-Environment Interactions: Vol. 2. Long Term Socio-Ecological Research: Studies in Society: Nature Interactions Across Spatial and Temporal Scales (pp. 369-408). Dordrecht: Springer. 
Guha, R., \& Martinez-Alier, J. (2013). Varieties of environmentalism: Essays north and south. London: Earthscan.

Guha, R., \& Gadgil, M. (2000). The use and abuse of nature. New Delhi: Oxford University Press.

Guth, W., \& Kliemt, H. (1994). Competition or co-operation: On the evolutionary economics of trust, exploitation and moral attitudes. Metroeconomica, 45, 155-187.

Haase, D., \& Schwarz, N. (2009). Simulation Models on Human--Nature Interactions in Urban Landscapes: A Review Including Spatial Economics, System Dynamics, Cellular Automata and Agent-based Approaches. Living Reviews in Landscape Research, 3.

Halleck Vega, S., \& Elhorst, J. P. (2015). THE SLX MODEL. Journal of Regional Science, 55, 339363.

Harding, A., \& Blokland, T. (2014). Urban Theory. A critical introduction to power, cities and urbanism in the 21st century. London: SAGE Publications Ltd.

Harpham, T. (1994). Urbanization and mental health in developing countries: A research role for social scientists, public health professionals and social psychiatrists. Social Science \& Medicine (1982), 39(2), 233-245.

Harriss, J. (2003). 'Widening the radius of trust': ethnographic explorations of trust and Indian business. Journal of the Royal Anthropological Institute, 9, 755-773.

Harvey, D. (1973). Social justice and the city. London: Arnold.

Haushofer, J., \& Fehr, E. (2014). On the psychology of poverty. Science (New York, N.Y.), 344, 862867.

Hawcroft, L. J., \& Milfont, T. L. (2010). The use (and abuse) of the new environmental paradigm scale over the last 30 years: A meta-analysis. Journal of Environmental Psychology, 30, 143-158.

Hayes, A. F. (2015). An Index and Test of Linear Moderated Mediation. Multivariate Behavioral Research, 50, 1-22.

Heitzman, J. (2008). The city in South Asia. Asia's great cities. London: Routledge.

Helm, S. V., Pollitt, A., Barnett, M. A., Curran, M. A., \& Craig, Z. R. (2018). Differentiating environmental concern in the context of psychological adaption to climate change. Global Environmental Change, 48, 158-167.

Henrich, J., Heine, S. J., \& Norenzayan, A. (2010). The weirdest people in the world? Behavioral and Brain Sciences, 33(2-3), 61-83.

Herzer, D., \& Vollmer, S. (2012). Inequality and growth: Evidence from panel cointegration. The Journal of Economic Inequality, 10, 489-503.

Hirschman, A. O. (1970). Exit, voice, and loyalty: Responses to decline in firms, organizations, and states. Cambridge, MA: Harvard University Press. 
Hite, D. M., Voelker, T., \& Robertson, A. (2014). Measuring Perceived Anonymity: The Development of a Context Independent Instrument. Journal of Methods and Measurement in the Social Sciences, $5(1), 22-39$.

Hoffmann, E., Jose, M., Nölke, N., \& Möckel, T. (2017). Construction and Use of a Simple Index of Urbanisation in the Rural-Urban Interface of Bangalore, India. Sustainability, 9, 2146.

Hofstede, G. (2013). Dimension data matrix: Base culture data for six dimensions of culture as presented in Cultures and Organizations. Retrieved from https://geerthofstede.com/research-andvsm/dimension-data-matrix/

Holt, C. A., \& Laury, S. K. (2002). Risk aversion and incentive effects. American Economic Review, 92(5), 1644-1655.

Houser, D., Xiao, E., McCabe, K., \& Smith, V. (2008). When punishment fails: Research on sanctions, intentions and non-cooperation. Games and Economic Behavior, 62, 509-532.

Howe, L. D., Galobardes, B., Matijasevich, A., Gordon, D., Johnston, D., Onwujekwe, O., . . . Hargreaves, J. R. (2012). Measuring socio-economic position for epidemiological studies in lowand middle-income countries: A methods of measurement in epidemiology paper. International Journal of Epidemiology, 41, 871-886.

Hruschka, D. J., \& Henrich, J. (2013). Institutions, parasites and the persistence of in-group preferences. PloS One, 8, e63642.

Inglehart, R., \& Baker, W. E. (2000). Modernization, Cultural Change, and the Persistence of Traditional Values. American Sociological Review, 65(1), 19-51.

Inglehart, R., Haerpfer, C., Moreno, A., \& et al. (2018). World Values Survey: All Rounds - CountryPooled Datafile Version. Retrieved from http://www.worldvaluessurvey.org/WVSDocumentationWVL.jsp.

IPCC. (2018). The Intergovernmental Panel on Climate Change. Special Report on Global Warming of $1.5^{\circ} \mathrm{C}$ : Summary for Policymakers, approved by Governments. Retrieved from https://www.ipcc.ch/2018/10/08/summary-for-policymakers-of-ipcc-special-report-on-globalwarming-of-1-5c-approved-by-governments/

Jackson, T. (2005). Motivating Sustainable Consumption. A review of evidence on consumer behaviour and behavioural change.

James, H. S. (2015). Generalized Morality, Institutions and Economic Growth, and the Intermediating Role of Generalized Trust. Kyklos, 68, 165-196.

Johansson-Stenman, O., Mahmud, M., \& Martinsson, P. (2013). Trust, trust games and stated trust: Evidence from rural Bangladesh. Journal of Economic Behavior \& Organization, 95, 286-298.

Johnson, N. D., \& Mislin, A. A. (2011). Trust games: A meta-analysis. Journal of Economic Psychology, 32, 865-889. 
Jones, W. H., Couch, L., \& Scott, S. (1997). Trust and Betrayal. In R. Hogan, J. A. Johnson, \& S. R. Briggs (Eds.), Handbook of personality psychology (pp. 465-482). San Diego: Academic Press.

Kaiser, F. G., Hartig, T., Brügger, A., \& Duvier, C. (2011). Environmental Protection and Nature as Distinct Attitudinal Objects. Environment and Behavior, 45, 369-398.

Kanjilal, K., \& Ghosh, S. (2013). Environmental Kuznet's curve for India: Evidence from tests for cointegration with unknown structuralbreaks. Energy Policy, 56, 509-515.

Kent, E. F. (2013). Sacred Groves and Local Gods: Religion and Environmentalism in South India: Oxford University Press on Demand.

Khan, A., Khan, M. N., \& Adil, M. (2012). Exploring the New Ecological Paradigm (NEP) Scale in India: Item Analysis, Factor Structure and Refinement. Asia-Pacific Journal of Management Research and Innovation, 8, 389-397.

Klöckner, C. A. (2013). A comprehensive model of the psychology of environmental behaviour-A meta-analysis. Global Environmental Change, 23, 1028-1038.

Koger, S. (2013). Psychological and Behavioral Aspects of Sustainability. Sustainability, 5, 30063008.

Kolstad, I., \& Wiig, A. (2012). Testing The Pearl Hypothesis: Natural resources and trust. Resources Policy, 37, 358-367.

Kong, D. T. (2012). Examining a Climatoeconomic Contextualization of Generalized Social Trust Mediated by Uncertainty Avoidance. Journal of Cross-Cultural Psychology, 44, 574-588.

Kraas, F., \& Mertins, G. (2014). Megacities and global change. In F. e. a. Kraas (Ed.), Megacities: Our Global Urban Future..

Krishna, A. (2007). How Does Social Capital Grow? A Seven-Year Study of Villages in India. The Journal of Politics, 69, 941-956.

Lange, H., Meier. L., \& Anuradha, N. S. (2009). Highly Qualified Employees in Bangalore, India: Consumerist Predators? In H. Lange \& L. Meier (Eds.), The New Middle Classes (pp. 281-298). Berlin, Heidelberg: Springer.

Lee, S., Adair, W. L., Mannix, E. A., \& Kim, J. (2012). The Relational Versus Collective "We" and Intergroup Allocation: The Role of Nested Group Categorization. Journal of Experimental Social Psychology, 48(5), 1132-1138.

Lele, S., Srinivasan, V., Jamwal, P., Thomas, B. K., Eswar, M., \& Zuhail, T. M. (2013). Water management in the Arkavathy Basin: A Situation Analysis. ENVIRONMENT and DEVELOPMENT Discussion Paper. (1).

LeSage, J. P., \& Pace, R. K. (2009). Introduction to spatial econometrics. Statistics, textbooks and monographs: Vol. 196. Boca Raton: CRC Press. 
Letki, N. (2006). Investigating the Roots of Civic Morality: Trust, Social Capital, and Institutional Performance. Political Behavior, 28(4), 305-325.

Leung, A. K.Y., Koh, K., \& Tam, K.-P. (2015). Being environmentally responsible: Cosmopolitan orientation predicts pro-environmental behaviors. Journal of Environmental Psychology, 43, 7994.

Lewicka, M. (2011). Place attachment: How far have we come in the last 40 years? Journal of Environmental Psychology, 31, 207-230.

Little, T. D., Cunningham, W. A., Shahar, G., \& Widaman, K. F. (2002). To Parcel or Not to Parcel: Exploring the Question, Weighing the Merits. Structural Equation Modeling: a Multidisciplinary Journal, 9, 151-173.

Lusardi, A., \& Mitchell, O. S. (2008). Planning and financial literacy: How do women fare? The American Economic Review, 98(2), 413-417.

Manapat, M. L., Nowak, M. A., \& Rand, D. G. (2013). Information, irrationality, and the evolution of trust. Journal of Economic Behavior \& Organization, 90, S57-S75.

Mani, A., Mullainathan, S., Shafir, E., \& Zhao, J. (2013). Poverty Impedes Cognitive Function. Science, 341, 976.

Mardani, A., Streimikiene, D., Cavallaro, F., Loganathan, N., \& Khoshnoudi, M. (2019). Carbon dioxide (CO2) emissions and economic growth: A systematic review of two decades of research from 1995 to 2017. Science of the Total Environment, 649, 31-49.

Martinez-Alier, J. (2002). The Environmentalism of the Poor: Edward Elgar Publishing.

Marwell, G., \& Schmitt, D. R. (1972). Cooperation and Interpersonal Risk: Cross-Cultural and CrossProcedural Generalizations. Journal of Experimental Social Psychology, 8, 594-599.

Matilal, B. K. (2017). Dharma and rationality. In P. Bilimoria, J. Prabhu, \& R. Sharma (Eds.), Classical Traditions and Contemporary Challenges: Vol. 1. Indian Ethics (pp. 89-112). London: Routledge.

Mawdsley, E. (2004). India's Middle Classes and the Environment. Development and Change, 35, 79 103.

McCrae, R. R., Kurtz, J. E., Yamagata, S., \& Terracciano, A. (2011). Internal consistency, retest reliability, and their implications for personality scale validity. Personality and Social Psychology Review : an Official Journal of the Society for Personality and Social Psychology, Inc, 15, 28-50.

McCrae, R. R., Terracciano, A., \& et al. (2005). Personality Profiles of Cultures: Aggregate Personality Traits. Journal of Personality and Social Psychology, 89(3), 407-425.

McPhearson, T., Pickett, S. T. A., Grimm, N. B., Niemelä, J., Alberti, M., Elmqvist, T., . . Qureshi, S. (2016). Advancing Urban Ecology toward a Science of Cities. BioScience, 66, 198-212. 
Meyfroidt, P. (2013). Environmental cognitions, land change, and social-ecological feedbacks: an overview. Journal of Land Use Science, 8, 341-367.

Mikulincer, M., \& Shaver, P. R. (2003). The attachment behavioral system in adulthood: Activation, psychodynamics, and interpersonal processes. ADVANCES in EXPERIMENTAL SOCIAL PSYCHOLOGY, 35, 53-152.

Milgram, S. (1970). The experience of living in cities. Science (New York, N.Y.), 167(3924), 14611468.

Morewedge, C. K. (2013). It Was a Most Unusual Time: How Memory Bias Engenders Nostalgic Preferences. Journal of Behavioral Decision Making, 26, 319-326.

MRSI, Indian Market Research Society of India. (2011). Socio-Economic Classification 2011. The SEC System. Retrieved from http://imrbint.com/research/The-New-SEC-system 3rdMarch2011.pdf

Munasinghe, M. (1999). Is environmental degradation an inevitable consequence of economic growth: Tunneling through the environmental Kuznets curve. Ecological Economics, 29, 89-109.

Murphy, R. O., Ackermann, K. A., \& Handgraaf, M. (2011). Measuring Social Value Orientation. SSRN Electronic Journal. Advance online publication.

Murthy, K. B.V., \& Bhasin, N. (2016). Environmental Kuznets Curve: CO2 emissions, pollution havens and type of economic development. In J. R. McIntyre, S. Ivanaj, V. Ivanaj, \& R. Narayan Kar (Eds.), Emerging Dynamics of Sustainability in Multinational Enterprises (pp. 209-231). UK: Edward Elgar Publishing.

Nagendra, H. (2016). Nature in the city: Bengaluru in the past, present, and future. Oxford: Univ. Press.

Nagendra, H. (2018). The global south is rich in sustainability lessons that students deserve to hear. Nature, 557, 485-488.

Nagendra, H., \& Ostrom, E. (2014). Applying the social-ecological system framework to the diagnosis of urban lake commons in Bangalore, India. Ecology and Society, 19.

Nair, J. (2005). The promise of the metropolis: Bangalore's twentieth century. New Delhi: Oxford Univ. Press.

Nesler, M. S., Aguinis, H., Quigley, B. M., Lee, S.-J., \& Tedeschi, J. T. (1999). The Development and Validation of a Scale Measuring Global Social Power Based on French and Raven's Power Taxonomy. Journal of Applied Social Psychology, 29(4), 750-771.

Nijman, J. (2015). India’s Urban Future. American Behavioral Scientist, 59, 406-423.

Nisbet, E. K., Zelenski, J. M., \& Murphy, S. A. (2008). The Nature Relatedness Scale. Environment and Behavior, 41, 715-740. 
Noftle, E. E., \& Shaver, P. R. (2006). Attachment dimensions and the big five personality traits: Associations and comparative ability to predict relationship quality. Journal of Research in Personality, 40, 179-208.

Nowak, M. A. (2006). Five Rules for the Evolution of Cooperation. Science, 314(5805), 1560-1563.

Ostrom, E. (2009). A general framework for analyzing sustainability of social-ecological systems. Science, 325, 419-422.

Pao, H., \& Tsai, C. (2011). Multivariate Granger causality between CO2 emissions, energy consumption, FDI (foreign direct investment) and GDP (gross domestic product): Evidence from a panel of BRIC (Brazil, Russian Federation, India, and China) countries. Energy Policy, 36(1), 685693.

Parnell, S., \& Oldfield, S. (Eds.). (2014). The Routledge Handbook on Cities of the Global South. Oxon and New York: Routledge.

Paxton, P. (2007). Association Memberships and Generalized Trust: A Multilevel Model Across 31 Countries. Social Forces, 86(1), 47-76.

Paxton, P., \& Glanville, J. L. (2015). Is Trust Rigid or Malleable?: A Laboratory Experiment. Social Psychology Quarterly, 78, 194-204.

Perkins, H. E. (2010). Measuring love and care for nature. Journal of Environmental Psychology, 30, $455-463$.

Piekut, A., \& Valentine, G. (2016). Perceived Diversity and Acceptance of Minority Ethnic Groups in Two Urban Contexts. European Sociological Review, $0(0), 1-16$.

Pisano, I., \& Lubell, M. (2017). Environmental Behavior in Cross-National Perspective. Environment and Behavior, 49, 31-58.

Plassmann, F., \& Khanna, N. (2016). Household Income and Pollution. The Journal of Environment \& Development, 15, 22-41.

Platteau, J.-P. (1994). Behind the market stage where real societies exist--Part II: The role of moral norms. The Journal of Development Studies, 30(3), 753-817.

Platteau, J.-P. (2000). Institutions, social norms, and economic development. Fundamentals of development economics: Vol. 1. Amsterdam: Harwood Academic Publ.

Podsakoff, P. M., MacKenzie, S. B., Lee, J.-Y., \& Podsakoff, N. P. (2003). Common method biases in behavioral research: A critical review of the literature and recommended remedies. The Journal of Applied Psychology, 88, 879-903.

Pohl, D. \& Schrenk, M. (2005). Naturerfahrungen und Naturzugänge von Kindern. In M. Schrenk \& W. Holl-Giese (Eds.), Bildung für nachhaltige Entwicklung —Ergebnisse empirischer Untersuchungen (pp. 33-46). Hamburg: Dr. Kovac. 
Poumanyvong, P., \& Kaneko, S. (2010). Does urbanization lead to less energy use and lower CO2 emissions? A cross-country analysis. Ecological Economics, 70, 434-444.

Pulver, S., Ulibarri, N., Sobocinski, K. L., Alexander, S. M., Johnson, M. L., McCord, P. F., \& Dell'Angelo, J. (2018). Frontiers in socio-environmental research: components, connections, scale, and context. Ecology and Society, 23.

Putnam, R. D. (1993). Making democracy work: Civic traditions in modern Italy (5. print). Princeton, NJ: Princeton Univ. Press.

Rao, M. S. A. (Ed.). (1992). Texts and readings in the social sciences. Urban sociology in India: Reader and source book. New Delhi: Orient Longman.

Raubenheimer, J. (2004). An item selection procedure to maximise scale reliability and validity. SA Journal of Industrial Psychology, 30.

Redman, C. L., Grove, J. M., \& Kuby, L. H. (2004). Integrating Social Science into the Long-Term Ecological Research (LTER) Network: Social Dimensions of Ecological Change and Ecological Dimensions of Social Change. Ecosystems, 7.

Robbins, B. G. (2016). What is Trust? A Multidisciplinary Review, Critique, and Synthesis. Sociology Compass, 10, 972-986.

Robinson, T. P. (2014). Café culture in Pune: Being young and middle class in urban India. New Delhi: Oxford University Press.

Roca, J. (2003). Do individual preferences explain the Environmental Kuznets curve? Ecological Economics, 45, 3-10.

Romano, A., Balliet, D., Yamagishi, T., \& Liu, J. H. (2017). Parochial trust and cooperation across 17 societies. Proceedings of the National Academy of Sciences of the United States of America, 114, 12702-12707.

Roy, A. (2009). The 21st-Century Metropolis: New Geographies of Theory. Regional Studies, 43, 819-830.

Saberwal, S. (1996). Roots of crisis: Interpreting contemporary Indian society. New Delhi, Thousand Oaks: Sage Publications.

Sassen, S. (1993). The Global City (Vol. 13). Princeton: Princeton University Press.

Scannel, L., \& Gifford, R. (2013). Comparing the Theories of Interpersonal and Place Attachment. In L. C. Manzo \& P. Devine-Wright (Eds.), Place Attachment: Advances in Theory, Methods and Applications. Taylor \& Francis.

Scarlett, L., Boyd, J., Brittain, A., Shabma, L., \& Brennan, T. (2013). Catalysts for Conservation: Exploring Behavioral Science Insights for Natural Resources Investments. 
Schlüter, M., Baeza, A., Dressler, G., Frank, K., Groeneveld, J., Jager, W., . . Wijermans, N. (2017). A framework for mapping and comparing behavioural theories in models of social-ecological systems. Ecological Economics, 131, 21-35.

Schultz, P. W. (2000). Empathizing With Nature: The Effects ofPerspective Taking on Concern for Environmental Issues. Journal of Social Issues, 56, 391-406.

Schultz, P. W. (2002). Inclusion with nature: The psychology of human-nature relations. In Psychology of sustainable development (pp. 61-78). Springer.

Schultz, P. W., Gouveia, V. V., Cameron, L. D., Tankha, G., Schmuck, P., \& Franěk, M. (2016). Values and their Relationship to Environmental Concern and Conservation Behavior. Journal of Cross-Cultural Psychology, 36, 457-475.

Scott, A. J., \& Storper, M. (2015). The Nature of Cities: The Scope and Limits of Urban Theory. International Journal of Urban and Regional Research, 39, 1-15.

Seawright, J., \& Gerring, J. (2008). Case Selection Techniques in Case Study Research. Political Research Quarterly, 61, 294-308.

Seto, K. C., Parnell, S., \& Elmqvist, T. (2013). A Global Outlook on Urbanization. In T. Elmqvist, M. Fragkias, J. Goodness, B. Güneralp, P. J. Marcotullio, R. I. McDonald, . . C. Wilkinson (Eds.), Urbanization, Biodiversity and Ecosystem Services: Challenges and Opportunities. Dordrecht: Springer Netherlands.

Shaver, P. R., \& Brennan, K. A. (1992). Attachment Styles and the "Big Five" Personality Traits: Their Connections With Each Other and With Romantic Relationship Outcomes. Personality and Social Psychology Bulletin, 18, 536-545.

Shin, H. H., \& Park, T. H. (2004). Individualism, Collectivism and Trust: The Correlates Between Trust and Cultural Value Orientations among Australian National Public Officers. International Review of Public Administration, 9, 103-119.

Shrapnel, M., \& Davie, J. (2001). The influence of personality in determining farmer responsiveness to risk. The Journal of Agricultural Education and Extension, 7, 167-178.

Simon, D. (2008). Urban Environments: Issues on the Peri-Urban Fringe. Annual Review of Environment and Resources, 33, 167-185.

Simone, A. (2014). People as Infrastructure: Intersecting Fragments in Johannesburg. In J. Gieseking \& W. Mangold (Eds.), People, Place and Space Reader. New York: Routledge.

Singelis, T. M., Triandis, H. C., Bhawuk, D. P. S., \& Gelfand, M. J. (1995). Horizontal and Vertical Dimensions of Individualism and Collectivism: A Theoretical and Measurement Refinement. Cross-Cultural Research, 29, 240-275.

Sinha, J. B. P., Sinha, T. N., Verma, J., \& Sinha, R. B. N. (2001). Collectivism coexisting with individualism: an Indian scenario. Asian Journal of Social Psychology, 4, 133-145. 
Sinha, J. B.P. (2014). Psycho-Social Analysis of the Indian Mindset. New Delhi, s.1.: Springer India.

Solon, G., Haider, S., \& Wooldridge, J. (2013). What Are We Weighting For? Cambridge, MA: National Bureau of Economic Research.

Sørensen, J. F. L. (2014). Rural-Urban Differences in Bonding and Bridging Social Capital. Regional Studies, 50, 391-410.

Sridhar, K. S., Reddy, A. V., \& Srinath, P. (2010). Is it Push or Pull? Recent Evidence from Migration in India.

Stock, J. H., Wright, J. H., \& Yogo, M. (2002). A Survey of Weak Instruments and Weak Identification in Generalized Method of Moments. Journal of Business \& Economic Statistics, 20, $518-529$.

Sudhira, H. S., \& Nagendra, H. (2013). Local Assessment of Bangalore: Graying and Greening in Bangalore - Impacts of Urbanization on Ecosystems, Ecosystem Services and Biodiversity. In T. Elmqvist, M. Fragkias, J. Goodness, B. Güneralp, P. J. Marcotullio, R. I. McDonald, . . . C. Wilkinson (Eds.), Urbanization, Biodiversity and Ecosystem Services: Challenges and Opportunities (pp. 75-91). Dordrecht: Springer Netherlands.

Summers, N., \& VanHeuvelen, T. (2017). Heterogeneity in the Relationship between Country-Level Affluence and Environmental Concern. Social Forces, 96, 329-360.

Tabellini. (2008). The Scope of Cooperation: values and incentives. Quarterly Journal of Economics, 123(3), 905-950.

Tam, K.-P. (2013). Concepts and measures related to connection to nature: Similarities and differences. Journal of Environmental Psychology, 34, 64-78.

Taylor, P. J. (2017). Cities in climate change. International Journal of Urban Sciences, 21, 1-14.

Thaler, R. H. (2016). Behavioral economics: past, present, and future. American Economic Review, 106(7), 1577-1600.

Thomas, V. G., Saegert, S., Cantor, D. W., Gorman-Smith, D., Maton, K. I., Soriano, F. I., \& Thornotn, D. W. (2005). Toward an Urban Psychology: Research, Action, and Policy.

Thomson, R., Yuki, M., Talhelm, T., Schug, J., Kito, M., Ayanian, A. H., . . Visserman, M. L. (2018). Relational mobility predicts social behaviors in 39 countries and is tied to historical farming and threat. Proceedings of the National Academy of Sciences of the United States of America, 115, 7521-7526.

Tönnies, F. (1887). Gemeinschaft und Gesellschaft. Grundbegriffe der reinen Soziologie. Leipzig: Fues's Verlag.

Triandis, H. C. (2001). Individualism-Collectivism and Personality. Journal of Personality, 69, $907-$ 924. 
Triandis, H. C., \& Gelfand, M. J. (1998). Converging Measurement of Horizontal and Vertical Individualism and Collectivism. Journal of Personality and Social Psychology, 74(1), 118-128.

Tu, L., Khare, A., \& Zhang, Y. (2012). A short 8-item scale for measuring consumers' local-global identity. International Journal of Research in Marketing, 29, 35-42.

United Nations. (2018). World Urbanization Prospects: The 2018 Revision.

Universidad Autonoma de Madrid. (2019). Ecogradientes: Evaluación de los flujos de servicios de los ecosistemas en gradientes rural-urbanos: aplicabilidad a la planificación socio-ecológica del territorio. Retrieved from https://ecogradientes.wordpress.com/

Universities of Kassel \& Göttingen. (2016). FOR2432. SOCIAL-ECOLOGICAL SYSTEMS IN THE INDIAN RURAL-URBAN INTERFACE: FUNCTIONS, SCALES, AND DYNAMICS OF TRANSITION. Retrieved from http://www.uni-kassel.de/fb11agrar/en/sections/home/for2432.html

University of Washington. (2019). Urban Ecology Research Lab. Retrieved from http://urbaneco.washington.edu/wp/

Upadhya, C. (2009). India's 'new Middle Class' and the Globalising City: Software Professionals in Bangalore, India. In H. Lange \& L. Meier (Eds.), The New Middle Classes (pp. 253-269). Berlin, Heidelberg: Springer.

Vakoch, D. (Ed.). (2013). Altruism in Cross-Cultural Perspective. New York: Springer.

Van de Vijver, F., \& Tanzer, N. K. (2004). Bias and equivalence in cross-cultural assessment: An overview. Revue Européenne De Psychologie Appliquée/European Review of Applied Psychology, 54, 119-135.

Van Hoorn, A. (2014). Individualist-Collectivist Culture and Trust Radius. Journal of Cross-Cultural Psychology, 46, 269-276.

Van Lange, P.A.M., Rockenbach, B., \& Yamagishi, T. (Eds.). (2015). Series in Human Cooperation: Vol. 2. Trust in Social Dilemmas. Oxford: Oxford University Press.

Vandello, J. A., \& Cohen, D. (1999). Patterns of individualism and collectivism across the United States. Journal of Personality and Social Psychology, 77, 279-292.

Verma, J. (1985). The ingroup and its relevance to individual behaviour: A study of collectivism and individualism. Psychologia: an International Journal of Psychology in the Orient.

Verma, J., \& Triandis, H. C. (1999). The measurement of collectivism in India. In W. J. Lonner \& D. L. Dinnel, D. K. Forgays, \& S. A. Hayes (Eds.), Merging past, present, and future in cross-cultural psychology: Selected papers from the Fourteenth International Congress of the International Association for Cross-Cultural Psychology. Lisse, Netherlands: Swets \& Zeitlinger Publishers.

Videras, J., Owen, A. L., Conover, E., \& Wu, S. (2012). The influence of social relationships on proenvironment behaviors. Journal of Environmental Economics and Management, 63, 35-50. 
WBGU. (2016). Forschung zur nachhaltigen Urbanisierung. In Wissenschaftlicher Beirat der Bundesregierung Globale Umweltveränderungen (Ed.), Der Umzug der Menschheit: Die transformative Kraft der Städte: Hauptgutachten (pp. 451-484).

Widdop Quinton, H., \& Khatun, F. (2018). Childhoodnature Alternatives: Adolescents in India, Nepal, and Bangladesh Explore Their Nature Connectedness. In A. Cutter-Mackenzie, K. Malone, \& E. Barratt Hacking (Eds.), Research Handbook on Childhoodnature : Assemblages of Childhood and Nature Research (pp. 1-32). Cham: Springer International Publishing.

Wirth, L. (1938). Urbanism as a Way of Life. American Journal of Sociology, 44(1), 1-24.

Witkin, H. A., \& Berry, J. W. (1975). Psychological Differentiation in Cross-Cultural Perspective. Journal of Cross-Cultural Psychology, 6, 4-87.

Witt, A. H.-d. (2013). Pathways to Environmental Responsibility: A Qualitative Exploration of the Spiritual Dimension of Nature Experience. Journal for the Study of Religion, Nature \& Culture, $7(2)$.

Woods, M. (2016). Engaging the global countryside: Globalization, hybridity and the reconstitution of rural place. Progress in Human Geography, 31, 485-507.

Wooldridge, J. M. (1996). Estimating systems of equations with different instruments for different equations. Journal of Econometrics, 74, 387-405.

World Bank. GDP per capita, PPP (current international \$): India (1990-2016). Retrieved from https://data. worldbank.org/indicator/NY.GDP.PCAP.PP.CD?end=2016\&locations=IN\&start=1990 \&view $=$ chart

Yaghoobi, A., Mohammadzade, S., Chegini, A. A., Yarmohammadi Vasel, M., \& Zoghi Paidar, M. R. (2016). The Relationship Between Attachment Styles, Self-Monitoring and Cybercrime in Social Network Users. International Journal of High Risk Behaviors \& Addiction, 5, e27785.

Yamagishi, T. (2003). The Group Heuristic: A Psychological Mechanism That Creates a SelfSustaining System of Generalized Exchanges. In Santa Fe Institute (Ed.), Workshop on the Coevolution of Institutions and Behavior.

Yamagishi, T. (2011). Trust: The Evolutionary Game of Mind and Society. The Science of the Mind. Tokyo: Springer.

Yamagishi, T., Cook, K. S., \& Watabe, M. (1998). Uncertainty, Trust, and Commitment Formation in the United States and Japan. American Journal of Sociology, 104, 165-194.

$\mathrm{Yu}, \mathrm{X}$. (2014). Is environment 'a city thing' in China?: Rural-urban differences in environmental attitudes. Journal of Environmental Psychology, 38, 39-48.

Yuki, M. (2003). Intergroup Comparison versus Intragroup Relationships: A Cross-Cultural Examination of Social Identity Theory in North American and East Asian Cultural Contexts. Social Psychology Quarterly, 66(2), 166-183. 
Yuki, M., Maddux, W. W., Brewer, M. B., \& Takemura, K. (2005). Cross-Cultural Differences in Relationship- and Group-Based Trust. Personality and Social Psychology Bulletin, 31, 48-62. 


\section{Annex: Questionnaire ${ }^{42}$}

\begin{tabular}{|c|c|}
\hline \multicolumn{2}{|c|}{ Latent individual-level } \\
\hline $\begin{array}{l}\text { New Environmental } \\
\text { Paradigm }\end{array}$ & $\begin{array}{l}\text { How much do you agree with the following statements: (1) } \\
\text { Strongly disagree, (2) Somewhat disagree, (3) Indifferent, (4) } \\
\text { Somewhat agree, (5) Strongly agree, (6) No answer } \\
\text { Eco-Crisis: Humans are severly abusing the environment. } \\
\text { Balance of Nature: When humans interfer with nature it often } \\
\text { produces disastrous consequences. } \\
\text { (Limits to Growth: Humans are becoming too many.) } \\
\text { (Anti-Anthropocentrism: Humans are allowed to change the } \\
\text { natural environment so their life becomes more comfortable.) }\end{array}$ \\
\hline \multicolumn{2}{|c|}{$\begin{array}{l}\text { When you were young (in the past year for current farming), how often did you (1) At least } \\
\text { once a day, (2) At least every second day, (3) At least once a week, (4) At least every } \\
\text { second week, (5) At least once a month, (6) At least every second month, (7) At least every } 6 \\
\text { months, (8) At least once a year, (9) Never. }\end{array}$} \\
\hline $\begin{array}{l}\text { Religious nature } \\
\text { experience }\end{array}$ & felt at unity with nature around me \\
\hline $\begin{array}{l}\text { Recreational nature } \\
\text { experience }\end{array}$ & went swimming in a river or lake \\
\hline $\begin{array}{l}\text { Aesthetic nature } \\
\text { experience }\end{array}$ & spent time simply watching animals and plants \\
\hline $\begin{array}{l}\text { Educational nature } \\
\text { experience }\end{array}$ & $\begin{array}{l}\text { talked to family or friends about environmental destruction and / } \\
\text { or protection }\end{array}$ \\
\hline $\begin{array}{l}\text { Farming (past and } \\
\text { current) }\end{array}$ & took care of animals and plants \\
\hline \multicolumn{2}{|c|}{$\begin{array}{l}\text { Now, please indicate if these statements describe yourself well. (1) Strongly disagree, (2) } \\
\text { Somewhat disagree, (3) Indifferent, (4) Somewhat agree, (5) Strongly agree, (6) No answer }\end{array}$} \\
\hline Nature connection & I enjoyed contact with nature overall when I was young. \\
\hline Agreeableness & I am sympathetic, warm. \\
\hline Intraversion & I am sometimes reserved, quiet. \\
\hline Openness & I am conventional, uncreative (inverted). \\
\hline Conscientousness & I tend to be disorganized, careless (inverted). \\
\hline Neuroticism & I am calm and emotionally stable (inverted). \\
\hline Knowledge & I understand causes and consequences of climate change well. \\
\hline Collectivism & $\begin{array}{l}\text { Vertical: I would stay in a group if they needed me, even if I were } \\
\text { not happy with the group. } \\
\text { Horizontal: It is important for me to maintain harmony within my } \\
\text { group. }\end{array}$ \\
\hline Individualism & Vertical: I often feel like deserving more then others. \\
\hline
\end{tabular}

\footnotetext{
${ }^{42}$ Abridged from implementation in CAPI-software (surveybe).
} 


\begin{tabular}{|c|c|}
\hline & $\begin{array}{l}\text { Horizontal: I enjoy being unique and different from others in } \\
\text { many respects. }\end{array}$ \\
\hline Anonymity & $\begin{array}{l}\text { If I come across a person on the street, chances are they will know } \\
\text { who I a (inverted). }\end{array}$ \\
\hline Heterogeneity & $\begin{array}{l}\text { A lot of people I come across } \\
\text {...have a different mother tongue. } \\
\text {...come from a different town. } \\
\text {... adher to a different religion. }\end{array}$ \\
\hline Globalization & $\begin{array}{l}\text { International trade has changed how things are done at work. } \\
\text { People's identification with local traditions is very weak here. } \\
\text { How many of the following brands do you frequently come across at } \\
\text { your main occupation? (McDonald`s, Facebook, Youtube, Apple, } \\
\text { CocaCola, Visa, Nike, Ebay, Starbucks, Toyota, Samsung) }\end{array}$ \\
\hline Power & Others have an influence on how well I get along. \\
\hline $\begin{array}{l}\text { Fairness, benevolence, } \\
\text { integrity }\end{array}$ & $\begin{array}{l}\text { Fairness: People I interact with always try to be fair to everyone. } \\
\text { Integrity: Whenever I do business with someone, they will do their } \\
\text { best to keep their promises. } \\
\text { Benevolence: People I come across usually seem to have my best } \\
\text { interest in mind. } \\
\text { Competence: People I have come to know usually were really } \\
\text { good at what their business was there. }\end{array}$ \\
\hline Governance & $\begin{array}{l}\text { When recruiting public sector employees, something about the } \\
\text { applicant - other than pure qualifications for the job - frequently } \\
\text { decide who gets the job (inverted). } \\
\text { Generally speaking, government officials frequently decide by } \\
\text { taking something about the specific person that asks the favor into } \\
\text { account (inverted). }\end{array}$ \\
\hline \multicolumn{2}{|c|}{ Manifest individual-level } \\
\hline Education & Years (weighted by highest formal degree obtained) \\
\hline Assets & $\begin{array}{l}\text { Count number of assets owned from list: Land, electricity, ceiling } \\
\text { fan, gas stove, } 2 \text {-wheeler, colour TV, refrigerator, washing machine, } \\
\text { car, AC }\end{array}$ \\
\hline Sex & Male/female \\
\hline Age & (open) \\
\hline Religion & Hindu, Muslim,Christian,None, Other \\
\hline Formal land titles & $\begin{array}{l}\text { Have you or one of your family members owned a plot in the past } \\
\text { that you were forced to sell or abandon, other than out of your free } \\
\text { will? }\end{array}$ \\
\hline $\begin{array}{l}\text { Time in main } \\
\text { occupation }\end{array}$ & $\begin{array}{l}\text { How many months do you already work in your current main } \\
\text { occupation? }\end{array}$ \\
\hline Time in village & How many months do you already live in this ward/village? \\
\hline
\end{tabular}




\begin{tabular}{|c|c|}
\hline \multicolumn{2}{|c|}{ Game-elicited individual } \\
\hline $\begin{array}{l}\text { Generalized Social } \\
\text { Trust \& Morality ( } \& \\
\text { particularized; i.e. } \\
\text { both sides of the Trust } \\
\text { Game) }\end{array}$ & $\begin{array}{l}\text { Trust: Here you have INR100. You can either keep the money or } \\
\text { give some of it to a person you have never met and will never } \\
\text { meet. If you do, I will triple the money that you sent. The person } \\
\text { can 1.) keep all the money, or 2.) give you X INR back. How } \\
\text { many do you send (particularized: if you know the person)? } \\
\text { Morality: Now imagine you have just received Y INR from } \\
\text { another person you have never met and will never meet, and I } \\
\text { have tripled the amount, so you get Y*r INR. How many would } \\
\text { you send back (particularized: if you know the person)? }\end{array}$ \\
\hline Abstraction & Series of numeric literacy questions (Lusardi \& Mitchell, 2008) \\
\hline $\begin{array}{l}\text { Social Value } \\
\text { Orientation }\end{array}$ & Series of decomposed social dilemma games (Murphy et al., 2011) \\
\hline Time preference & Series of discount decision games (Coller \& Williams, 1999) \\
\hline Risk preference & Series of risk aversion games (Holt \& Laury, 2002) \\
\hline \multicolumn{2}{|l|}{ Village level } \\
\hline Urbanization & distance to city center, population size of agglomeration, builtup $\%$ \\
\hline $\begin{array}{l}\text { Public Good } \\
\text { availability }\end{array}$ & $\begin{array}{l}\text { count of infrastructure present in village: Schools\&univerities, } \\
\text { hospitals\&doctors, markets\&shops, banks, bus/railway } \\
\text { stations\&post offices, ward/panchayat office\&police } \\
\text { stations\&NGOs }\end{array}$ \\
\hline Water access & $\begin{array}{l}\text { count of available sources multiplied by ease of access (from } \\
\text { "everyone for free” to "private”): lake,river,canal,government } \\
\text { open\&borewell, pipe, overhead tank, handpump }\end{array}$ \\
\hline
\end{tabular}




\section{Promovierenden-Erklärung}

\section{der Georg-August-Universität Göttingen}

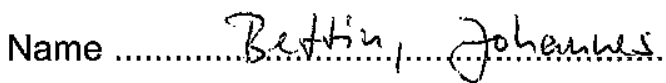

(Name, Vorname)

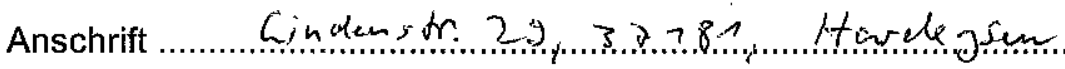

(Straße, PLZ, Wohnort)

Ich beabsichtige, eine Dissertation zum Thema Social- Sologich Pighences \& Utbann zation an der Georg-August-Universität Göttingen anzufertigen. Dabei werde ich von in Jnalia Oig1 M. Wollm betreut.

Ich gebe folgende Erklärung ab:

1. Die Gelegenheit zum vorliegenden Promotionsvorhaben ist mir nicht kommerziell vermittelt worden. Insbesondere habe ich keine Organisation eingeschaltet, die gegen Entgelt Betreuerinnen und Betreuer für die Anfertigung von Dissertationen sucht oder die mir obliegenden Pflichten hinsichtlich der Prüfungsleistungen für mich ganz oder teilweise erledigt.

2. Hilfe Dritter wurde bis jetzt und wird auch künftig nur in wissenschaftlich vertretbarem und prüfungsrechtlich zulässigem Ausmaß in Anspruch genommen. Insbesondere werden alle Teile der Dissertation selbst angefertigt; unzulässige fremde Hilfe habe ich dazu weder unentgeltlich noch entgeltlich entgegengenommen und werde dies auch zukünftig so halten.

3. Die Ordnung zur Sicherung der guten wissenschaftlichen Praxis an der Universität Göttingen wird von mir beachtet.

4. Eine entsprechende Promotion wurde an keiner anderen Hochschule im In- oder Ausland beantragt; die eingereichte Dissertation oder Teile von ihr wurden/werden nicht für ein anderes Promotionsvorhaben verwendet.

Mir ist bekannt, dass unrichtige Angaben die Zulassung zur Promotion ausschließen bzw. später zum Verfahrensabbruch oder zur Rücknahme des erlangten Grades führen können.

(Ort), (Datum)

(Unterschrift) 